NBER WORKING PAPER SERIES

\title{
NETWORKS AND THE MACROECONOMY: AN EMPIRICAL EXPLORATION
}

\author{
Daron Acemoglu \\ Ufuk Akcigit \\ William Kerr \\ Working Paper 21344 \\ http://www.nber.org/papers/w21344
}

\author{
NATIONAL BUREAU OF ECONOMIC RESEARCH \\ 1050 Massachusetts Avenue \\ Cambridge, MA 02138 \\ July 2015
}

This is a revised version of the paper presented in the 30th NBER Macro Annual Conference. We are grateful to the organizers/editors, Martin Eichenbaum and Jonathan Parker, and our discussants, Lawrence Christiano and Xavier Gabaix, for their very helpful directions and comments. We also thank seminar participants for their comments and ideas, Brendan Price and Pascual Restrepo for data assistance, and Alexis Brownell for excellent research assistance. Finally, we gratefully acknowledge financial support from the National Science Foundation, the Alfred P. Sloan Foundation, and the Ewing Marion Kauffman Foundation. The views expressed herein are those of the authors and do not necessarily reflect the views of the National Bureau of Economic Research.

NBER working papers are circulated for discussion and comment purposes. They have not been peerreviewed or been subject to the review by the NBER Board of Directors that accompanies official NBER publications.

(C) 2015 by Daron Acemoglu, Ufuk Akcigit, and William Kerr. All rights reserved. Short sections of text, not to exceed two paragraphs, may be quoted without explicit permission provided that full credit, including $(\odot$ notice, is given to the source. 
Networks and the Macroeconomy: An Empirical Exploration

Daron Acemoglu, Ufuk Akcigit, and William Kerr

NBER Working Paper No. 21344

July 2015

JEL No. E32

\begin{abstract}
$\underline{\text { ABSTRACT }}$
The propagation of macroeconomic shocks through input-output and geographic networks can be a powerful driver of macroeconomic fluctuations. We first exposit that in the presence of Cobb-Douglas production functions and consumer preferences, there is a specific pattern of economic transmission whereby demand-side shocks propagate upstream (to input-supplying industries) and supply-side shocks propagate downstream (to customer industries) and that there is a tight relationship between the direct impact of a shock and the magnitudes of the downstream and the upstream indirect effects. We then investigate the short-run propagation of four different types of industry-level shocks: two demand-side ones (the exogenous component of the variation in industry imports from China and changes in federal spending) and two supply-side ones (TFP shocks and variation in knowledge/ideas coming from foreign patenting). In each case, we find substantial propagation of these shocks through the input-output network, with a pattern broadly consistent with theory. Quantitatively, the networkbased propagation is larger than the direct effects of the shocks. We also show quantitatively large effects from the geographic network, capturing the fact that the local propagation of a shock to an industry will fall more heavily on other industries that tend to collocate with it across local markets. Our results suggest that the transmission of various different types of shocks through economic networks and industry interlinkages could have first-order implications for the macroeconomy.
\end{abstract}

\author{
Daron Acemoglu \\ Department of Economics, E18-269D \\ MIT \\ 77 Massachusetts Avenue \\ Cambridge, MA 02139 \\ and CIFAR \\ and also NBER \\ daron@mit.edu \\ Ufuk Akcigit \\ Department of Economics \\ University of Chicago \\ 1126 East 59th Street \\ Saieh Hall, Office 403 \\ Chicago, IL 60637 \\ and NBER \\ uakcigit@uchicago.edu
}

\author{
William Kerr \\ Harvard Business School \\ Rock Center 212 \\ Soldiers Field \\ Boston, MA 02163 \\ and NBER \\ wkerr@hbs.edu
}




\section{Introduction}

How small shocks are amplified and propagated through the economy to cause sizable fluctuations is at the heart of much macroeconomic research. Potential mechanisms that have been proposed range from investment and capital accumulation responses in real business cycle models (e.g., Kydland and Prescott, 1982), to Keynesian multipliers (e.g., Diamond, 1982, Kiyotaki, 1988, Blanchard and Kiyotaki, 1987, Hall, 2009, Christiano, Eichenbaum and Rebelo, 2011), to credit market frictions facing firms, households or banks (e.g., Bernanke and Gertler, 1989, Kiyotaki and Moore, 1997, Guerrieri and Lorenzoni, 2012, Mian and Sufi, 2013), to the role of real and nominal rigidities and their interplay (Ball and Romer, 1990), and to the consequences of (potentially inappropriate or constrained) monetary policy (e.g., Friedman and Schwartz, 1971, Eggertsson and Woodford, 2003, Farhi and Werning, 2013).

A class of potentially-promising approaches based on the spread of small shocks from firms or disaggregated sectors through their economic and other links to other units in the economy has generally been overlooked, however. The idea is simple. A shock to a single firm (or sector) could have a much larger impact on the macroeconomy if it reduces the output of not only this firm (or sector), but also of others that are connected to it through a network of input-output linkages. The macroeconomic importance of this idea was downplayed by Lucas's (1977) famous essay on business cycles on the basis of the argument that if shocks that hit firms or disaggregated sectors are idiosyncratic, they would then wash out when we aggregate across these units and look at macroeconomic fluctuations - due to a law of large numbers-type argument. Despite this powerful dismissal, this class of approaches has attracted recent theoretical attention. An important paper by Gabaix (2011) showed that when the firm-size distribution has very fat tails, so that shocks hitting the larger firms cannot be balanced out by those affecting smaller firms, the law of large numbers need not apply, opening the way to sizable macroeconomic fluctuations from idiosyncratic firm-level shocks. ${ }^{1}$ Carvalho (2008), Acemoglu, Ozdaglar and Tahbaz-Salehi (2010, 2014), Acemoglu, Carvalho, Ozdaglar and Tahbaz-Salehi (2012) and Baqaee (2015) built on the multi-sector framework first developed by Long and Plosser (1983) to show how input-output linkages can also neutralize the force of the law of large numbers because shocks hitting sectors that are particularly important as suppliers to other sectors will not wash out and can translate into aggregate fluctuations.

One attractive aspect of these network-based approaches to the amplification and propagation of shocks is that they naturally lend themselves to an empirical analysis that can inform the importance of the proposed mechanisms, and the current paper undertakes such an empirical investigation. We are not the first to empirically study these interactions. One branch of

\footnotetext{
${ }^{1}$ Earlier contributions on this theme include Jovanovic (1987) and Durlauf (1993) who showed how idiosyncratic shocks can accumulate into aggregate risk in the presence of strong strategic complementarities, and Bak, Chen, Scheinkman and Woodford (1993) who proposed a model of macroeconomic "self-organized criticality" capable of generating macroeconomic fluctuations from small shocks due to nonlinear interactions between firms and industries.
} 
existing research has provided model-based quantitative evaluation of the importance of these interactions (e.g., Horvath, 1998, 2000, Carvalho, 2008, Foerster, Sarte and Watson, 2011). A number of recent papers have instead focused on observable large shocks to a set of firms or industries and have traced their impact through the input-output network. Acemoglu, Autor, Dorn, Hanson and Price (2015) do this focusing on the spread of the impact of increased Chinese competition into the U.S. economy through input-output linkages and local labor markets, though focusing on 10-year or 20-year effects. Boehm, Flaaen and Nayar (2014), Barrot and Sauvagnat (2014), and Carvalho, Nirei and Saito (2014) focus on the transmission of natural disasters, such as the 2011 Japanese earthquake, over the global input-output network. ${ }^{2}$ Our paper contributes to this literature by studying the spread of four different types of shocks through the U.S. input-output network at business cycle frequencies. We also add to this by evaluating the contribution of the "geographic network" of industries — which measures the collocation patterns of industries across different commuting zones — to the inter-industry propagation of macroeconomic shocks. ${ }^{3}$

We begin by developing some theoretical implications of the propagation of shocks through the input-output linkages. Most notably, theory predicts that supply-side (productivity) shocks propagate downstream much more powerfully than upstream - meaning that downstream customers of directly-hit industries are affected more strongly than their upstream suppliers. In contrast, demand shocks (e.g., from imports or government spending) propagate upstream - meaning that upstream suppliers of directly hit industries are affected more strongly than their downstream customers. This pattern results from the fact that supply-side shocks change the prices faced by customer industries, creating powerful downstream propagation, while demand-side shocks have much more minor (or no) effects on prices and propagate upstream as affected industries adjust their production levels and thus input demands. In the simplified benchmark model studied in much of the literature, where both production functions and consumer preferences are Cobb-Douglas (so that income and substitution effects cancel out), these effects emerge particularly clearly: there is no upstream effect from supply-side shocks and no downstream effect from demand-side shocks. In addition, we show that there is a restriction on the quantitative magnitudes of the own effect (measuring how a shock to an industry affects that industry) and the network effects.

Our empirical work focuses on four different types of industry-level shocks, all propagating through the input-output linkages at the level of 392 industries as measured by the Bureau of Economic Analysis input-output tables. Our four shocks are: (1) variation from the exogenous component of imports from China; (2) changes in federal government spending (affecting industries differentially on the basis of their dependence on demand from the federal govern-

\footnotetext{
${ }^{2}$ Acemoglu, Akcigit and Kerr (2015) look at the medium-run spread of new ideas through the innovation (knowledge-flow) network of the U.S. economy.

${ }^{3}$ Though our evidence shows that microeconomic (industry-level) shocks are important and propagate strongly, it does not directly speak to the issues discussed in the previous paragraph, that is, to whether a law of large numbers-type argument will ensure that they wash out at the macro level.
} 
ment); (3) total factor productivity (TFP) shocks; and (4) knowledge/productivity stimuli coming from variation in foreign industry patents. For each one of these shocks, we construct downstream and upstream network effects by using information from the input-output tables - namely by taking the inner product of the corresponding row or column of the input-output matrix with a vector of shocks at the industry level. We then estimate parsimonious models of industry-level value added, employment and productivity growth on their own lags, an industry's own shocks, and downstream and upstream effects from shocks hitting other industries. ${ }^{4}$

A brief summary of our results is as follows. For each one of these four shocks, we find propagation through the input-output network to be statistically and economically important, and broadly consistent with theory. In particular, for the two demand-side shocks - Chinese imports and federal government spending — we find that upstream propagation is substantially stronger than downstream effects, which are often zero or of opposite sign. In contrast, for the two supply-side shocks - TFP and foreign patenting — there is strong downstream propagation, and limited or no upstream effects. In addition, the quantitative restrictions between own effects and network effects implied by theory are often verified. We also find the general patterns to be quite robust to different weighting schemes, additional controls, longer time scales, different lag structures, and so on.

The quantitative network effects are sizable and typically larger than the quantitative impact of own shocks. Figure 1a gives an indication of the magnitude of network effects by graphing the impulse response functions that result from a one-time one standard-deviation shock to every manufacturing industry. ${ }^{5}$ The different panels show that network effects are more pronounced than own effects. For example, one standard-deviation increase in imports from China will have a direct (own) effect of reducing value added growth by $3.46 \%$ in 10 years. Factoring in the (upstream) network effects, the total impact of the same shock is a $22.1 \%$ decline in value added growth. This implies a sizable "network multiplier" (defined as the size of the total impact relative to the direct impact of the shock) of $22.1 / 3.46 \simeq 6.4$. The implied employment multiplier is similar, approximately 5.9 .

We finally consider the effect of geographic collocation ("overlay") of industries. The geographic overlay of industries reflects the importance of localized networks, as industries with

\footnotetext{
${ }^{4}$ We should add at this point that despite our use of the term "shocks," we would like to be cautious in claiming that our estimates correspond to causal effects of purely exogenous shocks on endogenous economic outcomes. Even though we specify our regression equations to guard against the most obvious forms of endogeneity (contemporaneous shocks affecting both left- and right-hand side variables and Manski's (1993) reflection problem that would result from having grouped endogenous variables on the right-hand side), our shocks themselves may be endogenous to economic decisions in the recent past. For imports from China, because we are focusing on the exogenous component of the variation, we are fairly confident that our estimates are informative about causal effects. The same applies, perhaps with some additional caveats, to federal spending shocks, since we exploit variation across industries in their differential responsiveness to such aggregate changes. For the TFP and foreign patenting measures, the endogeneity concerns are more severe. Nevertheless, even in these cases we believe that our regressions are informative about the propagation of these "pre-determined" shocks through the input-output and geographic networks.

${ }^{5}$ Here, consistent with theory, "network effects" refer to downstream effects for supply-side shocks and upstream effects for demand-side shocks. The details of how Figure 1 is constructed are provided below.
} 
substantial exchanges frequently locate near each other to reduce transportation costs and facilitate information transfer (e.g., Fujita, Krugman and Venables, 1999). ${ }^{6}$ After deriving a theoretically-motivated measure of how industry-level shocks should propagate through the geographic overlay of industries, we show that geographic effects add another dimension of network-based propagation. While our main results are robust to these additional controls for geographic patterns, which demonstrates that input-output networks are operating above-andbeyond localized factors like regional business cycles, the geographic network also turns out to be a powerful transmitter of shocks from one industry to others. In fact, even though our estimates of the spread of shocks across collocating industries are slightly less robust than our baseline results, the effects appear quantitatively as large or even larger.

Overall, we interpret our results as suggesting that network-based propagation, particularly but not exclusively through the input-output linkages, might be playing a sizable role in macroeconomic fluctuations, and certainly a more important one than typically presumed in modern macroeconomics.

The rest of the paper proceeds as follows. Section 2 presents the theoretical model on inputoutput networks and shock propagation. Section 3 describes our data and provides descriptive statistics. Section 4 presents our empirical results focusing exclusively on national input-output connections, and Section 5 further adds in the geographic overlay. The last section concludes, while Appendix A and Online Appendices B and C contain further results and omitted proofs.

\section{Theory}

In this section, we develop some simple theoretical implications of input-output linkages, and then turn to a discussion of the macroeconomic consequences of the geographic concentration of industries in certain areas.

\subsection{Input-Output Linkages}

We start with a model closely related to Long and Plosser (1983) and Acemoglu, Carvalho, Ozdaglar and Tahbaz-Salehi (2012), which will clarify the role of input-output linkages.

Consider a static perfectly competitive economy with $n$ industries, and suppose that each industry $i=1, \ldots, n$ has a Cobb-Douglas production function of the form:

$$
y_{i}=e^{z_{i}} l_{i}{ }^{\alpha_{i}^{l}} \prod_{j=1}^{n} x_{i j}^{a_{i j}} .
$$

Here $x_{i j}$ is the quantity of goods produced by industry $j$ used as inputs by industry $i, l_{i}$ is labor, and $z_{i}$ is a Hicks-neutral productivity shock (representing both technological and other

\footnotetext{
${ }^{6}$ Recent work looking at the local coagglomeration of industries includes Ellison, Glaeser and Kerr (2010), Greenstone, Hornbeck and Moretti (2010), and Helsley and Strange (2014).
} 
factors affecting productivity). We assume that, for each $i, \alpha_{i}^{l}>0$, and $a_{i j} \geq 0$ for all $j$ (where $a_{i j}=0$ implies that the output of industry $j$ is not used as an input for industry $i$ ), and

$$
\alpha_{i}^{l}+\sum_{j=1}^{n} a_{i j}=1
$$

so that the production function of each industry exhibits constant returns to scale. ${ }^{7}$

As equation (1) makes clear, the output of each industry is used as input for other industries or consumed in the final good sector. Incorporating the demand from other industries, the market-clearing condition for industry $i$ can be written as

$$
y_{i}=c_{i}+\sum_{j=1}^{n} x_{j i}+G_{i},
$$

where $c_{i}$ is final consumption of the output of industry $i$, and $G_{i}$ denotes government purchases of good $i$, which are assumed to be wasted or spent on goods households do not directly care about. We introduce government purchases to be able to model demand-side shocks in a simple fashion.

The preference side of this economy is summarized by a representative household with a utility function

$$
u\left(c_{1}, c_{2}, \ldots, c_{n}, l\right)=\gamma(l) \prod_{i=1}^{n} c_{i}^{\beta_{i}},
$$

where $\beta_{i} \in(0,1)$ designates the weight of good $i$ in the representative household's preferences (with the normalization $\sum_{i=1}^{n} \beta_{i}=1$ ), and $\gamma(l)$ is a decreasing (differentiable) function capturing the disutility of labor supply.

The government imposes a lump-sum tax, $T$, to finance its purchases. Denoting the price of the output of industry $i$ by $p_{i}$, this implies $T=\sum_{i=1}^{n} p_{i} G_{i}$. Since its income comes only from labor, $w l$, the representative household's budget constraint can be written as

$$
\sum_{i=1}^{n} p_{i} c_{i}=w l-T .
$$

We focus on the competitive equilibrium of this static economy, which is defined in the usual fashion, so that all firms maximize profits and the representative household maximizes

\footnotetext{
${ }^{7}$ The main results we emphasize do not depend on the absence of physical capital, for example, with a production function that takes the form

$$
y_{i}=e^{z_{i}} l_{i}^{\alpha_{i}^{l}} k_{i}^{\alpha_{i}^{k}} \prod_{j=1}^{n} x_{i j}^{a_{i j}} .
$$

We suppress capital to simplify the notation and discussion.

More consequential is our assumption that this is a static economy where each industry simultaneously buys inputs from others. Long and Plosser (1983), instead, assumed that an industry at time $t$ uses as inputs products produced by other industries at date $t-1$. We discuss the implications of our timing assumption and the robustness of our results to this structure in Appendix C, available online.
} 
its utility, in both cases taking all prices as given, and the market-clearing conditions for each good and labor are satisfied. The amount of government spending and taxes are taken as given in this competitive equilibrium. We also choose the wage as the numeraire (i.e., set $w=1$ ).

The Cobb-Douglas production functions in (1), combined with profit maximization, imply

$$
\frac{p_{j} x_{i j}}{p_{i} y_{i}}=a_{i j}
$$

In preparation for our main results we will present, let $\mathbf{A}$ denote the matrix of $a_{i j}$ 's,

$$
\mathbf{A}=\left(\begin{array}{ccccc}
a_{11} & a_{12} & & \ldots & \\
a_{21} & a_{22} & & & \\
& & \ddots & & \\
& & & & \\
& & & & a_{n n}
\end{array}\right)
$$

We also define

$$
\mathbf{H} \equiv(\mathbf{I}-\mathbf{A})^{-1}
$$

as the Leontief inverse of the input-output matrix $\mathbf{A}$, and denote its typical entry by $h_{i j}$.

Proposition 1 The impact of sectoral productivity (supply-side) shocks on the output of sector $i$ is

$$
d \ln y_{i}=\underbrace{d z_{i}}_{\text {own effect }}+\underbrace{\sum_{j=1}^{n}\left(h_{i j}-\mathbf{1}_{j=i}\right) \times d z_{j}}_{\text {network effect }}
$$

where $h_{i j}$ is the ij-th element of $\mathbf{H}$ (the Leontief inverse of $\mathbf{A}$ ), and $\mathbf{1}_{j=i}$ is the indicator function for $j=i$. This equation implies that in response to productivity shocks, there are no upstream effects (i.e., no effects on suppliers of affected industries) and only downstream effects (i.e., only effects on customers of affected industries).

Suppose $\gamma(l)=(1-l)^{\lambda}$. Then the impact of government spending (demand-side) shocks on the output of sector $i$ is

$$
d \ln y_{i}=\underbrace{\frac{d \tilde{G}_{i}}{p_{i} y_{i}}}_{\text {own effect }}+\underbrace{\sum_{j=1}^{n}\left(\hat{h}_{j i}-\mathbf{1}_{j=i}\right) \times \frac{1}{p_{j} y_{j}} \times d \tilde{G}_{j}}_{\text {network effect }}-\underbrace{\sum_{j=1}^{n} \hat{h}_{j i} \times \frac{1}{p_{j} y_{j}} \times \frac{\beta_{j}}{1+\lambda} \times \sum_{k=1}^{n} d \tilde{G}_{k}}_{\text {resource constraint effect }}
$$

where $\tilde{G}_{j}=p_{j} G_{j}$ is nominal government spending on sector $j$ 's output, $\hat{h}_{i j}$ is the $i j$-th element of the Leontief inverse matrix $\hat{\mathbf{H}}=(\mathbf{I}-\hat{\mathbf{A}})^{-1}$, and $\hat{\mathbf{A}}$ is the matrix with entries given by $\hat{a}_{i j}=\frac{p_{j} x_{i j}}{p_{j} y_{j}}$ (i.e., sales from industry $j$ to industry $i$ normalized by sales of industry $j$ ). This implies that demand-side shocks do not propagate downstream (i.e., to customers of affected industries), only upstream (i.e., only to suppliers of affected industries). 
This proposition is proved in Appendix A. Equations (6) and (7) form the basis of our empirical strategy, and link the output of sector $i$ to its own "shock," $d z_{i}$, and to "shocks" hitting all other industries working through the input-output linkages of the economy. In particular, in equation (6), $d z_{i}$ is the own shock, while $\sum_{j=1}^{n}\left(h_{i j}-\mathbf{1}_{j=i}\right) d z_{j}$ is the network effect. Notice that this expression includes the propagation of the own shock through the input-output linkages, $h_{i i}-1$, together with the network effect, and then subtracts the own effect (via the indicator function $\mathbf{1}_{j=i}$, which takes the value 1 when $j=i$ and the value 0 otherwise), so as not to double count this direct effect. ${ }^{8}$ Similarly, in equation $(7), \frac{d \tilde{G}_{i}}{p_{i} y_{i}}$ is the own shock and $\sum_{j=1}^{n}\left(\hat{h}_{j i}-\mathbf{1}_{j=i}\right) \frac{1}{p_{j} y_{j}} d \tilde{G}_{j}$ is the network effect. ${ }^{9}$ These equations have several important implications.

First, what matters for the network effects is not directly the entries of the input-output matrix, A or $\hat{\mathbf{A}}$, but its Leontief inverse. The intuition is instructive about the workings of the model. For example, a negative productivity shock to industry $j$ will reduce its production and increase its price. This will adversely impact all of the industries that purchase inputs from industry $j$. But this direct impact will be further augmented in the competitive equilibrium because these first-round-affected industries will change their production and prices, creating indirect negative effects on other customer industries ("downstream effects"). The Leontief inverse captures these indirect effects

Second, the network effects in response to the demand-side and supply-side shocks are rather different. For supply-side shocks, the network effect, $\sum_{j=1}^{n}\left(h_{i j}-\mathbf{1}_{j=i}\right) d z_{j}$, implies that the impact goes downstream (and not at all upstream). For demand-side shocks, the network effect is given by the term $\sum_{j=1}^{n}\left(\hat{h}_{j i}-\mathbf{1}_{j=i}\right) \frac{1}{p_{j} y_{j}} d \tilde{G}_{j}$, indicating upstream propagation - the $\hat{h}_{j i}$ term signifies the spread of a shock to industries that are suppliers of the affected industries. Equation (7), in addition, includes the resource constraint effect, the term $\sum_{j=1}^{n} \hat{h}_{j i} \frac{1}{p_{j} y_{j}} \frac{\beta_{j}}{1+\lambda} \sum_{k=1}^{n} d \tilde{G}_{k}$, which reflects the impact of government spending on the representative household's budget constraint - the government's spending, financed by taxes, leaves fewer resources for private consumption. The parameter $\beta_{j}$ here captures the fact that the impact of the lower net income of the representative household on the consumption of sector $j$ depends on the share of this sector in consumption, given by $\beta_{j}$. When $\gamma^{\prime}=0$ so that there is no labor supply response and thus $\lambda=0$, this impact is maximized. On the other hand, when there is a positive labor supply response, this effect is partially offset by increased production across the economy. It is also worth noting that these effects are still propagated through the input-output matrix as shown by the $\hat{h}_{j i}$ terms, because a decline in the consumption of good $j$ causes sector $j$ to cut production and its input purchases from other sectors, leading to the upstream transmission of the direct implications of the resource constraint.

The next two examples illustrate in greater detail why supply-side or productivity shocks

\footnotetext{
${ }^{8}$ The diagonals of the Leontief inverse matrix, $\mathbf{H}$, are no less than 1 , so that $h_{i i}-1$ is nonnegative.

${ }^{9}$ In this case, the functional form assumption $\gamma(l)=(1-l)^{\lambda}$ is imposed to simplify the expressions.
} 
propagate downstream, while demand shocks propagate upstream.

Example 1 (Downstream propagation of supply-side shocks) Consider an economy with three sectors, with the input-output network as shown in Panel A of Figure 2. Sector 1 is the sole customer of sector 2, sector 2 is the sole customer of sector 3 and sector 3 is the sole customer of sector 1 . The sectoral production functions are therefore given as

$$
y_{1}=e^{z_{1}} l_{1}^{\alpha_{1}^{l}} x_{12}^{a_{12}}, y_{2}=e^{z_{2}} l_{2}^{\alpha_{2}^{l}} x_{23}^{a_{23}}, \text { and } y_{3}=e^{z_{3}} l_{3}^{\alpha_{3}^{l}} x_{31}^{a_{31}}
$$

and are all assumed to satisfy constant returns to scale. It follows from Proposition 1 that sector 1 's output is: ${ }^{10}$

$$
d \ln y_{1}=\frac{d z_{1}+a_{12} d z_{2}+a_{12} a_{23} d z_{3}}{1-a_{12} a_{23} a_{31}} .
$$

This expression shows that sector 1's output depends on the shocks to all three sectors. However, this is purely because of the propagation of productivity (supply-side) shocks downstream. For example, sector 3's productivity shock, $z_{3}$, affects $y_{1}$ not because of upstream propagation, but because of the chain of downstream propagation: sector 1 is a customer of sector 2 , and sector 2 is a customer of sector 3. Indeed, the coefficient of $z_{3}$ in this expression, $a_{12} a_{23}$, illustrates this indirect effect. To see further that there is no upstream propagation, consider a modification of this input-output network as shown in Panel B of Figure 2, where the link between sector 2 and sector 3 is severed (i.e., $a_{23}=0$ ). The output of sector 1 then becomes

$$
d \ln y_{1}=d z_{1}+a_{12} d z_{2}
$$

with no impact from $z_{3}$. This verifies that it was the indirect downstream transmission of sector 3 's productivity shock that impacted sector 1 . With the link between sectors 2 and 3 severed, this indirect transmission ceases, and there is no longer any impact of $z_{3}$ on sector 1 . Had it been the upstream propagation of productivity shocks, we would have seen a similar dependence of sector 1's output on $z_{3}$ since the input linkage between these two sectors has not changed.

The intuition for why there are no economic effects working upstream through the inputoutput network - as shown in Proposition 1 and Example 1 - is related to the Cobb-Douglas nature of the production functions and preferences. Any impact on upstream industries will depend on the balance of a quantity effect (less is produced in industry $j$ after an adverse productivity shock) and price effect (each unit produced in industry $j$ is now more expensive). With Cobb-Douglas technologies and preferences from households, these two effects exactly cancel out. ${ }^{11}$ Downstream propagation, on the other hand, is a consequence of the fact that an

\footnotetext{
${ }^{10}$ Detailed derivations for this and the next example are provided in Appendix C, available online.

${ }^{11}$ Clearly Cobb-Douglas is an approximation, though arguably not a bad one since the U.S. input-output matrix appears to be fairly stable over time, as shown, for example, in Acemoglu et al. (2012) (and with nonCobb-Douglas technologies this would not be the case). Our empirical results also give additional credence to the notion that Cobb-Douglas is a useful approximation for our purposes. In any case, it should be emphasized
} 
adverse productivity shock to a sector leads to an increase in the price of that sector's output, encouraging its customer industries to use this input less intensively and thus reduce their own production. This downstream propagation is also the reason why the impact of a shock depends only on input-output linkages, and not on the consumption shares, the $\beta_{j}$ 's. The consumption shares influence the level of production in different sectors, but not the proportional responses to productivity shocks; productivity shocks translate into proportional declines in prices and thus proportional downstream transmission, regardless of consumption shares.

The next example illustrates the propagation of demand-side shocks.

Example 2 (Upstream propagation of demand-side shocks) Consider again the economy depicted in Panel A of Figure 2, but now with government spending shocks, expressed in nominal terms as $d \tilde{G}_{1}$, $d \tilde{G}_{2}$, and $d \tilde{G}_{3}$, rather than productivity shocks (and thus setting $\left.d z_{1}=d z_{2}=d z_{3}=0\right)$. We also set $\beta_{1}=\beta_{2}=\beta_{3}=1 / 3$. In this case, the change in the nominal output of sector 1 (with tildes again denoting nominal variables) can be derived as

$$
d \tilde{y}_{1}=\frac{1}{1-a_{12} a_{23} a_{31}}\left\{\begin{array}{c}
d \tilde{G}_{1}+a_{23} a_{31} d \tilde{G}_{2}+a_{31} d \tilde{G}_{3} \\
-\frac{\left(1+a_{31}+a_{23} a_{31}\right)}{3(1+\lambda)}\left[d \tilde{G}_{1}+d \tilde{G}_{2}+d \tilde{G}_{3}\right]
\end{array}\right\}
$$

Once again, shocks to all three sectors influence the nominal output of sector 1, but this time it is because of the cumulative indirect effects working upstream. In particular, the effect of the shock to sector 2, $d \tilde{G}_{2}$, on sector 1 is working upstream through its impact on sector 3 and then sector 3's impact on sector 1, as can be seen from the fact that this term is multiplied by $a_{23} a_{31}$ in the first line. The resource constraint effect is shown in the second line. Similar to our analysis in the previous example, we can verify that the network effects shown in the first line are not working through downstream propagation by considering Panel B of Figure 2. When the link between sectors 2 and 3 is severed (or equivalently when $a_{23}=0$ ), the change in the nominal output of sector 1 becomes

$$
d \tilde{y}_{1}=d \tilde{G}_{1}+a_{31} d \tilde{G}_{3}-\frac{\left(1+a_{31}\right)}{3(1+\lambda)}\left[d \tilde{G}_{1}+d \tilde{G}_{2}+d \tilde{G}_{3}\right]
$$

where the second term is again the indirect effect working through the household budget constraint. The absence of an impact from the government spending shock to sector 2 now confirms that all propagation of demand-side shocks is upstream.

The intuition for why demand-side shocks propagate only upstream, as demonstrated in Proposition 1 and Example 2, is also instructive. With government spending shocks, affected

that the qualitative nature of the results emphasized in the proposition - that supply shocks will have larger downstream effects than upstream effects - holds true with non-Cobb-Douglas technologies and preferences, since even in this case quantity and price effects would at least partially offset each other (and in fact, Acemoglu, Ozdaglar and Tahbaz-Salehi, 2015b, show that similar results to those in Proposition 1 can be obtained as firstorder approximations under general production technologies). 
industries have to increase their production to meet the increased demand from the government. But given that they are using inputs from other supplier industries, this is only possible if industries supplying inputs to them also expand their inputs (proportionately to the role of these inputs in the production function of the affected industries). This is the logic for upstream propagation of demand-side shocks. Why is there no downstream propagation? Since all sectors have constant returns to scale, prices in this economy are entirely independent of the demand side. Government spending shocks change quantities but not prices (see Appendix A). But this implies that the channel through which downstream propagation took place in response to productivity shocks - changing relative prices - is entirely absent, accounting for the lack of downstream propagation in response to demand-side shocks.

A third implication of equations (6) and (7) concerns the magnitudes of the coefficients of the own and network effects. The simplest way of seeing this is to reorganize these equations so that equation (6) becomes

$$
d \ln y_{i}=h_{i i} \times d z_{i}+\sum_{j \neq i} h_{i j} \times d z_{j}
$$

which implies that if the indirect impacts of the own shock are included with the direct effect (and excluded from the network effect), then the coefficients of the own and the network effects, when properly scaled by the entries of the Leontief inverse, should be equal. ${ }^{12}$ The same is true for the demand-side shocks in equation (7), which can be rearranged as

$$
d \ln y_{i}=\hat{h}_{i i} \frac{d \tilde{G}_{i}}{p_{i} y_{i}}+\sum_{j \neq i} \hat{h}_{j i} \frac{d \tilde{G}_{j}}{p_{j} y_{j}}-\sum_{j=1}^{n} \hat{h}_{j i} \frac{\beta_{j}}{1+\lambda} \sum_{k=1}^{n} d \tilde{G}_{k}
$$

again showing the equality of the coefficients of the properly scaled own and network effects (the first two terms). These results readily extend to the employment equation by observing that the employment effects are derived from the output effects, and are thus proportional to them.

Fourth, equations (6) and (7) also imply that what matters in our theoretical framework are the contemporaneous shocks (e.g., $d z_{i}$ ), not some future anticipated shocks. ${ }^{13}$ This motivates our use of current (or one-period lagged) shocks on the right-hand side of our estimating equations.

Finally, we further note that the implications of import shocks are also very similar to government spending shocks, since a decline in imports (without imposing trade balance) is

\footnotetext{
${ }^{12}$ In fact, this equation implies that the coefficients of the own and network effects should both be equal to one, though this prediction depends on the choice of units of the shocks, the $d z$ 's. In practice, the coefficients will be different than one but still equal to each other depending on the specific choices of units for measuring our shocks.

${ }^{13}$ This can be seen straightforwardly by considering a dynamic version of the model (without additional intertemporal linkages), in which case equations (6) and (7) would apply with time subscripts, with only $d z_{i t}$ being relevant for time $t$ outcomes. In the presence of irreversible investments and/or other intertemporal linkages at the sectoral level, expectations of future shocks would also matter.
} 
analogous to an increase in government spending on the same sectors, and for this reason, we have not separately introduced these shocks in our theoretical model.

\subsection{The Effects of the Geographic Network}

Another important set of interlinkages, which could be represented as network effects, relates to geographic overlay over industries (corresponding to how industries collocate in various local labor markets, for example as measured by commuting zones). Thinking through these geographic interactions is important to ensure that our empirical work can distinguish inputoutput network effects from these geographic interlinkages; moreover, these local linkages are also of direct interest as another transmitter of industry-level shocks.

Let us start with a simple reduced-form model capturing local demand effects

$$
d \ln y_{r, i}=\eta \sum_{j \neq i} \frac{y_{r, j}}{y_{r}} d \ln y_{r, j}+d z_{i},
$$

where $y_{r, i}$ is the output of industry $i$ in region $r$, and $d z_{i}$ is an industry shock normalized to have a unit impact on the industry's output (in a region). In what follows, take $\eta$ to be small (and in particular less than 1).

This equation captures the idea that if industries in a given region (local labor market) are hit by negative shocks, this will reduce economic activity and adversely affect output and employment in other industries, which is consistent with empirical evidence reported in Autor, Dorn and Hanson (2013) and Mian and Sufi (2015). For example, if a large employer in a given local labor market shuts down, this will reduce the demand and thus employment and output of other local employers. The most obvious channel for this is through some local demand effects, though other local linkages would also lead to a relationship similar to (8).

The functional form in this equation is intuitive and implies that the impact of a proportional decline in industry $j$ on industry $i$ in the same region will be scaled by the importance of industry $j$ in the region's output $\left(y_{r, j} / y_{r}\right)$. Note also that, for simplicity's sake, we ignore the network effects coming from input-output linkages in this subsection.

The next step is to solve the within-region equilibrium implied by (8). Doing this with matrix algebra, we can write

$$
\mathbf{d} \ln \mathbf{y}_{r, i}=(\mathbf{I}-\mathbf{B})^{-1} \mathbf{d} \mathbf{z}_{i}
$$

where

$$
\mathbf{B}=\left(\begin{array}{ccccc}
0 & \eta \frac{y_{r, 2}}{y_{r}} & \eta \frac{y_{r, 3}}{y_{r}} & \ldots & \\
& 0 & 0 & & \\
& & 0 & 0 & \\
& & & & 0
\end{array}\right)
$$

Given our analysis of input-output models, it is not surprising that a Leontief inverse type matrix is playing a central role here. But in this instance, it is useful for us to go beyond 
this matrix representation. In particular, when $\eta$ is small as we have assumed, second- and higher-order terms in $\eta$ can be ignored, and the within-region equilibrium can be expressed in the following form: ${ }^{14}$

$$
d \ln y_{r, i} \approx d z_{i}+\eta \sum_{j \neq i} \frac{y_{r, j}}{y_{r}} d z_{j}
$$

Intuitively, this equation describes the within-region equilibrium as a function of shocks to all industries (solving out all "endogenous" terms from the right-hand side). Now using the fact that $d \ln y_{r, i}=d y_{r, i} / y_{r, i}$, and summing across regions, we obtain

$$
d y_{i}=\sum_{r} d y_{r, i} \approx y_{i} d z_{i}+\eta \sum_{r} \sum_{j \neq i} \frac{y_{r, i} y_{r, j}}{y_{r}} d z_{j},
$$

which then enables us to obtain a simple representation of the geographic effects:

$$
d \ln y_{i} \approx d z_{i}+\eta \sum_{j \neq i} \text { geographic_overlay }_{i, j} d z_{j}
$$

where

$$
\text { geographic_overlay }_{i, j} \equiv \sum_{r} \frac{y_{r, i} y_{r, j}}{y_{i} y_{r}}
$$

is the non-centered cross-region correlation coefficient of industries $i$ and $j$, normalized by their national levels of production, and represents their tendency to collocate.

Intuitively, this equation captures the fact that industries will be impacted not only by their direct shocks but also by the shocks of other industries that tend to collocate with them. For example, if coal and steel industries are always in the same few regions, the steel industry will be negatively affected nationally not only when there is a negative shock to itself but also when there is a negative shock to the coal industry, because when the coal industry is producing less in the region, other industries in that region are also adversely affected, and steel is overrepresented among these industries that happen to be in the same region as coal.

Though the term we have for geographic overlay is simple and intuitive, it is based on an approximation that involves ignoring all terms that are second or higher order in $\eta$, thus posing the natural question of whether including some of these additional terms would lead to additional insights. To provide a partial answer to this question, we now include secondorder terms (thus ignoring only third- or higher-order terms in $\eta$ ), which leads to a natural generalization of (10). In particular, the within-region equilibrium can now be expressed as

$$
d \ln y_{r, i} \approx d i_{i}+\eta \sum_{j \neq i} \frac{y_{r, j}}{y_{r}} d z_{j}+\eta^{2} \sum_{j \neq i} \frac{y_{r, j}}{y_{r}} \sum_{k \neq j} \frac{y_{r, k}}{y_{r}} d z_{k} .
$$

\footnotetext{
${ }^{14}$ More formally, when $\eta$ is small, the inverse $(\mathbf{I}-\mathbf{B})^{-1}$ necessarily exists, and thus has an infinite series expansion of the form:

$$
(\mathbf{I}-\mathbf{B})^{-1}=\mathbf{I}+\mathbf{B}+\mathbf{B}^{2}+\mathbf{B}^{3}+\ldots
$$

Moreover, when $\eta$ is small, we can also approximate this inverse with the first two terms, which leads to the next equation. We describe below calculations and empirical tests with higher-order terms.
} 
Now summing across regions and repeating the same steps as above, we obtain

$$
d \ln y_{i}=d z_{i}+\eta \sum_{j \neq i} \text { geographic_overlay }_{i, j} d z_{j}+\eta^{2} \sum_{j \neq i} \sum_{k \neq j, i} \overline{\text { geographic_overlay }}_{i, j, k} d z_{j}
$$

where the additional geographic overlay term, which includes triple collocation patterns, is

$$
\overline{\text { geographic_overlay }}_{i, j, k} \equiv \sum_{r} \frac{y_{r, i} y_{r, j} y_{r, k}}{y_{i} y_{r}^{2}} .
$$

\section{Data and Descriptive Statistics}

This section describes our various data sources and the construction of the key measures of downstream and upstream effects and the geographic network.

\subsection{Data Sources}

Our core industry-level data for manufacturing come from the NBER-CES Manufacturing Industry Database (Becker, Grey and Marvakov, 2013). We utilize data for the years 19912009. Using the first change as a baseline, our estimations cover 17 changes from 1992-1993 to 2008-2009. In the first four changes, we have 392 four-digit industries; thereafter, we have 384 industries for 6560 total observations. Though the theoretical predictions derived in the previous section are in terms of total industry output (shipments), our baseline analysis focuses on (real) value added due to its adjustment for energy costs, non-manufacturing inputs, and inventory changes which are all outside of our model. We show similar results using real and nominal shipments in Appendix B, available online.

To construct our linkages between industries, we use the Bureau of Economic Analysis' 1992 Input-Output Matrix and the 1991 County Business Patterns database as described further below. In the next section, we describe the data used for each shock when introducing it.

\subsection{Upstream and Downstream Networks}

The construction of downstream and upstream effects follows Acemoglu et al. (2015). We construct the matrix A introduced in Section 2 from the 1992 "Make" and "Use" Tables of the Bureau of Economic Analysis. This matrix has input share entries corresponding to

$$
a_{i j} \equiv \frac{\text { Sales }_{j \rightarrow i}}{\text { Sales }_{i}} .
$$

As emphasized in Section 2, this quantity measures the total sales of inputs from industry $j$ to industry $i$, normalized by the total sales (or equivalently the total costs) of industry $i$. Intuitively, it corresponds to how many dollars worth of the output of sector $j$ (say tires) sector $i$ (say the car industry) needs to purchase to produce one dollar worth of its own output. When production functions are Cobb-Douglas, as we have assumed in our theoretical analysis, these 
input shares are constant regardless of prices. Equation (6) shows that network effects from supply-side shocks directly depend on these input shares. The Leontief inverse of the inputoutput matrix is then computed from the matrix of these input-output shares as $(\mathbf{I}-\mathbf{A})^{-1}$

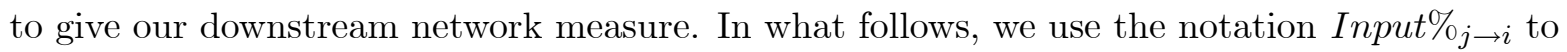
represent the elements of the Leontief inverse of the input-output matrix. ${ }^{15}$

For constructing the network effects from demand-side shocks, we again follow equation (7), which decomposes the response of a sector into an own effect, a network effect and the resource constraint effect. We first ignore the last one and focus on the network effect. The presence of the $\hat{h}_{j i}$ (or $\hat{a}_{j i}$ ) terms in this equation underscores the different aspects of inputoutput linkages involved in upstream propagation. The empirical counterparts of the $\hat{a}_{i j}$ terms are

$$
\frac{\text { Sales }_{i \rightarrow j}}{\text { Sales }_{i}} \equiv a_{j i} \frac{\text { Sales }_{j}}{\text { Sales }_{i}}
$$

which we use to compute the upstream network measures. We use Output $\%_{i \rightarrow j}$ to represent these Leontief inverse terms. We return to the resource constraint effect later.

\subsection{Geographic Overlay}

We also measure the geographic overlay of two industries using the metric developed in the theory section,

$$
\text { geographic_overlay }_{i, j} \equiv \sum_{r} \frac{y_{r, i} y_{r, j}}{y_{i} y_{r}} .
$$

We define regions through BEA commuting zones and utilize 1991 County Business Patterns data to measure the overlay. We also calculate the higher-order geographic overlay term (11). In practice, however, we observe very little additional explanatory power with the second metric and thus focus simply on the direct collocation case.

\subsection{Correlation Matrices}

Table 1a shows the correlation matrix of these interconnections, excluding own-industry interconnections (i.e., network diagonals). Upstream and downstream material flows are moderately correlated at 0.4 and somewhat less strongly correlated with geographic overlay, indicating that input-output linkages operate, for the most part, beyond common geographies.

Table 1b depicts the correlation of our four measures of shocks with each other, and shows that our different shocks are only weakly correlated, assuaging concerns that we may be tracing the effects of omitted shocks when modeling the effect of each shock one at the time. Column 5 of Table $1 \mathrm{~b}$ reports the average between-industry correlation for each shock (e.g., how correlated is, say, the federal spending shock of an industry with the federal spending shocks of other industries). This is relevant in part because a high between-industry correlation of

\footnotetext{
${ }^{15}$ We use this notation rather than $h_{i j}$ as in Section 2 to emphasize that these are the empirical counterparts of the theoretical notions developed above.
} 
shocks might create spurious network effects in the presence of an omitted higher-order impact of own shocks. The relatively low between-industry correlations, except for the federal spending shock, are comforting in this regard. The higher between-industry correlation for the federal spending shock is unsurprising since it is constructed from the interaction of aggregate time-series variation in federal spending with a time-invariant measure of federal spending dependency of each industry (as detailed further below).

\section{Results: The Input-Output Network}

This section provides our primary empirical results that quantify shock propagation through the input-output networks, leaving the analysis of the geographic network to the next section. We focus on four shocks: (1) import penetration; (2) federal spending changes; (3) TFP growth; and (4) foreign patenting growth. The first two correspond to demand-side shocks, while the latter two are supply-side, approximating productivity shocks. We first consider each shock by itself, describing how we measure it, and studying its empirical properties in isolation. After cycling through all four shocks independently, we jointly model them and provide an extended discussion of economic magnitudes.

\subsection{Empirical Approach}

Throughout, our main estimating equations are direct analogs of equations (6) and (7) in the theory section, and take the following form:

$$
\begin{aligned}
\Delta \ln Y_{i, t}= & \delta_{t}+\psi \Delta \ln Y_{i, t-1}+\beta^{\text {own }} \text { Shock }_{i, t-1} \\
& +\beta^{\text {upstream }} \text { Upstream }_{i, t-1}+\beta^{\text {downstream }} \text { Downstream }_{i, t-1}+\varepsilon_{i, t},
\end{aligned}
$$

where $i$ indexes industries, $\delta_{t}$ denotes a full set of time effects, $\varepsilon_{i, t}$ is an error term, and $Y_{i, t}$ stands for one of three industry-level variables from the NBER manufacturing database: real value added (using the industry's shipments deflator), employment, and real labor productivity (real value added divided by employment).

In our baseline results, time periods correspond to years. We start with a model that only considers the core regressors outlined in equation (12), and then we show robustness checks that add extra controls. We allow only a single lag of the dependent variable on the right-hand side for parsimony. The role of additional lags is taken up in robustness checks.

The key regressors are $S h o c k_{i, t-1}$, the industry's own direct shock (taken from one of the four shocks introduced above), and Upstream $_{i, t-1}$ and Downstream Dot $_{i-1}$ which stand for the shocks working through the network. These network shocks are always computed from the interaction of the vector of shocks hitting other industries and a vector representing the interlinkages between the focal industry and the rest (e.g., the row or the column of the inputoutput matrix); we provide exact details below. 
The upstream and downstream terminology in network analyses has some ambiguity. In the remainder, we follow our usage in Section 2 and label "upstream effects" as those arising from shocks to customers of an industry that flow up the input-output chain; in parallel, we describe "downstream effects" as those arising from shocks to suppliers of an industry that flow down the input-output chain. Henceforth, for clarity, we use "upstream" and "downstream" terms to describe exclusively the effects. When there is a need to describe where the shock originates, we will use the terms "customer" and "supplier" to avoid confusion.

Thus, we measure downstream effects (due to supplier shocks) and upstream effects (due to customer shocks) closely mimicking the theoretical equations, (6) and (7). In particular, these are given by the weighted averages of shocks hitting all industries using entries of the Leontief inverse matrices as weights:

$$
\text { Downstream }_{i, t}=\sum_{j}\left(\text { Input }_{j \rightarrow i}^{1991}-\mathbf{1}_{j=i}\right) \cdot \text { Shock }_{j, t},
$$

and

$$
\text { Upstream }_{i, t}=\sum_{j}\left(\text { Output }_{i \rightarrow j}^{1991}-\mathbf{1}_{j=i}\right) \cdot \text { Shock }_{j, t},
$$

where $\mathbf{1}_{j=i}$ is an indicator function for $j=i$, and the summation is over all industries, including industry $i$ itself. Thus as in the equations (6) and (7), when computing the downstream effect for sector $i$, we take into account the indirect linkages from this industry to itself (e.g., the fact that industry $i$ supplies to industry $j$, which is also a supplier to $i$ ), but we subtract the direct effect of the shock, since in our regressions we will directly control for the shock to sector $i$.

Several other points are worth noting. First, as already observed, input-output linkages (and thus the Leontief inverse entries) are pre-determined and measured in 1991. Thus, downstream and upstream effects are simply a function of shocks in connected industries working through a pre-determined input-output network.

Second, we lag both own and network shocks by one period, simply to avoid any concern about contemporaneous measurement issues from our dependent variables to shocks (e.g., in the case of TFP) and about contemporaneous joint determination. It should be stressed, however, that we do not claim that this timing will enable us to estimate causal effects. Rather, we rely on the plausible exogeneity of shocks, especially for imports from China and federal government spending, and caution that this exogeneity is likely to be absent in the case of the TFP and foreign patenting shocks.

Third, equation (12) is formulated in changes, and shocks are always specified in changes as detailed below. The specification could have alternatively been written in levels together with an industry fixed effect. The advantage of the current formulation is that it both follows more directly from and connects to our theoretical model, and imposes that the error term is stationary in differences, which is generally a better description of macro time series.

Finally, in what follows, unless otherwise stated, we standardize the $S h o c k_{i, t-1}$ variable so that a unit increase corresponds to a one standard-deviation change in the positive direction 
(e.g., decrease in imports or increase in TFP), and the Upstream $_{i, t-1}$ and Downstream Dit, $_{1}$ variables are constructed in the same units. This implies that the coefficient on the $S h o c k_{i, t-1}$ variable will measure the impact of a one standard-deviation increase in the industry's own shock, whereas the coefficients on Upstream $_{i, t-1}$ and Downstream Dit-1 $_{i}$ will measure the impact of a one standard-deviation increase in the shock of all customers and suppliers of an industry. Moreover, all of these coefficients are directly comparable and are expected to be positive where theory predicts a network-based effect.

\subsection{China Import Shocks}

Our first shock relates to the growth of imports from China and follows Autor et al. (2013) and Acemoglu et al. (2015). Acemoglu et al. (2015) show this pattern for decade-long adjustments, and we extend this analysis to shorter frequencies considered in macroeconomics. As highlighted in Section 2, this demand-side shock should have greater upstream effects than downstream effects, and in the case of Cobb-Douglas, downstream effects should not be present at all.

We first define ChinaTrade to capture this industry exposure to rising Chinese trade,

$$
\text { ChinaTrade }_{j, t}=-\frac{\text { U.S. Imports from China }}{j, t} .
$$

This variable, however, is clearly endogenous, as it will tend to be higher when the industry in question has lower productivity growth for other reasons, creating greater room for a rise in imports, and is thus not a good measure of shocks for our analysis. To deal with this endogeneity concern, we follow Autor et al. (2013) and Acemoglu et al. (2015) and instrument this variable with its exogenous component, defined as the change in import penetration from China to eight major non-U.S. countries relative to 1991 U.S. market volume, with the nations being Austria, Denmark, Finland, Germany, Japan, New Zealand, Spain, and Switzerland:

$$
\text { ChinaTrade }_{j, t}^{I V}=-\frac{\text { Non-U.S. Imports from China }}{j, t} .
$$

This instrument has the advantage of not being directly affected by changes in productivity or demand in the U.S. economy. ${ }^{16}$

The downstream and upstream effects are calculated from (13) and (14) adapted to this case. For example, for the downstream effects coming from supplier industries, we model the shock:

$$
\text { Downstream }_{i, t}^{\text {Trade }}=\sum_{j}\left(\text { Input }_{j \rightarrow i}^{1991}-\mathbf{1}_{j=i}\right) \cdot \Delta \text { ChinaTrade }_{j, t} .
$$

\footnotetext{
${ }^{16}$ First-stage equations naturally also control for all other covariates from the second stage, including the lagged dependent variable, to ensure consistent estimation. But of course, the only excluded instrument is the exogenous component of the change in import penetration.
} 
We also construct the network instruments using the same reasoning as in (13) and (14). For example, for the downstream effects this simply takes the form of

$$
\text { Downstream }_{i, t}^{\text {TradeIV }}=\sum_{j}\left(\text { Input }_{j \rightarrow i}^{1991}-\mathbf{1}_{j=i}\right) \cdot \Delta \text { ChinaTrade }_{j, t}^{I V} .
$$

In summary, we have three endogenous variables, ChinaTrade ${ }_{j, t}$, Downstream Trade $_{i, t}$ and Upstream ${ }_{i, t}^{\text {Trade }}$, and three instruments, ChinaTrade ${ }_{j, t}^{I V}$, Downstream ${ }_{i, t}^{\text {TradeIV }}$ and Upstream $_{i, t}^{\text {TradeIV }}$. The first stages for these three variables are shown in Appendix Table 1 (all appendix tables are included in Appendix B).

Table 2a presents our estimates of own and network effects from this exercise, using a table format which we replicate for each subsequent shock. Table 2a presents our baseline results for the three outcome variables, considering one and three lags for the dependent variable, and shows strong upstream effects on supplier industries (similar to Acemoglu et al. 2015).

More specifically, recall that we have standardized (in terms of standard-deviation units) and normalized all of our shocks to be positive, so that an increase in imports from China corresponds to a negative value of the shocks, and thus positive coefficients imply that rising imports from China reduce value added and employment in the affected industries. In this light, the results in Column 1 indicate that a one standard-deviation own-industry shock reduces the focal industry's value added growth by 3.4\%. ${ }^{17}$ More interestingly given our focus, they also indicate that a similar one standard-deviation change in customers of an industry leads to a $7.6 \%$ decline in value added growth through upstream effects. Downstream effects are of opposite sign and statistically insignificant, though they are sometimes quantitatively sizable. Lack of (same-signed) significant downstream effects in response to demand-side shocks is consistent with our main theoretical implications outlined in Section 2. Finally, the bottom row of the table tests the other implication from the theory highlighted in Proposition 1, that the relevant diagonal entry from the Leontief inverse matrix (i.e., the coefficient on $h_{i i}$. $\Delta$ ChinaTrade $\left._{i, t-1}\right)$ should be equal to the upstream effect from other industries. For value added, this restriction is marginally rejected at $10 \%$, though it is not rejected in any of the other columns. ${ }^{18}$

Column 2 shows that the overall pattern is similar when two more lags of the dependent variable are included on the right-hand side, even though these lags show some evidence of additional persistence. In particular, the quantitative implications are very similar, and it is again the upstream effects that are significant while the downstream ones are not.

Our regression specifications follow directly from Proposition 1 (for example, in the case of

\footnotetext{
${ }^{17}$ The unweighted standard deviation in industry growth rates for our sample is 0.15 for log value added growth and 0.10 for log employment growth.

${ }^{18}$ This restriction is not tested directly from the reported regression, but from the related regression described in Section 2, following Proposition 1, where own effects reflect the diagonal elements of the Leontief inverse matrix. We report specifications in which the own effects are not scaled in this manner to maintain transparency about the direct first-order effects of own-industry shocks. In any case, the coefficient estimates when we undertake this scaling are similar to those reported in the tables in the paper.
} 
the China import shocks, equation (7)). The coefficient estimates in these regression equations do not directly translate into quantitative effects for "multipliers," however. This is because the upstream effect (the relevant dimension of the network effects in this case) corresponds to the impact of the shock of all other industries, weighted by their upstream linkages, on the focal industry. Instead, to obtain an economically meaningful multiplier, measuring how large the total impact of a shock is relative to its direct effect, we need to measure its impact on all other industries. To achieve this, we convert upstream and downstream effects into a weighted average of shocks in other industries using the Leontief inverse elements of weights. ${ }^{19}$ We use these adjusted estimates to construct the impulse response functions depicted in Figure 1a and for computing the relevant multipliers. Panel A of Figure 1a depicts the impulse response of value added to a one standard-deviation Chinese import shock obtained from this exercise (with a specification corresponding to Column 2 of Table 2a). These impulse responses show that the quantitative magnitude of the network effects (in this case, upstream effects, since we are focusing on demand-side shocks) are considerably larger than the direct effect: the direct effect (from the own shock) after ten periods is a $3.46 \%$ increase in value added growth, while the total impact is a $22.09 \%(3.46+18.64)$ increase in value added. This yields a multiplier of $6.4(\simeq 22.09 / 3.46)$, and implies that input-output linkages more than double the direct effects of demand-side shocks. It can be seen from the figure that the implied multipliers are very similar at different horizons.

Columns 3 and 4 turn to employment. The overall pattern and even the quantitative magnitudes are very similar, with clear upstream effects and no downstream effects, and the theory-implied restrictions receive support from our estimates. Panel A of Figure 1b depicts the impulse response of employment to the same shock as in Figure 1a. The implied multiplier in this case (for employment changes) is 5.86 .

Columns 5 and 6 turn to labor productivity. Here we find no robust patterns, which is not surprising since Columns 1-4 document that the numerator and denominator move in the same direction and by similar amounts.

Table $2 \mathrm{~b}$ reports multiple robustness checks. Our results are very similar without the own-

\footnotetext{
${ }^{19}$ More specifically, focusing on upstream effects, recall that Upstream $_{i, t}=\sum_{j}\left(\right.$ Output $\left._{i \rightarrow j}^{1991}-\mathbf{1}_{j=i}\right)$. $S h o c k_{j, t}$, whereas for this term to capture the quantitative impact of shocks on supplier industries, we would need it to take the form

$$
\sum_{j} \frac{\left(\text { Output } \%_{i \rightarrow j}^{1991}-\mathbf{1}_{j=i}\right)}{\sum_{k}\left(\text { Output } \%_{i \rightarrow k}^{1991}-\mathbf{1}_{k=i}\right)} \cdot \text { Shock }_{j, t},
$$

so that it corresponds to a weighted average of shocks hitting industries.

The simplest and most transparent approach to make this adjustment is to divide our coefficient estimates by the average of the $\sum_{k}\left(\right.$ Output $\left.\%_{i \rightarrow k}^{1991}-\mathbf{1}_{k=i}\right)$ 's, i.e., by $\frac{1}{n} \sum_{i} \sum_{k}\left(\right.$ Output $\%_{i \rightarrow k}^{1991}-\mathbf{1}_{k=i}$ ) (where $n$ is the number of industries). The adjustment for the downstream effect is very similar. From the U.S. input-output matrix, this adjustment factor is 2.156 .

An alternative method would be to rerun all of our specifications using the adjusted upstream and downstream measures (computed as weighted averages as indicated above). This method yields estimates of network multipliers for value added and employment of 5.9 and 8.0, respectively, which are comparable to the 6.4 and 5.9 multipliers estimated by the direct adjustment method outlined here and reported below.
} 
shock term. Our baseline estimates are unweighted, and we obtain similar results when we weight observations by log 1991 value added or by 1991 employment levels. We also consider a series of more demanding specifications where we include a full set of two-, three- and four-digit SIC dummies. Since our specification in equation (12) is in changes, this amounts to including linear time trends for these industry groupings. The results are generally robust, although the downstream effects do move around and sometimes become larger, even if still far from significance.

The final column of Table $2 \mathrm{~b}$ returns to the resource constraint effect identified in Proposition 1. As noted above, our baseline specifications focusing on demand-side shocks have ignored this resource constraint effect, corresponding to the third term in equation (7). To the extent that this term is correlated with our network effect, it may lead to biased estimates. We compute the empirical equivalent of this third term following equation (7) closely. We sum nominal manufacturing imports from China to obtain the term $\sum_{k=1}^{n} d \tilde{G}_{k}$, multiply it with an estimate of $\beta_{j}$, computed as the value added share of industry $j$, divide it by $p_{j} y_{j}$, and then multiply it with the corresponding entries of the Leontief inverse of the upstream linkages to obtain $\sum_{j=1}^{n} \hat{h}_{j i} \frac{1}{p_{j} y_{j}} \beta_{j} \sum_{k=1}^{n} d \tilde{G}_{k}$ (ignoring the term $1+\lambda$ in the denominator). We then add this term as an additional regressor instrumented by an additional instrument computed in the same way from Chinese imports by the same eight non-U.S. advanced economies. The final column of Table $2 \mathrm{~b}$ shows that this specification leads to somewhat larger network effects, but the overall picture remains unchanged.

Appendix Table 2a repeats this analysis with log real shipments growth as the outcome variable, and also shows similar results.

An additional issue is that the presence of the lagged dependent variable on the right-hand side of our estimating equation, (12), introduces the possibility of biased estimates when the time dimension is short due to the challenges of obtaining consistent estimates of the persistence parameter, $\psi$, with short panels as noted by Nickell (1981). We further investigate this issue in Appendix Table 2b. In particular, our main concern here is with the network effects, which may inherit the bias of the parameter $\psi$ in short panels. One way of ensuring that this bias is not responsible for our results is to impose different values for the parameter $\psi$ and verify that this has no or little impact on our results (see Acemoglu, Naidu, Restrepo and Robinson, 2014). Appendix Table 2b performs this exercise for the China trade shock and documents that both own and upstream effects are highly significant and similar to our baseline estimates for any value of $\psi$ between our estimate of this parameter in Table $2 \mathrm{a}(\psi=0)$ and the full unit root limit $(\psi=1)$, becoming only a little weaker at the full unit root case of $\psi=1$ (while downstream effects remain insignificant except marginally at $\psi=1$ ).

Appendix Table 2c considers longer time periods, thus linking our results more closely to Acemoglu et al. (2015), who focused on a decadal panel. For two-year periods, we prepare nine time periods from 1991 - 1993 to 2007 - 2009. For three-year periods, we consider six time 
periods from 1991 - 1994 to 2006 - 2009. For four-year periods, we consider four time periods from 1991-1995 to 2003-2007. For five-year periods, we consider 1991-1996, 1996-2001, and $2001-2006$. In each case, the first period is used to create the network lags. The downstream customer effects and own-industry effects tend to grow with longer time periods.

In addition to these robustness checks, Appendix Table 6 shows very similar outcomes when we consider nominal value added and shipments growth instead of our baseline real value added growth and the real shipments shown in Appendix Table 2a. Appendix Table 7 also reports results where we vary the number of lags included for own-industry shocks and network shocks. We report in the table the sums of the coefficients across the deeper lags and their statistical significance. These variants yield quite similar conclusions to our reported estimations.

\subsection{Federal Spending Shocks}

The next analysis considers changes in U.S. federal government spending levels, which are anticipated to operate similar to trade shocks by affecting industries through heightened demand from industrial customers. We first calculate from the 1992 BEA Input-Output Matrix the share of sales for each industry that went to the federal government,

$$
\text { FedSales } \%_{i}=\frac{\text { Sales }_{i \rightarrow F e d}}{\text { Sales }_{i}} .
$$

This share ranges from zero dependency for about $10 \%$ of industries to over $50 \%$ for the top percentile of industries in terms of dependency. Some prominent examples and their share of sales include 3731 Ship Building and Repairing (76\%), 3761 Guided Missiles and Space Vehicles (74\%), 3482 Small Arms Ammunition (65\%), and 3812 Search, Detection, Navigation, Guidance, Aeronautical and Nautical Systems and Instruments (51\%).

We interact this measure with the log change in federal government expenditures,

$$
\text { FederalShock } k_{i, t}=\text { FedSales } \%_{i}^{1991} \cdot \Delta \ln \text { FederalSpending }{ }_{t-1},
$$

holding fixed the industry dependency at its 1991 level. Intuitively, the specification anticipates greater "shocks" from aggregate federal budget changes for industries that have larger initial shares of sales to the federal government. The change in federal spending is lagged one year to reflect the fact that procurement frequently extends into the following year. Once again following (13) and (14), the downstream effects in this case are defined as

$$
\text { Downstream }_{i, t}^{\text {Federal }}=\sum_{j}\left(\text { Input }_{j \rightarrow i}^{1991}-\mathbf{1}_{j=i}\right) \cdot \text { FederalShock } k_{j, t} .
$$

A similar approach is taken for the other network metrics.

Because this variable focuses on federal spending changes in the aggregate (driven by, among other things, swings in political moods, ideology, identity of the government, wars and budget exigencies), and is then constructed with the interaction of these aggregate changes with the time-invariant and pre-determined dependency of each industry on federal spending, 
we believe that it can be taken as plausibly exogenous to the contemporaneous productivity or supply-side shocks hitting the focal industry.

The structure of Table $3 \mathrm{a}$ is identical to those examining trade shocks. The results are also similar. For example, in Table 3a, upstream effects are again significant and quantitatively sizable (about three to five times as large as own effects). Downstream effects are now of the same sign as the upstream effect, but continue to be statistically insignificant. The theoryimplied restriction reported in the bottom row is again broadly supported (it is never rejected at $5 \%$ ). In addition, the own effect is insignificant when we only control for one lag of the dependent variable, but significant both in Columns 2 and 4 when we control for three lags.

Table $3 \mathrm{~b}$ and Appendix Tables 3a-3c, 6 and 7 perform the same robustness checks as those discussed for trade shocks and show that the above-mentioned patterns are generally quite robust. All in all, the propagation of this very different demand-side shock appears remarkably similar to the propagation of the import shocks, and in both cases in line with the theory we have used to motivate our approach.

The economic magnitudes are once more far from trivial. Panel B of Figures $1 \mathrm{a}$ and $1 \mathrm{~b}$ depict the impulse response functions for own and upstream effects computed in the same way as for Panel A, and indicate that there are once again sizable network effects. The implied network multipliers for value added and employment at the 10-year horizon are 6.42 and 5.00, respectively.

\subsection{TFP Shocks}

We next turn to supply-side shocks, starting with TFP. Baseline TFP shocks for manufacturing industries are the lagged change in four-factor TFP taken from the NBER Productivity Database. Importantly, these TFP measures control for materials, and thus should not be mechanically a function of downstream effects (changes in prices and quantities in industries supplying inputs to the focal industry).

Similar to our other network-based measures, these are constructed by aggregating these industry-level log components of TFP in connected industries. Continuing our illustration using downstream effects from shocks to supplier industries and again following on (13) and (14), we model

$$
\text { Downstream }{ }_{i, t}^{T F P}=\sum_{j}\left(\text { Input }_{j \rightarrow i}^{1991}-\mathbf{1}_{j=i}\right) \cdot \Delta \ln T F P_{j, t}
$$

We should caution that the case for the exogeneity of the TFP shocks is weaker, because past TFP may be endogenous to other shocks (e.g., to capacity utilization or labor hoarding) which have a persistent impact on value added and factor demands. With this caveat, we still believe that predetermined TFP shocks are informative about how supply-side shocks spread through the input-output network.

The structure of Table 4a is identical to those examining trade and federal spending shocks. Consistent with theory, it is now downstream effects that are more sizable and important, 
though in this case there are some statistically significant estimates of upstream effects as well. For example, in Column 1 of Table 4a, downstream effects are estimated to have a coefficient of 0.060 (standard error $=0.020$ ), while upstream effects come in at 0.024 (standard error $=$ 0.011). Interestingly, own effects are small and imprecise for value added, but more precisely estimated (though still about half of the upstream effects) for employment. The theoretical restriction tested in the bottom row is now rejected for value added, where the own effects are small, but is in closer alignment for employment. The robustness checks reported in Appendix B confirm this overall pattern. ${ }^{20}$

Economic magnitudes can again be gleaned from Panel $\mathrm{C}$ of Figures 1a and 1b; the implied multipliers are 15.56 and 4.43 for value added growth and employment growth over ten years, respectively. The larger multiplier for value added in this case reflects the smaller direct (own) impact.

\subsection{Foreign Patenting Shocks}

Our final shock represents changes in patented technology frontiers. Since this shock also captures supply-side changes in productivity, responses to it should be similar to those to TFP shocks.

Baseline patent shocks for manufacturing industries in Table 5a are the lagged log change in USPTO granted patents filed by overseas inventors associated with the industry. We measure foreign patent shocks using USPTO granted patents through 2009. We develop a new concordance of patent classes to four-digit manufacturing industries that extends the earlier work of Silverman (1999), Johnson (1999), and Kerr (2008). Continuing our downstream effects example, we have

$$
\text { Downstream }{ }_{i, t}^{\text {ForeignPatent }}=\sum_{j}\left(\text { Input }_{j \rightarrow i}^{1991}-\mathbf{1}_{j=i}\right) \cdot \Delta \ln \text { Patents } \text { Foreign }_{j, t} .
$$

These foreign patents quantify technology changes in the world technology frontier external to the U.S. economy (e.g., patents filed by car manufacturers in Germany and Japan signal advances in automobile technologies that have not originated in the United States). There are two additional difficulties in this case, however. First, foreign patenting may be correlated with past technological improvements in the U.S. sectors, which might have persistent effects. Second, improved technology abroad may directly impact U.S. firms through fiercer product market competition, not just through technology and productivity spillovers (e.g., Bloom, Shankerman and Van Reenen, 2013). ${ }^{21}$ These concerns make us more cautious in interpreting the foreign patenting shocks, especially for own effects, though we believe that this analysis is still informative about network-based propagation.

\footnotetext{
${ }^{20}$ However, in this case, Appendix Table $4 \mathrm{~b}$ shows that the results are sensitive to the exact value of the persistence parameter, $\psi$.

${ }^{21}$ Bloom et al. (2013) develop a strategy for controlling for this competition effect, but the implementation of their strategy is not feasible given our industry-level data.
} 
Table 5a shows strong downstream effects with again no evidence of sizable upstream effects. The theory-implied restrictions in the bottom row of the table are typically rejected, reflecting the very small and sometimes incorrectly-signed estimates of own effects. One possible explanation for this pattern of own effects is that, as already noted, an increase in foreign patents in one's own industry likely signals fiercer competition from international competitors. The network effects, which should be less impacted by these considerations, are again quite similar to our theory's predictions.

Panel D of Figures 1a and 1b again depict the impulse responses of value added and employment. We do not compute multipliers in this case, since the own effects are imprecisely estimated and potentially biased for the reasons explained above, thus making multiplier estimates harder to interpret.

\subsection{VAR Analysis}

Our empirical specification, (12), directly builds on our theoretical model (in particular, equations (6) and (7)), and expresses the endogenous response of value added and employment to shocks hitting all industries. An alternative is to follow vector auto regression (VAR) models and express endogenous variables as a function of own shocks and the values of the endogenous variables of linked industries. The analog of equation (12) in this case would be

$$
\begin{aligned}
\Delta \ln Y_{i, t}= & \delta_{t}+\psi \Delta \ln Y_{i, t-1}+\beta^{\text {own }} S_{h o c k} k_{i, t-1} \\
& +\beta^{\text {upstream }} \Delta \ln Y_{i, t-1}^{\text {Upstream }}+\beta^{\text {downstream }} \Delta \ln Y_{i, t-1}^{\text {Downstream }}+\varepsilon_{i, t},
\end{aligned}
$$

which only features the shock hitting sector $i$, and models upstream and downstream effects from the changes in value added of linked industries - the terms $\Delta \ln Y_{i, t-1}^{U p s t r e a m}$ and $\Delta \ln Y_{i, t-1}^{\text {Downstream }}$. This equation could also be derived from our theoretical framework. Relative to our baseline empirical model, (12), this specification faces two related problems. First, the terms $\Delta \ln Y_{i, t-1}^{\text {Upstream }}$ and $\Delta \ln Y_{i, t-1}^{\text {Downstream }}$ generate a version of Manski's well-known reflection problem (Manski, 1993), as outcome variables of one industry are being regressed on the contemporaneous (or one-period lagged) outcomes of other industries, creating the possibility of spurious correlation. Second, these terms are also more likely to be correlated with each other, potentially leading to multicollinearity, which will make distinguishing these various effects more difficult.

These problems notwithstanding, we now estimate equation (16) to show that the results from this complementary approach are broadly similar. To avoid the most severe form of the reflection problem, throughout we instrument for the upstream and downstream effects, $\Delta \ln Y_{i, t-1}^{\text {Upstream }}$ and $\Delta \ln Y_{i, t-1}^{\text {Downstream }}$, using the first and second lags of each shock as experienced in the network (i.e., our instruments are the core regressors in equation (12), Upstream $_{i, t-1}$ and Downstream Dit-1 $_{i}$. We report two specifications per shock. In the first, we model and instrument the focal part of the network relevant for each shock (e.g., upstream 
effects for supply-side shocks and downstream effects for demand-side shocks). In the second specification, we include and instrument for both upstream and downstream effects. Also, in the case of China trade shocks, we continue to instrument for the own shock, Shock $k_{i, t-1}$ as well.

The results of this exercise are reported in Table 6 and are quite consistent with our baseline findings. Even though this empirical specification is more demanding for the reasons explained above, the specifications focusing on China trade and TFP shocks give similar results, and specifications using federal spending shocks also lead to similar results for value added, though not for employment. Foreign patenting results do not hold with this approach, however. ${ }^{22}$

\subsection{Combined Shock Analysis}

Table 7 estimates own, upstream and downstream effects simultaneously from several of the shocks so far analyzed in isolation. This is relevant for two related reasons. First, we would like to verify that our downstream and upstream effects indeed capture network-based propagation of different types of shocks rather than some other omitted characteristics, and attempting to simultaneously estimate these effects provides some information on this concern. Second, it is important to quantify whether the simultaneous operation of all of these networked effects creates attenuation, which is relevant for our quantitative evaluation.

Table 7 shows the estimates of upstream and downstream effects in this joint analysis are remarkably similar to our previous results. Appendix Table 8 also shows this similarity when we exclude the foreign patenting shocks due to the concerns about own effects discussed above. These results bolster our confidence in the patterns documented so far and also suggest that the quantitative magnitudes of the propagation through these input-output networks is larger when we consider all four shocks simultaneously.

To quantify impacts from this joint exercise, we now consider one standard-deviation changes of the three shocks, imports from China, federal spending and TFP, simultaneously. The impulse response functions from this exercise are shown in Figure 2 in Appendix B, and the combined multipliers for value added and employment growth in Panels A and B are 11.47 and 8.23, respectively. Thus, the network elements jointly continue to account for more fluctuation than direct components. The lower panels show similar results when including foreign patenting shocks.

\footnotetext{
${ }^{22}$ Appendix Figure 1 reports impulse response functions akin to Figures 1a and $1 \mathrm{~b}$ using the results from Table 6, where we trace out a one-standard deviation upstream or downstream network component in terms of value added or employment, as instrumented by each shock, alongside the direct effect of the shock. For brevity, we only plot the stable and theory-consistent estimates, which are the ones that are meaningful to compare to our baseline results. The resulting magnitudes are comparable to, though somewhat larger than, our main estimates.
} 


\subsection{Monte Carlo Verification}

Though our empirical strategy so far has closely followed our theoretical model, there are several aspects in which the true data generating process might be more complicated than the one implied by our model. First, our model abstracted from dynamic interactions between sectors, whereas the original Long and Plosser (1983) paper assumed that an industry could only use as inputs at time $t$ the output produced by other industries at time $t-1$. This dynamic structure implies that rather than shocks being transmitted through the Leontief inverse of the input-output matrix as in our equations (6) and (7), they would be transmitted from one period to the next directly through the input-output matrix. Over time, this transmission would still lead to a cumulative impact as summarized by the Leontief inverse (as we show in Appendix C). Nevertheless, we might be concerned that this type of slow adjustment would lead to significant misspecification in our empirical work, where we impose equations (6) and (7). In Appendix C, we conduct a Monte Carlo exercise where data are generated at quarterly frequency using the Long and Plosser (1983) timing (and shocks are serially correlated), and regressions are run at the annual frequency using the specifications we have utilized so far (thus filtering the observed shocks through the Leontief inverse of the input-output matrix). We find that the time averaging of the higher frequency data to annual observations ensures that specifications based on the Leontief inverse do not lead to any major misspecification. In particular, our results, described in detail in Appendix Figures 4-7, indicate that regressions run time-averaged data can recover whether upstream or downstream linkages are important.

A second concern is whether measurement error in the input-output matrix might be significantly amplified when we compute the Leontief inverses. Another Monte Carlo exercise we perform in Appendix $\mathrm{C}$ verifies that even if the input-output matrix is measured with error, regressions of the sort we have used are capable of recovering the correct parameters. We take these two Monte Carlo exercises as useful confirmation of the robustness and informativeness of our empirical strategy.

\section{Additional Results: The Geographic Network}

We next turn to an analysis of the geographic network's impact on the propagation of shocks. The theory in Section 2 describes how shocks to an industry can also propagate regionally (e.g., within commuting zones) because they expand or depress economic activity, impacting the decisions of other industries in the area. Though a full analysis of these local interactions is beyond the scope of the present effort (see, for example, the treatment of Acemoglu et al. (2015) for medium-frequency import shocks on local economies), we can nonetheless get a sense of the importance of these channels of propagation by looking at the impact of a shock to a particular industry on other industries that tend to collocate with it. This is essentially the idea of the geographic network introduced above. 
Table 8 considers all four geographic effects simultaneously, which is particularly relevant since they are all working through the same local geographic networks. In Columns 1 and 3 we only model own-industry effects and geographic spillovers, while Columns 2 and 4 add the downstream and upstream network effects as well. Our most important observation from this analysis is the stability of the network effects compared to Table 7 . The latter continues to adhere to theory and shows that our network effects are not proxying for regional spillovers or similar local conditions. The second observation is that the geographic effects are almost always precisely estimated and are quite substantial in size for demand-side shocks.

Appendix Table 9a shows that these joint patterns are robust to the specification checks considered earlier for input-output linkages. Appendix Table 9b considers each of the four shocks in isolation rather than jointly modeling them. Similar to the results presented in Table 8, the inclusion of geographic effects has little impact on our estimates of downstream and upstream network effects, which continue to adhere to theory. On the other hand, the geographic effects themselves are less stable and often substantially smaller when measured in isolation compared to the joint format. We thus remain cautious about strong interpretations of the size of the geographic effects compared to the overall stability that these specifications show for our network components.

With these caveats, the economic magnitudes of Table 8's effects are substantial. Figure 3 in Appendix B shows the impulse response functions including own and network effects in response to a one standard-deviation shock in specifications that also include geographic effects, further reported in Appendix Table 9c. The implied magnitudes of some of these geographic effects are quite large and suggest a fruitful and important area for deeper investigation. ${ }^{23}$

\section{Conclusion}

Idiosyncratic firm- or industry-level shocks could spread through a network of interconnections in the economy, propagating and amplifying their initial impact. Though their potential import was initially downplayed because of the belief that their aggregation across many units (disaggregated industries or firms) would limit their macroeconomic impact, there has been a recent revival of interest in such network-based propagation of microeconomic shocks. This paper contributes to an empirical investigation of the role of such propagation, focusing primarily on input-output linkages but also on connections through the geographic collocation patterns of industries.

One feature that makes propagation through the input-output network particularly attractive for empirical study is that theory places fairly tight restrictions on the form of the transmission of these effects. In particular, in response to demand-side shocks, upstream

\footnotetext{
${ }^{23}$ Following Autor et al. (2013), Acemoglu et al. (2015) estimate an aggregate reduction of over 1.5 million manufacturing jobs through direct and network effects from the China trade shocks. In terms of our framework, their estimates correspond to a combination of own effects and geographic spillovers; they also control for changes in the underlying population in regions in their econometric specification.
} 
propagation (to the suppliers of the directly affected industries) should be more pronounced than downstream propagation (to the customers of the directly affected industries), whereas in response to supply-side shocks, the reverse ordering should hold. In fact, when production technologies and consumer preferences are Cobb-Douglas, there should only be upstream propagation with demand-side shocks and only downstream propagation with supply-side shocks. Moreover, the quantitative magnitudes of the direct effects and the downstream/upstream effects are pinned down by theory.

After reviewing these theoretical basics, we turn to an empirical investigation of the propagation of four different types of shocks - China import shocks and federal government spending shocks on the demand side, and TFP and foreign patenting shocks on the supply side. In each case, we study these shocks first in isolation and then in combination with the other shocks, and separately estimate own (direct) effects as well as downstream and upstream effects. Throughout, our focus is on annual variation, which appears more relevant for the question of macroeconomic fluctuations, though we verify the robustness of our results to lower-frequency analysis.

Our empirical results paint a fairly uniform pattern across the different types of shocks. In each case, the patterns are consistent with theory - in the case of demand-side shocks, upstream effects strongly overshadow downstream effects, which are often zero or in the opposite direction, and the converse is true with supply-side shocks. Moreover, the theory-implied quantitative restrictions are often verified, excepting the foreign patenting shocks. Equally important, we also find the network-based propagation of shocks to be quantitatively sizable, and in each case, more important than the direct effect of the shock - sometimes more than five times as important. These patterns appear to be fairly robust across specifications and different control strategies.

In addition to the propagation of shocks through the input-output network, the geographic spread of economic shocks could potentially be important. For example, many economic transactions, particularly for non-tradables, take place within the local economy (e.g., a county or commuting zone). If so, a negative shock to an industry concentrated in an area will impact firms and workers in that area. Though a full analysis of this geographic dimension requires detailed data with geography/industry breakdown, we also undertake a preliminary investigation of these linkages by focusing on the collocation patterns of industries. The idea is simple: if two industries tend to collocate strongly, meaning that wherever one industry plays a major role in the local economy, the other industry is also likely to be overrepresented, then shocks to the first industry will tend to be felt more strongly by this collocating industry than other, geographically less-connected industries. We derive a theoretical relationship showing how industry-level shocks spread to other industries depending on collocation patterns and then empirically investigate this linkage.

Our results in this domain are somewhat less robust, but still indicate a fairly sizable 
impact of the propagation of shocks through the geographic collocation network. In fact, quantitatively this channel appears to be, if anything, somewhat more important than the transmission of shocks to the input-output network. Interestingly, however, controlling for this geographic channel does not attenuate or weaken the evidence we find for the propagation of shocks with input-output network.

Though ours is not the first paper showing that certain shocks spread through the network of input-output linkages (and also of geographic connections), we still consider our paper as part of the early phase of this emerging literature documenting the empirical power of networkbased propagation of shocks. Several areas of future work look promising from our vantage point. First, as already noted, the geographic spread of shocks can be better studied by using data and empirical methods that cover multiple geographic scales and levels of interaction, and even better would be to incorporate measures of the geographic span of the operations and plants of multi-unit firms using the Census Bureau's Longitudinal Business Database.

Second, the input-output network we utilize is still fairly aggregated. The theoretical logic applies at any level of disaggregation, and even at the level of firms. Though firm inputoutput linkages require some care (since many such relations may be non-competitive due to the presence of relationship-specific investments or holdup problems), the same ideas can also be extended to the firm-level network of input-output linkages. Atalay, Hortacsu and Syverson (2014) and Atalay, Hortacsu, Roberts and Syverson (2011) take first steps in constructing such firm-level networks, which can then be used for studying this type of propagation.

Third, the simple but powerful nature of the theory we have already exploited in this paper also suggests that more structural approaches could be quite fruitfully applied in this domain, which will enable more rigorous testing of some of the theoretical predictions of this class of models. For example, the Leontief inverse matrix also puts a considerable amount of discipline about the co-movement of value added and employment across industries resulting from shocks spreading through the input-output network, which can be formally investigated.

Fourth, the role of the input-output and the geographic networks in the propagation of industry-level (micro) shocks suggests that these networks may also be playing a role in the amplification of macro shocks — such as aggregate demand, monetary and financial shocks which appears a generally understudied area.

Fifth, the two types of networks we have focused on are by no means the only ones that may matter for macroeconomic outcomes. Two others that have recently been investigated are the financial network, which can lead to the propagation and contagion of shocks hitting some financial institutions to the rest of the financial system (e.g., Allen and Gale, 2000, Acemoglu, Ozdaglar and Tahbaz-Salehi, 2015a, Elliott, Golub and Jackson, 2014, Cabrales, Gottardi and Vega-Redondo, 2014), and the idea/innovation network, which can lead to the spread of new knowledge, innovations and practices (studied, e.g., in Acemoglu, Akcigit and Kerr, 2015, as well as indirectly in Bloom et al., 2013). Our decision to abstract from these was partly because 
of our empirical frame, which centers on industry-level shocks, and also because of our focus on shorter-run fluctuations (whereas the propagation of new ideas and innovations through the innovation network is likely to be more important at five- or ten-year frequencies or even longer). Nevertheless, combining these various types of network linkages may be a fruitful area for future research.

Finally, in addition to the propagation of shocks to other industries or firms, the network linkages emphasized here can also fundamentally change the nature of macroeconomic outcomes and their volatility. For example, Acemoglu, Ozdaglar and Tahbaz-Salehi (2014) show how tail macroeconomic risk can be created from the propagation of microeconomic shocks through the input-output network, while Schennach (2013) suggests that these types of network effects may change the persistence properties of macroeconomic time-series. These new areas also constitute fruitful directions for future research.

\section{References}

Acemoglu, Daron, Ufuk Akcigit, and William Kerr (2015), "The Innovation Network", MIT Working Paper.

Acemoglu, Daron, David Autor, David Dorn, Gordon Hanson, and Brendan Price (2015), "Import Competition and the Great U.S. Employment Sag of the 2000s", Journal of Labor Economics, forthcoming.

Acemoglu, Daron, Vasco Carvalho, Asuman Ozdaglar, and Alireza Tahbaz-Salehi (2012), "The Network Origins of Aggregate Fluctuations", Econometrica, 80:5, 1977-2016.

Acemoglu, Daron, Suresh Naidu, Pascual Restrepo, and James A Robinson (2014), "Democracy Does Cause Growth", NBER Working Paper.

Acemoglu, Daron, Asuman Ozdaglar, and Alireza Tahbaz-Salehi (2014), "Microeconomic Origins of Macroeconomic Tail Risks", NBER Working Paper.

Acemoglu, Daron, Asuman Ozdaglar, and Alireza Tahbaz-Salehi (2015a), "Systemic Risk and Stability in Financial Networks", American Economic Review, 105:2, 564-608.

Acemoglu, Daron, Asuman Ozdaglar, and Alireza Tahbaz-Salehi (2015b), "Networks, Shocks and Propagation", Handbook of Network Economics, forthcoming.

Allen, Franklin and Douglas Gale (2000), "Financial Contagion", Journal of Political Economy, 108:1, 1-33.

Atalay, Enghin, Ali Hortacsu, and Chad Syverson (2014), "Vertical Integration and Input Flows", American Economic Review, 104:4, 1120-1148.

Atalay, Enghin, Ali Hortacsu, Jimmy Roberts, and Chad Syverson (2011), "Network Structure of Production", Proceedings of the National Academy of Sciences, 108:13, 5199-5202.

Autor, David, David Dorn, and Gordon Hanson (2013), "The China Syndrome: Local Labor Market Effects of Import Competition in the United States", American Economic Review, 103:6, 2121-2168.

Bak, Per, Kan Chen, Jose Scheinkman, and Michael Woodford (1993), "Aggregate Fluctuations from Independent Sectoral Shocks: Self-organized Criticality in a Model of Production and Inventory Dynamics", Ricerche Economiche, 47:1, 3-30.

Ball, Laurence and David Romer (1990), "Real Rigidities and the Non-neutrality of Money", Review of Economic Studies, 57:2, 183-203. 
Baqaee, David (2015), "Labor Intensity in an Interconnected Economy", Harvard Working Paper.

Barrot, Jean-Noel, and Julien Sauvagnat (2014), "Input Specificity and the Propagation of Idiosyncratic Shocks in Production Networks", MIT Working Paper.

Becker, Randy, Wayne Gray, and Jordan Marvakov (2013), "NBER-CES Manufacturing Industry Database: Technical Notes", National Bureau of Economic Research (http://www.nber.org/nberces/nberces5809/nberces_5809_technical_notes.pdf, accessed $2 / 1 / 15)$.

Bernanke, Ben and Mark Gertler (1989), "Agency Costs, Net Worth, and Business Fluctuations", American Economic Review, 79:1, 14-31.

Blanchard, Olivier J. and Nobuhiro Kiyotaki (1987), "Monopolistic Competition and the Effects of Aggregate Demand", American Economic Review, 77:4, 647-666.

Bloom, Nicholas, Mark Schankerman, and Jon Van Reenen (2013), "Identifying Technology Spillovers and Product Market Rivalry", Econometrica, 81, 1347-1393.

Boehm, Christoph, Aaron Flaaen, and Nitya Pandalai Nayar (2014), "Input Linkages and the Transmission of Shocks: Firm Level Evidence from the 2011 Tohoku Earthquake", Working Paper.

Cabrales, Antonio, Piero Gottardi, and Fernando Vega-Redondo (2014), "Risk-Sharing and Contagion in Networks", CESifo Working Paper 4715.

Carvalho, Vasco (2008), "Aggregate Fluctuations and the Network Structure of Intersectoral Trade", CREI Working Paper.

Carvalho, Vasco, Makoto Nirei, and Yukiko Saito (2014), "Supply Chain Disruptions: Evidence from the Great East Japan Earthquake", Working Paper.

Christiano, Lawrence, Martin Eichenbaum, and Sergio Rebelo (2011), "When Is the Government Spending Multiplier Large?", Journal of Political Economy, 119:1, 78-121.

Diamond, Peter (1982), "Aggregate Demand Management in Search Equilibrium", Journal of Political Economy, 90, 881-894.

Durlauf, Steven (1993), "Nonergodic Economic Growth", Review of Economic Studies, 60, 349-366.

Eggertsson, Gauti and Michael Woodford (2003), "The Zero Bound on Interest Rates and Optimal Monetary Policy", Brookings Papers on Economic Activity, 34:1, 139-211.

Elliott, Matthew, Benjamin Golub, and Matthew Jackson (2014), "Financial Networks and Contagion", American Economic Review, 104:10, 3115-3153.

Ellison, Glenn, Edward Glaeser, and William Kerr (2010), "What Causes Industry Agglomeration? Evidence from Coagglomeration Patterns", American Economic Review, 100:3, 11951213.

Farhi, Emmanuel and Ivan Werning (2013), "A Theory of Macroprudential Policies in the Presence of Nominal Rigidities", NBER Working Paper 19313.

Foerster, Andrew, Pierre-Daniel Sarte, and Mark Watson (2011), "Sectoral versus Aggregate Shocks: A Structural Factor Analysis of Industrial Production", Journal of Political Economy, $119,1-38$

Friedman, Milton and Anna J. Schwartz (1971), A Monetary History of the United States, 1867-1960, Princeton University Press.

Fujita, Masahisa, Paul Krugman, and Anthony Venables (1999), The Spatial Economy: Cities, Regions and International Trade, MIT Press.

Gabaix, Xavier (2011), "The Granular Origins of Aggregate Fluctuations", Econometrica, 79, 733-772. 
Greenstone, Michael, Richard Hornbeck, and Enrico Moretti (2010), "Identifying Agglomeration Spillovers: Evidence from Winners and Losers of Large Plant Openings", Journal of Political Economy, 118:3, 536-598.

Guerrieri, Veronica and Guido Lorenzoni (2012), "Credit Crises, Precautionary Savings, and the Liquidity Trap", University of Chicago Working Paper.

Hall, Robert (2009), "By How Much Does GDP Rise If the Government Buys More Output?", Brookings Papers on Economic Activity, 40:2, 183-249.

Helsley, Robert, and William Strange (2014), "Coagglomeration, Clusters, and the Scale and Composition of Cities", Journal of Political Economy, 122:5, 1064-1093.

Horvath, Michael (1998), "Cyclicality and Sectoral Linkages: Aggregate Fluctuations From Sectoral Shocks", Review of Economic Dynamics, 1, 781-808.

Horvath, Michael (2000), "Sectoral Shocks and Aggregate Fluctuations", Journal of Monetary Economics, 45, 69-106.

Johnson, Daniel (1999), "150 Years of American Invention: Methodology and a First Geographic Application", Wellesley College Economics Working Paper 99-01.

Jones, Chad (2013), "Misallocation, Economic Growth, and Input-Output Economics", in Advances in Economics and Econometrics, Tenth World Congress, Volume II, Cambridge University Press.

Jovanovic, Boyan (1987), "Micro Shocks and Aggregate Risk", Quarterly Journal of Economics, 102, 395-409.

Kerr, William (2008), "Ethnic Scientific Communities and International Technology Diffusion", Review of Economics and Statistics, 90:3, 518-537.

Kiyotaki, Nobuhiro (1988), "Multiple Expectational Equilibria under Monopolistic Competition", Quarterly Journal of Economics, 695-713.

Kiyotaki, Nobuhiro and John Moore (1997), "Credit Cycles", Journal of Political Economy, $105: 2,211-248$.

Kydland, Finn and Edward Prescott (1982), "Time to Build and Aggregate Fluctuations", Econometrica, 50, 1345-1371.

Long, John and Charles Plosser, (1983) "Real Business Cycles", Journal of Political Economy, 91:1, 39-69.

Lucas, Robert (1977), "Understanding Business Cycles", Carnegie-Rochester Conference Series on Public Policy, 5, 7-29.

Manski, Charles (1993), "Identification of Endogenous Social Effects: The Reflection Problem", Review of Economic Studies, 60:3, 531-542.

Mian, Atif, Kamalesh Rao, and Amir Sufi (2013), "Household Balance Sheets, Consumption, and the Economic Slump", Quarterly Journal of Economics, 128:4, 1687-1726.

Mian, Atif and Amir Sufi (2015), "What Explains the 2007-2009 Drop in Employment", Econometrica, forthcoming.

Nickell, Stephen (1981), "Biases in Dynamic Models with Fixed Effects", Econometrica, 49:6, $1417-1426$.

Schennach, Susanne (2013), "Long Memory via Networking", Centre for Microdata Methods and Practice Working Paper CWP13/13.

Silverman, Brian, (1999) "Technological Resources and the Direction of Corporate Diversification: Toward an Integration of the Resource-Based View and Transaction Cost Economics", Management Science, 45:8, 1109-1124. 


\section{Figures and Tables}

Figure 1a: Responses to a one standard-deviation shock taken in isolation, value-added

A. Chinese imports (reduction)

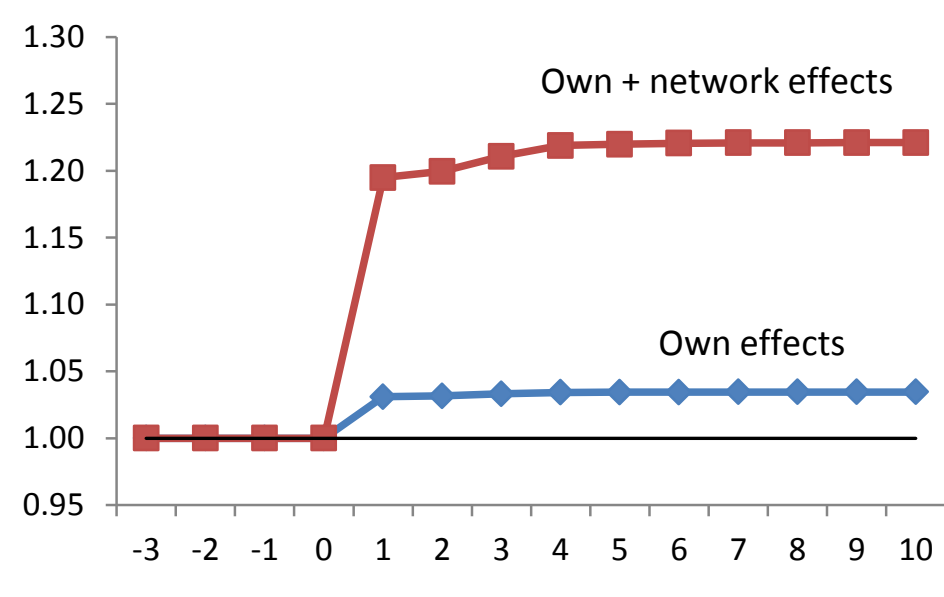

C. TFP

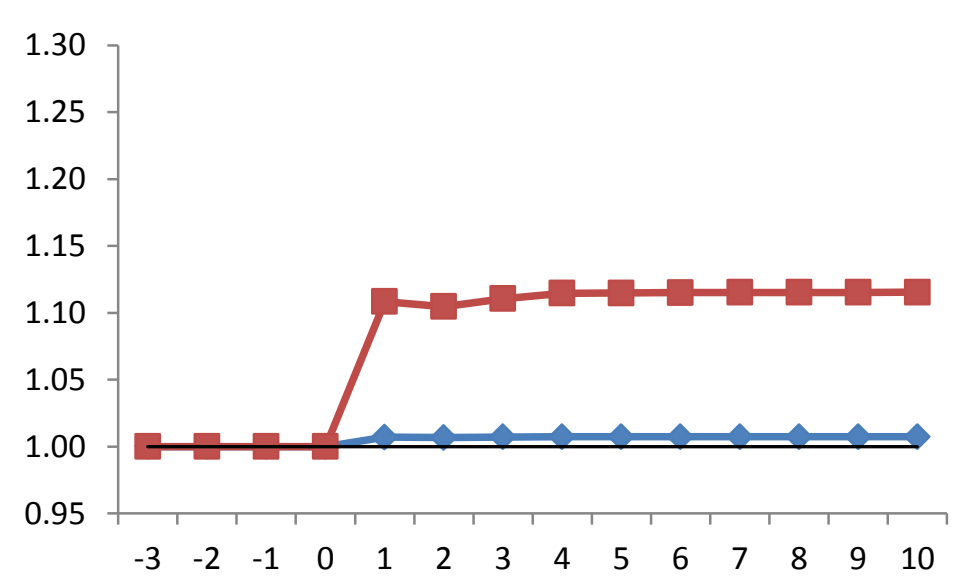

B. Federal government spending

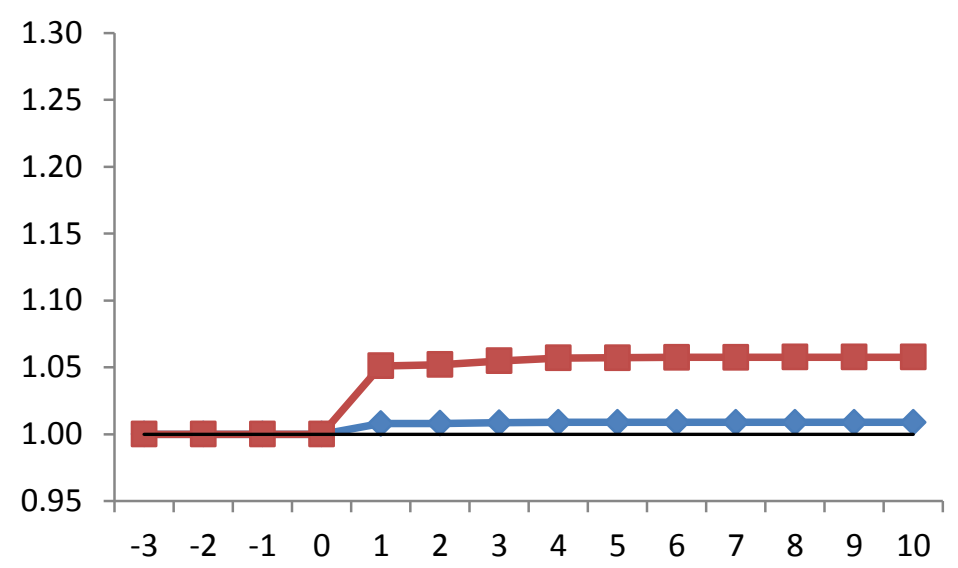

D. Foreign patenting

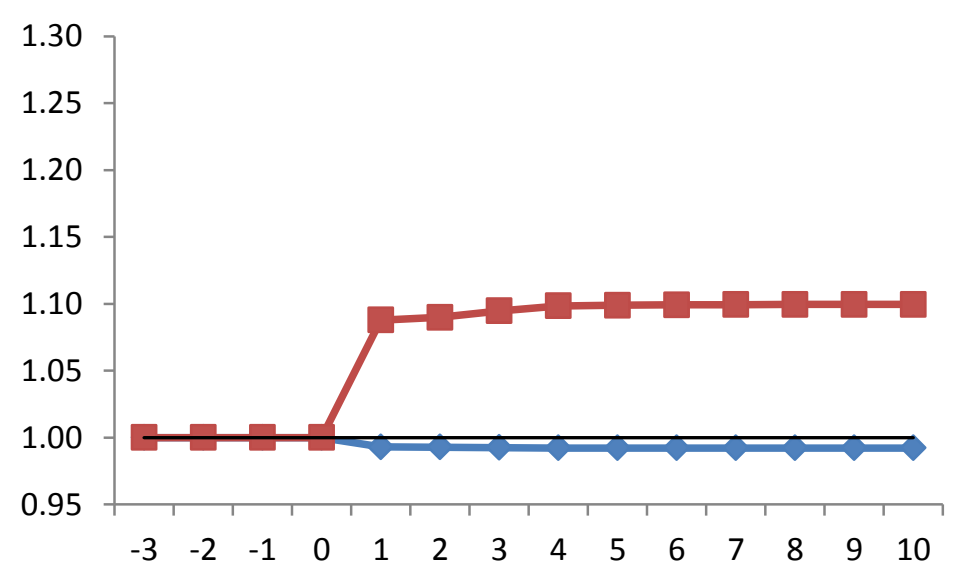

Notes: Figure plots estimated response to a one standard-deviation shock taken in isolation. Trade shocks are presented in positive terms to be visually comparable to the other shocks considered. Network effects focus on upstream contributions for the demand-side shocks of trade and federal spending and downstream contributions for the productivity shocks of TFP and foreign patenting. Responses are measured through log growth rates per the estimating equation and translated into levels off of a base initial level of one. The lag structure for the dependent variables includes three lags. 
Figure 1b: Responses to a one standard-deviation shock taken in isolation, employment

A. Chinese imports (reduction)

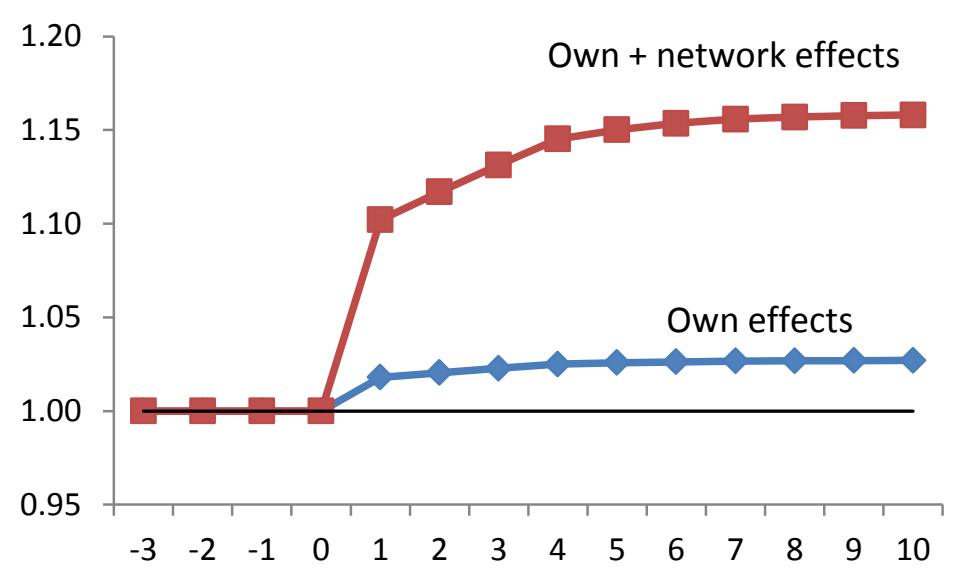

C. TFP

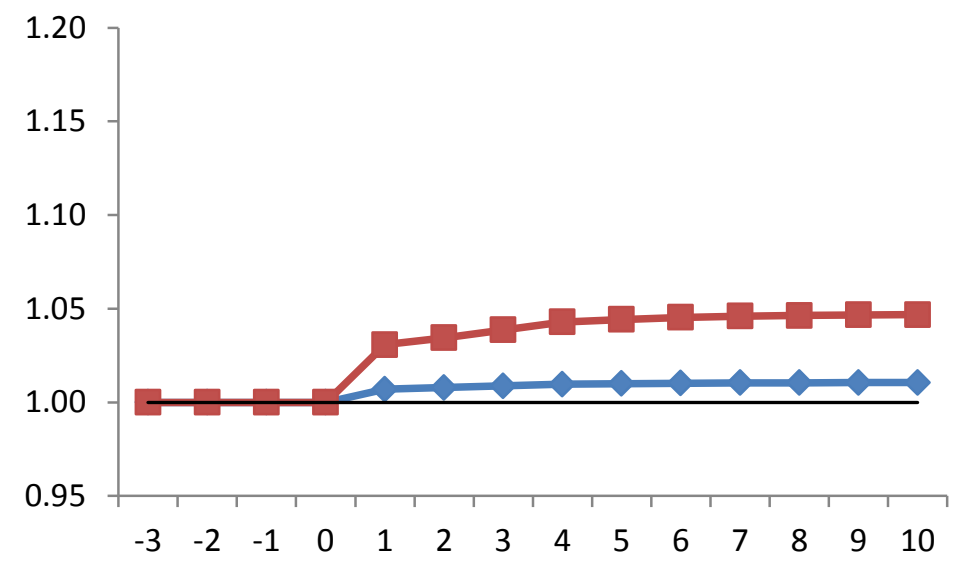

B. Federal government spending

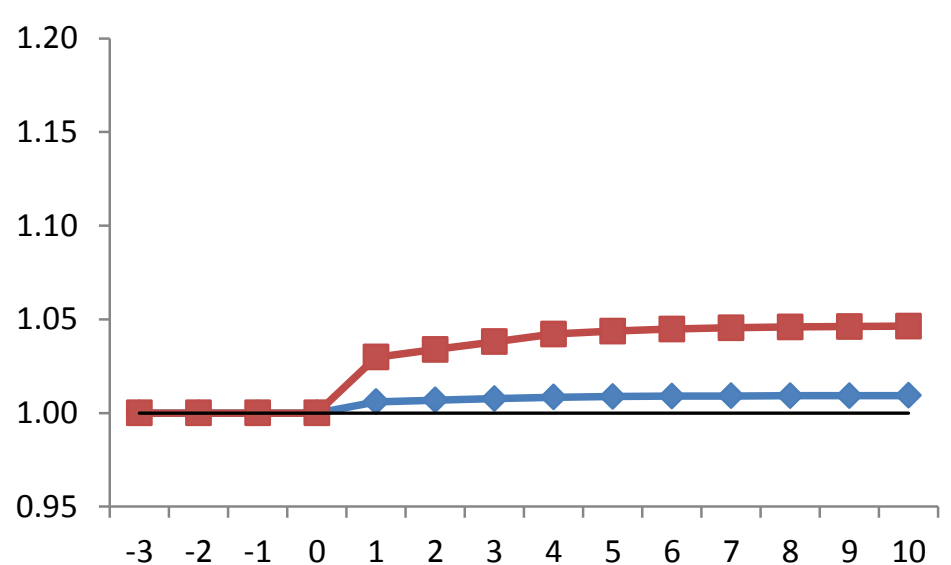

D. Foreign patenting

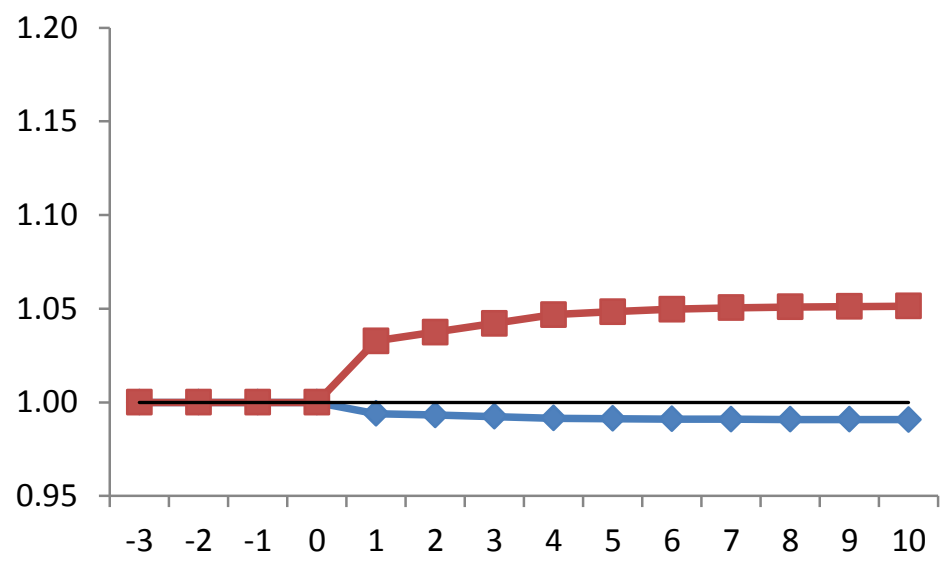

Notes: See Figure 1a. 
Figure 2: Theoretical examples

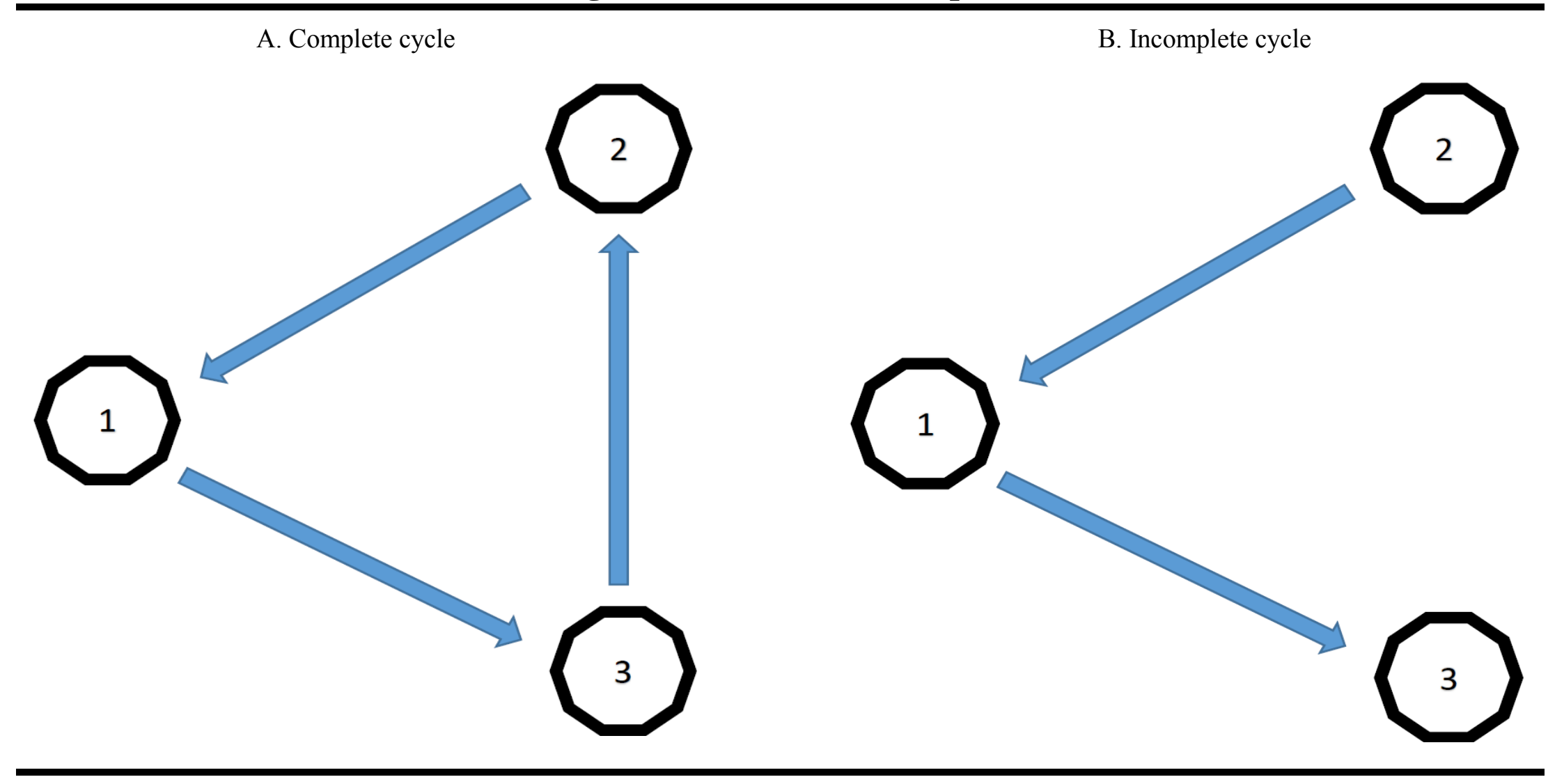


Table 1a: Correlation matrix of network interconnections

\begin{tabular}{|c|c|c|c|}
\hline & \multirow{2}{*}{$\begin{array}{c}\text { Downstream Leontief } \\
(1) \\
\end{array}$} & \multirow{2}{*}{$\begin{array}{c}\text { Upstream Leontief } \\
(2)\end{array}$} & \multirow{2}{*}{$\frac{\text { Geographic overlay }}{(3)}$} \\
\hline & & & \\
\hline Downstream Leontief & 1 & & \\
\hline Upstream Leontief & 0.400 & 1 & \\
\hline Geographic overlay & 0.108 & 0.275 & 1 \\
\hline \multicolumn{4}{|c|}{$\begin{array}{l}\text { Notes: Downstream networks represent inputs from supplier industries into the focal industry's production, expressed } \\
\text { as a share of the focal industry's sales (e.g., rubber inputs into the tire industry as a share of the tire industry's sales). } \\
\text { Upstream networks represent sales from the focal industry to industrial customers, expressed as a share of the focal } \\
\text { industry's sales (e.g., sales of tires to car manufacturers as a share of the tire industry's sales). Both networks are } \\
\text { measured from the } 1991 \text { BEA Input-Output Matrix. Shares allow for flows to non-manufacturing industries and } \\
\text { customers and thus do not sum to } 100 \% \text { within manufacturing. Leontief connections provide the full chain of } \\
\text { interconnections in the network matrix. Geographic overlay is measured as the sum across regions of the interaction of } \\
\text { a focal industry's employment share in the region times the share of regional activity for other industries. Regions are } \\
\text { defined through commuting zones and use } 1991 \text { industrial activity from the County Business Patterns database. } \\
\text { Correlations are statistically significant at the } 1 \% \text { level. }\end{array}$} \\
\hline
\end{tabular}

Table 1b: Correlation matrix of shocks

\begin{tabular}{lcccc}
\hline & China trade shock & Federal spending shock & TFP shock & \multicolumn{2}{c}{ Foreign patenting shock } & Correlation Coefficient \\
\cline { 2 - 5 } & $(1)$ & $(2)$ & $(3)$ & $(4)$ \\
\hline China trade shock & 1 & & & 0.200 \\
Federal spending shock & 0.031 & 1 & 1 & 0.452 \\
TFP shock & -0.021 & 0.017 & -0.002 \\
Foreign patenting shock & -0.023 & 0.030 & 0.003 & 1 \\
\hline
\end{tabular}

Notes: Baseline trade shocks for manufacturing industries are the lagged change in imports from China relative to 1991 US market volume, following Autor et al. (2013). A negative value is taken such that positive coefficients correspond to likely beneficial outcomes, similar to other shocks. All trade analyses instrument US imports with the rise in Chinese imports in eight other advanced countries, and this table reports the correlation of the IV component. Baseline federal spending shocks for manufacturing industries are the lagged log change in national federal spending interacted with the 1992 share of sales from industries that went to the federal government. Baseline TFP shocks for manufacturing industries are the lagged log change in four-factor TFP taken from the NBER Productivity Database. Baseline patent shocks for manufacturing industries are the lagged change in USPTO patents filed by overseas inventors associated with the industry. These correlations are presented after year fixed effects are removed from each shock. The Correlation Coefficient column presents the average pairwise correlation of the given shock series between any two industries. 
Table 2a: China trade shock analysis

\begin{tabular}{|c|c|c|c|c|c|c|}
\hline & \multicolumn{2}{|c|}{$\Delta$ Log real value added } & \multicolumn{2}{|c|}{$\Delta$ Log employment } & \multicolumn{2}{|c|}{$\Delta$ Log real labor productivity } \\
\hline & $(1)$ & $(2)$ & (3) & (4) & $(5)$ & $(6)$ \\
\hline$\Delta$ Dependent variable $\mathrm{t}-1$ & $\begin{array}{c}0.019 \\
(0.025)\end{array}$ & $\begin{array}{c}0.020 \\
(0.025)\end{array}$ & $\begin{array}{c}0.149 * * * \\
(0.020)\end{array}$ & $\begin{array}{c}0.132 * * * \\
(0.019)\end{array}$ & $\begin{array}{c}-0.117 * * * \\
(0.028)\end{array}$ & $\begin{array}{c}-0.120^{* * *} \\
(0.033)\end{array}$ \\
\hline$\Delta$ Dependent variable $\mathrm{t}-2$ & & $\begin{array}{c}0.047 * * \\
(0.024)\end{array}$ & & $\begin{array}{c}0.109 * * * \\
(0.020)\end{array}$ & & $\begin{array}{l}-0.057 \\
(0.037)\end{array}$ \\
\hline$\Delta$ Dependent variable $\mathrm{t}-3$ & & $\begin{array}{c}0.033 \\
(0.021)\end{array}$ & & $\begin{array}{c}0.089 * * * \\
(0.016)\end{array}$ & & $\begin{array}{c}-0.002 \\
(0.033)\end{array}$ \\
\hline Downstream effects t-1 & $\begin{array}{c}-0.140 \\
(0.086)\end{array}$ & $\begin{array}{c}-0.124 \\
(0.081)\end{array}$ & $\begin{array}{c}-0.056 \\
(0.040)\end{array}$ & $\begin{array}{c}-0.044 \\
(0.037)\end{array}$ & $\begin{array}{l}-0.100 \\
(0.099)\end{array}$ & $\begin{array}{l}-0.108 \\
(0.099)\end{array}$ \\
\hline Upstream effects $\mathrm{t}-1$ & $\begin{array}{c}0.076^{* * *} \\
(0.024)\end{array}$ & $\begin{array}{c}0.076^{* * *} \\
(0.023)\end{array}$ & $\begin{array}{c}0.049 * * * \\
(0.016)\end{array}$ & $\begin{array}{c}0.039 * * * \\
(0.015)\end{array}$ & $\begin{array}{c}0.021 \\
(0.013)\end{array}$ & $\begin{array}{c}0.021 \\
(0.014)\end{array}$ \\
\hline Own effects t-1 & $\begin{array}{c}0.034 * * * \\
(0.009)\end{array}$ & $\begin{array}{c}0.031 * * * \\
(0.009)\end{array}$ & $\begin{array}{c}0.023 * * * \\
(0.005)\end{array}$ & $\begin{array}{c}0.018 * * * \\
(0.004)\end{array}$ & $\begin{array}{c}0.007 \\
(0.007)\end{array}$ & $\begin{array}{c}0.007 \\
(0.007)\end{array}$ \\
\hline Observations & 6560 & 5776 & 6560 & 5776 & 6560 & 5776 \\
\hline p-value: Upstream=Own & 0.071 & 0.054 & 0.086 & 0.139 & 0.333 & 0.350 \\
\hline
\end{tabular}

Notes: Estimations consider network structures and the propagation of trade shocks. Baseline trade shocks for manufacturing industries are the lagged change in imports from China relative to 1991 US market volume, following Autor et al. (2013). A negative value is taken such that positive coefficients correspond to likely beneficial outcomes, similar to other shocks. Explanatory variables aggregate these industry-level components by the indicated network connecting industries. These network explanatory variables are expressed as lagged changes in non-log values. Downstream and upstream flows use the Leontief inverse to provide the full chain of material interconnections within manufacturing. All trade analyses instrument the direct and network effects from US imports with the rise in Chinese imports in eight other advanced countries. Upstream=Own test uses the exact formula discussed in the text and is calculated through unreported auxiliary regressions. Variables are winsorized at the $0.1 \%$ level and initial shocks are transformed to have unit standard deviation for interpretation. Estimations include year fixed effects, report standard errors clustered by industry, and are unweighted. $* * *$, and $* * *$ indicate statistical significance at the $10 \%, 5 \%$, and $1 \%$ levels, respectively. 
Table 2b: Robustness checks on China trade shock analysis

\begin{tabular}{|c|c|c|c|c|c|c|c|c|}
\hline & $\begin{array}{l}\text { Baseline } \\
\text { estimation }\end{array}$ & $\begin{array}{c}\text { Excluding } \\
\text { own lagged } \\
\text { shock }\end{array}$ & $\begin{array}{l}\text { Weighting by } \\
1991 \text { log value } \\
\text { added }\end{array}$ & $\begin{array}{c}\text { Weighting by } \\
1991 \\
\text { employees }\end{array}$ & $\begin{array}{l}\text { Adding SIC2 } \\
\text { fixed effects }\end{array}$ & $\begin{array}{l}\text { Adding SIC3 } \\
\text { fixed effects }\end{array}$ & $\begin{array}{l}\text { Adding SIC4 } \\
\text { fixed effects }\end{array}$ & $\begin{array}{l}\text { Adding } \\
\text { resource } \\
\text { constraints }\end{array}$ \\
\hline & $(1)$ & $(2)$ & (3) & $(4)$ & $(5)$ & $(6)$ & (7) & $(8)$ \\
\hline & \multicolumn{8}{|c|}{ A. $\Delta$ Log real value added } \\
\hline \multirow[t]{2}{*}{$\Delta$ Dependent variable $\mathrm{t}-1$} & 0.019 & 0.021 & 0.023 & 0.114 & -0.008 & $-0.038 *$ & $-0.071 * * *$ & 0.018 \\
\hline & $(0.025)$ & $(0.025)$ & $(0.026)$ & $(0.071)$ & $(0.025)$ & $(0.023)$ & $(0.020)$ & $(0.025)$ \\
\hline \multirow[t]{2}{*}{ Downstream effects $\mathrm{t}-1$} & -0.140 & -0.022 & $-0.152^{*}$ & $-0.209^{*}$ & 0.000 & 0.138 & 0.192 & $-0.163^{*}$ \\
\hline & $(0.086)$ & $(0.083)$ & $(0.086)$ & $(0.123)$ & $(0.109)$ & $(0.106)$ & $(0.129)$ & $(0.092)$ \\
\hline \multirow[t]{2}{*}{ Upstream effects $\mathrm{t}-1$} & $0.076^{* * *}$ & $0.068 * * *$ & $0.078 * * *$ & $0.075 * *$ & $0.051 * *$ & $0.053^{*}$ & 0.051 & $0.107 * *$ \\
\hline & $(0.024)$ & $(0.023)$ & $(0.023)$ & $(0.034)$ & $(0.023)$ & $(0.032)$ & $(0.042)$ & $(0.042)$ \\
\hline \multirow[t]{2}{*}{ Own effects $t-1$} & $0.034 * * *$ & & $0.033 * * *$ & 0.022 & $0.018 * *$ & 0.015 & 0.016 & $0.032 * * *$ \\
\hline & $(0.009)$ & & $(0.009)$ & $(0.014)$ & $(0.009)$ & $(0.010)$ & $(0.014)$ & $(0.009)$ \\
\hline Observations & 6560 & 6560 & 6560 & 6560 & 6560 & 6560 & 6560 & 6560 \\
\hline \multirow[t]{2}{*}{ p-value: Upstream=Own } & 0.071 & & 0.053 & 0.076 & 0.159 & 0.266 & 0.489 & 0.080 \\
\hline & \multicolumn{8}{|c|}{ B. $\Delta$ Log employment } \\
\hline \multirow[t]{2}{*}{$\Delta$ Dependent variable $\mathrm{t}-1$} & $0.149 * * *$ & $0.156 * * *$ & $0.153 * * *$ & $0.257 * * *$ & $0.097 * * *$ & $0.044 * *$ & 0.010 & $0.146^{* * *}$ \\
\hline & $(0.020)$ & $(0.021)$ & $(0.020)$ & $(0.034)$ & $(0.020)$ & $(0.019)$ & $(0.020)$ & $(0.020)$ \\
\hline \multirow[t]{2}{*}{ Downstream effects $\mathrm{t}-1$} & -0.056 & 0.024 & -0.055 & -0.034 & 0.009 & 0.036 & 0.080 & $-0.082 *$ \\
\hline & $(0.040)$ & $(0.037)$ & $(0.040)$ & $(0.059)$ & $(0.049)$ & $(0.054)$ & $(0.067)$ & $(0.047)$ \\
\hline \multirow[t]{2}{*}{ Upstream effects $\mathrm{t}-1$} & $0.049 * * *$ & $0.044 * * *$ & $0.051 * * *$ & $0.048 * *$ & $0.029^{*}$ & 0.014 & 0.012 & $0.084 * * *$ \\
\hline & $(0.016)$ & $(0.016)$ & $(0.016)$ & $(0.022)$ & $(0.016)$ & $(0.018)$ & $(0.025)$ & $(0.028)$ \\
\hline \multirow[t]{2}{*}{ Own effects $t-1$} & $0.023 * * *$ & & $0.023 * * *$ & $0.020 * * *$ & $0.009 * *$ & 0.005 & 0.001 & $0.021 * * *$ \\
\hline & $(0.005)$ & & $(0.005)$ & $(0.007)$ & $(0.004)$ & $(0.004)$ & $(0.005)$ & $(0.005)$ \\
\hline Observations & 6560 & 6560 & 6560 & 6560 & 6560 & 6560 & 6560 & 6560 \\
\hline p-value: Upstream=Own & 0.086 & & 0.069 & 0.185 & 0.209 & 0.616 & 0.667 & 0.027 \\
\hline
\end{tabular}


Table 3a: Federal spending shock analysis

\begin{tabular}{|c|c|c|c|c|c|c|}
\hline & \multicolumn{2}{|c|}{$\Delta$ Log real value added } & \multicolumn{2}{|c|}{$\Delta$ Log employment } & \multicolumn{2}{|c|}{$\Delta$ Log real labor productivity } \\
\hline & $(1)$ & $(2)$ & (3) & $(4)$ & $(5)$ & $(6)$ \\
\hline$\Delta$ Dependent variable $\mathrm{t}-1$ & $\begin{array}{c}0.019 \\
(0.025)\end{array}$ & $\begin{array}{c}0.018 \\
(0.024)\end{array}$ & $\begin{array}{c}0.158 * * * \\
(0.021)\end{array}$ & $\begin{array}{c}0.135 * * * \\
(0.019)\end{array}$ & $\begin{array}{c}-0.117 * * * \\
(0.030)\end{array}$ & $\begin{array}{c}-0.119 * * * \\
(0.036)\end{array}$ \\
\hline$\Delta$ Dependent variable $\mathrm{t}-2$ & & $\begin{array}{c}0.051^{* *} \\
(0.023)\end{array}$ & & $\begin{array}{c}0.116^{* * *} \\
(0.019)\end{array}$ & & $\begin{array}{c}-0.057 \\
(0.038)\end{array}$ \\
\hline$\Delta$ Dependent variable $\mathrm{t}-3$ & & $\begin{array}{l}0.038^{*} \\
(0.021)\end{array}$ & & $\begin{array}{c}0.102 * * * \\
(0.016)\end{array}$ & & $\begin{array}{c}-0.002 \\
(0.035)\end{array}$ \\
\hline Downstream effects t-1 & $\begin{array}{c}0.017 \\
(0.021)\end{array}$ & $\begin{array}{c}0.023 \\
(0.021)\end{array}$ & $\begin{array}{c}0.007 \\
(0.015)\end{array}$ & $\begin{array}{c}0.013 \\
(0.012)\end{array}$ & $\begin{array}{c}0.007 \\
(0.016)\end{array}$ & $\begin{array}{c}0.004 \\
(0.017)\end{array}$ \\
\hline Upstream effects t-1 & $\begin{array}{c}0.022 * * \\
(0.009)\end{array}$ & $\begin{array}{c}0.020^{* *} \\
(0.008)\end{array}$ & $\begin{array}{l}0.010^{*} \\
(0.006)\end{array}$ & $\begin{array}{c}0.011^{* *} \\
(0.005)\end{array}$ & $\begin{array}{c}0.012 \\
(0.008)\end{array}$ & $\begin{array}{c}0.010 \\
(0.008)\end{array}$ \\
\hline Own effects t-1 & $\begin{array}{c}0.004 \\
(0.003)\end{array}$ & $\begin{array}{c}0.008 * * \\
(0.004)\end{array}$ & $\begin{array}{c}0.003 \\
(0.003)\end{array}$ & $\begin{array}{c}0.006^{* * *} \\
(0.002)\end{array}$ & $\begin{array}{c}0.001 \\
(0.001)\end{array}$ & $\begin{array}{c}0.002 \\
(0.002)\end{array}$ \\
\hline Observations & 6560 & 5776 & 6560 & 5776 & 6560 & 5776 \\
\hline p-value: Upstream=Own & 0.076 & 0.191 & 0.321 & 0.383 & 0.147 & 0.330 \\
\hline
\end{tabular}

Notes: See Table 2a. Estimations consider network structures and the propagation of federal spending shocks. Baseline federal spending shocks for manufacturing industries are the lagged log change in national federal spending interacted with the 1992 share of sales from industries that went to the federal government. 
Table 3b: Robustness checks on federal spending shock analysis

\begin{tabular}{|c|c|c|c|c|c|c|c|c|}
\hline & $\begin{array}{l}\text { Baseline } \\
\text { estimation }\end{array}$ & $\begin{array}{c}\text { Excluding } \\
\text { own lagged } \\
\text { shock }\end{array}$ & $\begin{array}{c}\text { Weighting by } \\
1991 \text { log value } \\
\text { added }\end{array}$ & $\begin{array}{c}\text { Weighting by } \\
1991 \\
\text { employees }\end{array}$ & $\begin{array}{l}\text { Adding SIC2 } \\
\text { fixed effects }\end{array}$ & $\begin{array}{l}\text { Adding SIC3 } \\
\text { fixed effects }\end{array}$ & $\begin{array}{l}\text { Adding SIC4 } \\
\text { fixed effects }\end{array}$ & $\begin{array}{l}\text { Adding } \\
\text { resource } \\
\text { constraints }\end{array}$ \\
\hline & $(1)$ & $(2)$ & $(3)$ & (4) & $(5)$ & $(6)$ & $(7)$ & $(8)$ \\
\hline & \multicolumn{8}{|c|}{ A. $\Delta$ Log real value added } \\
\hline$\Delta$ Dependent variable $\mathrm{t}-1$ & $\begin{array}{c}0.019 \\
(0.025)\end{array}$ & $\begin{array}{c}0.019 \\
(0.025)\end{array}$ & $\begin{array}{c}0.023 \\
(0.026)\end{array}$ & $\begin{array}{l}0.115^{*} \\
(0.068)\end{array}$ & $\begin{array}{l}-0.011 \\
(0.025)\end{array}$ & $\begin{array}{l}-0.042 * \\
(0.024)\end{array}$ & $\begin{array}{c}-0.076^{* * *} \\
(0.021)\end{array}$ & $\begin{array}{c}0.019 \\
(0.025)\end{array}$ \\
\hline Downstream effects $\mathrm{t}-1$ & $\begin{array}{c}0.017 \\
(0.021)\end{array}$ & $\begin{array}{l}0.034^{*} \\
(0.019)\end{array}$ & $\begin{array}{c}0.015 \\
(0.020)\end{array}$ & $\begin{array}{c}0.008 \\
(0.014)\end{array}$ & $\begin{array}{l}-0.006 \\
(0.021)\end{array}$ & $\begin{array}{c}0.029 \\
(0.024)\end{array}$ & $\begin{array}{l}-0.040 \\
(0.062)\end{array}$ & $\begin{array}{c}0.017 \\
(0.021)\end{array}$ \\
\hline Upstream effects $\mathrm{t}-1$ & $\begin{array}{c}0.022 * * \\
(0.009)\end{array}$ & $\begin{array}{l}0.022 * * \\
(0.009)\end{array}$ & $\begin{array}{c}0.022 * * \\
(0.010)\end{array}$ & $\begin{array}{c}0.030 * * \\
(0.014)\end{array}$ & $\begin{array}{c}0.012 \\
(0.008)\end{array}$ & $\begin{array}{l}0.025^{*} \\
(0.015)\end{array}$ & $\begin{array}{c}0.069 * * * \\
(0.023)\end{array}$ & $\begin{array}{l}0.022^{*} \\
(0.012)\end{array}$ \\
\hline Own effects $t-1$ & $\begin{array}{c}0.004 \\
(0.003)\end{array}$ & & $\begin{array}{c}0.004 \\
(0.003)\end{array}$ & $\begin{array}{c}0.001 \\
(0.002)\end{array}$ & $\begin{array}{c}0.002 \\
(0.003)\end{array}$ & $\begin{array}{l}0.005 \\
(0.005)\end{array}$ & $\begin{array}{c}0.011 \\
(0.011)\end{array}$ & $\begin{array}{c}0.004 \\
(0.003)\end{array}$ \\
\hline $\begin{array}{l}\text { Observations } \\
\text { p-value: Upstream=Own }\end{array}$ & $\begin{array}{l}6560 \\
0.076\end{array}$ & 6560 & $\begin{array}{l}6560 \\
0.077\end{array}$ & $\begin{array}{l}6560 \\
0.027\end{array}$ & $\begin{array}{c}6560 \\
0.254\end{array}$ & $\begin{array}{l}6560 \\
0.183\end{array}$ & $\begin{array}{l}6560 \\
0.031\end{array}$ & $\begin{array}{l}6560 \\
0.130\end{array}$ \\
\hline & \multicolumn{8}{|c|}{ B. $\Delta$ Log employment } \\
\hline$\Delta$ Dependent variable $\mathrm{t}-1$ & $\begin{array}{c}0.158 * * * \\
(0.021)\end{array}$ & $\begin{array}{c}0.159 * * * \\
(0.021)\end{array}$ & $\begin{array}{c}0.163 * * * \\
(0.021)\end{array}$ & $\begin{array}{c}0.269^{* * *} \\
(0.033)\end{array}$ & $\begin{array}{c}0.099 * * * \\
(0.020)\end{array}$ & $\begin{array}{c}0.041 * * \\
(0.019)\end{array}$ & $\begin{array}{c}0.006 \\
(0.019)\end{array}$ & $\begin{array}{c}0.158 * * * \\
(0.021)\end{array}$ \\
\hline Downstream effects t-1 & $\begin{array}{c}0.007 \\
(0.015)\end{array}$ & $\begin{array}{c}0.021 * * \\
(0.010)\end{array}$ & $\begin{array}{c}0.006 \\
(0.013)\end{array}$ & $\begin{array}{c}0.007 \\
(0.007)\end{array}$ & $\begin{array}{l}-0.011 \\
(0.015)\end{array}$ & $\begin{array}{c}0.018 \\
(0.013)\end{array}$ & $\begin{array}{l}-0.046 \\
(0.046)\end{array}$ & $\begin{array}{c}0.009 \\
(0.014)\end{array}$ \\
\hline Upstream effects t-1 & $\begin{array}{l}0.010^{*} \\
(0.006)\end{array}$ & $\begin{array}{l}0.010^{*} \\
(0.006)\end{array}$ & $\begin{array}{c}0.009 \\
(0.006)\end{array}$ & $\begin{array}{c}0.009 \\
(0.005)\end{array}$ & $\begin{array}{c}0.004 \\
(0.005)\end{array}$ & $\begin{array}{c}0.016 * * * \\
(0.006)\end{array}$ & $\begin{array}{l}0.020^{*} \\
(0.011)\end{array}$ & $\begin{array}{c}0.006 \\
(0.007)\end{array}$ \\
\hline Own effects $t-1$ & $\begin{array}{c}0.003 \\
(0.003)\end{array}$ & & $\begin{array}{c}0.003 \\
(0.003)\end{array}$ & $\begin{array}{c}0.001 \\
(0.001)\end{array}$ & $\begin{array}{c}0.002 \\
(0.003)\end{array}$ & $\begin{array}{l}0.009 * * \\
(0.004)\end{array}$ & $\begin{array}{c}0.022 * * \\
(0.009)\end{array}$ & $\begin{array}{c}0.003 \\
(0.003)\end{array}$ \\
\hline $\begin{array}{l}\text { Observations } \\
\text { p-value: Upstream=Own }\end{array}$ & $\begin{array}{l}6560 \\
0.321\end{array}$ & 6560 & $\begin{array}{l}6560 \\
0.346\end{array}$ & $\begin{array}{l}6560 \\
0.156\end{array}$ & $\begin{array}{l}6560 \\
0.747\end{array}$ & $\begin{array}{l}6560 \\
0.160\end{array}$ & $\begin{array}{l}6560 \\
0.829\end{array}$ & $\begin{array}{l}6560 \\
0.717\end{array}$ \\
\hline
\end{tabular}


Table 4a: TFP shock analysis

\begin{tabular}{|c|c|c|c|c|c|c|}
\hline & \multicolumn{2}{|c|}{$\Delta$ Log real value added } & \multicolumn{2}{|c|}{$\Delta$ Log employment } & \multicolumn{2}{|c|}{$\Delta$ Log real labor productivity } \\
\hline & $(1)$ & (2) & (3) & (4) & $(5)$ & (6) \\
\hline$\Delta$ Dependent variable t-1 & $\begin{array}{l}-0.024 \\
(0.040)\end{array}$ & $\begin{array}{c}-0.031 \\
(0.041)\end{array}$ & $\begin{array}{c}0.141 * * * \\
(0.021)\end{array}$ & $\begin{array}{c}0.118 * * * \\
(0.020)\end{array}$ & $\begin{array}{c}-0.194 * * * \\
(0.029)\end{array}$ & $\begin{array}{c}-0.211^{* * * *} \\
(0.034)\end{array}$ \\
\hline$\Delta$ Dependent variable $\mathrm{t}-2$ & & $\begin{array}{c}0.049 * * \\
(0.023)\end{array}$ & & $\begin{array}{c}0.118 * * * \\
(0.019)\end{array}$ & & $\begin{array}{c}-0.071 * * \\
(0.034)\end{array}$ \\
\hline$\Delta$ Dependent variable $\mathrm{t}-3$ & & $\begin{array}{l}0.037^{*} \\
(0.020)\end{array}$ & & $\begin{array}{c}0.102 * * * \\
(0.016)\end{array}$ & & $\begin{array}{l}-0.008 \\
(0.032)\end{array}$ \\
\hline Downstream effects t-1 & $\begin{array}{c}0.060 * * * \\
(0.020)\end{array}$ & $\begin{array}{c}0.047 * * \\
(0.020)\end{array}$ & $\begin{array}{l}0.016^{*} \\
(0.009)\end{array}$ & $\begin{array}{c}0.011 \\
(0.009)\end{array}$ & $\begin{array}{c}0.047 * * * \\
(0.018)\end{array}$ & $\begin{array}{c}0.043^{* *} \\
(0.018)\end{array}$ \\
\hline Upstream effects $\mathrm{t}-1$ & $\begin{array}{c}0.024 * * \\
(0.011)\end{array}$ & $\begin{array}{l}0.020^{*} \\
(0.012)\end{array}$ & $\begin{array}{c}0.009 \\
(0.006)\end{array}$ & $\begin{array}{c}0.008 \\
(0.006)\end{array}$ & $\begin{array}{l}0.015 * \\
(0.009)\end{array}$ & $\begin{array}{c}0.014 \\
(0.009)\end{array}$ \\
\hline Own effects t-1 & $\begin{array}{c}0.004 \\
(0.007)\end{array}$ & $\begin{array}{c}0.007 \\
(0.006)\end{array}$ & $\begin{array}{c}0.006 * * * \\
(0.002)\end{array}$ & $\begin{array}{c}0.007 * * * \\
(0.002)\end{array}$ & $\begin{array}{c}0.011 * * \\
(0.005)\end{array}$ & $\begin{array}{c}0.013 * * * \\
(0.004)\end{array}$ \\
\hline Observations & 6560 & 5776 & 6560 & 5776 & 6560 & 5776 \\
\hline p-value: Downstream=Own & 0.005 & 0.034 & 0.041 & 0.161 & 0.101 & 0.276 \\
\hline
\end{tabular}

Notes: See Table 2a. Estimations consider network structures and the propagation of TFP shocks. Baseline TFP shocks for manufacturing industries are the lagged log change in four-factor TFP taken from the NBER Productivity Database. 
Table 4b: Robustness checks on TFP shock analysis

\begin{tabular}{|c|c|c|c|c|c|c|c|}
\hline & $\begin{array}{l}\text { Baseline } \\
\text { estimation }\end{array}$ & $\begin{array}{c}\text { Excluding } \\
\text { own lagged } \\
\text { shock }\end{array}$ & $\begin{array}{c}\text { Weighting by } \\
1991 \text { log value } \\
\text { added }\end{array}$ & $\begin{array}{c}\text { Weighting by } \\
1991 \\
\text { employees }\end{array}$ & $\begin{array}{l}\text { Adding SIC2 } \\
\text { fixed effects }\end{array}$ & $\begin{array}{l}\text { Adding SIC3 } \\
\text { fixed effects }\end{array}$ & $\begin{array}{l}\text { Adding SIC4 } \\
\text { fixed effects }\end{array}$ \\
\hline & $(1)$ & $(2)$ & $(3)$ & $(4)$ & $(5)$ & $(6)$ & $(7)$ \\
\hline & \multicolumn{7}{|c|}{ A. $\Delta$ Log real value added } \\
\hline$\Delta$ Dependent variable $\mathrm{t}-1$ & $\begin{array}{l}-0.024 \\
(0.040)\end{array}$ & $\begin{array}{l}-0.002 \\
(0.024)\end{array}$ & $\begin{array}{l}-0.024 \\
(0.040)\end{array}$ & $\begin{array}{l}-0.075 \\
(0.073)\end{array}$ & $\begin{array}{c}-0.080^{* *} \\
(0.039)\end{array}$ & $\begin{array}{c}-0.126^{* * *} \\
(0.038)\end{array}$ & $\begin{array}{c}-0.147 * * * \\
(0.039)\end{array}$ \\
\hline Downstream effects t-1 & $\begin{array}{c}0.060 * * * \\
(0.020)\end{array}$ & $\begin{array}{c}0.062 * * * \\
(0.021)\end{array}$ & $\begin{array}{c}0.060 * * * \\
(0.020)\end{array}$ & $\begin{array}{c}0.077 * * \\
(0.034)\end{array}$ & $\begin{array}{l}0.039^{*} \\
(0.020)\end{array}$ & $\begin{array}{c}0.027 \\
(0.018)\end{array}$ & $\begin{array}{c}0.027 \\
(0.019)\end{array}$ \\
\hline Upstream effects t-1 & $\begin{array}{l}0.024^{* *} \\
(0.011)\end{array}$ & $\begin{array}{l}0.024^{* *} \\
(0.011)\end{array}$ & $\begin{array}{c}0.025^{* *} \\
(0.011)\end{array}$ & $\begin{array}{c}0.054 * * * \\
(0.016)\end{array}$ & $\begin{array}{l}0.021^{*} \\
(0.011)\end{array}$ & $\begin{array}{c}0.017 \\
(0.012)\end{array}$ & $\begin{array}{c}0.020 \\
(0.013)\end{array}$ \\
\hline Own effects t-1 & $\begin{array}{c}0.004 \\
(0.007)\end{array}$ & & $\begin{array}{c}0.005 \\
(0.007)\end{array}$ & $\begin{array}{l}0.025^{*} \\
(0.014)\end{array}$ & $\begin{array}{c}0.010 \\
(0.006)\end{array}$ & $\begin{array}{c}0.014 * * \\
(0.006)\end{array}$ & $\begin{array}{r}0.012 * * \\
(0.005)\end{array}$ \\
\hline $\begin{array}{l}\text { Observations } \\
\text { p-value: Downstream=Own }\end{array}$ & $\begin{array}{l}6560 \\
0.005\end{array}$ & 6560 & $\begin{array}{l}6560 \\
0.007\end{array}$ & $\begin{array}{l}6560 \\
0.303\end{array}$ & $\begin{array}{l}6560 \\
0.198\end{array}$ & $\begin{array}{l}6560 \\
0.623\end{array}$ & $\begin{array}{l}6560 \\
0.171\end{array}$ \\
\hline & \multicolumn{7}{|c|}{ B. $\Delta$ Log employment } \\
\hline$\Delta$ Dependent variable $\mathrm{t}-1$ & $\begin{array}{c}0.141 * * * \\
(0.021)\end{array}$ & $\begin{array}{c}0.154 * * * \\
(0.021)\end{array}$ & $\begin{array}{c}0.146 * * * \\
(0.021)\end{array}$ & $\begin{array}{c}0.252 * * * \\
(0.032)\end{array}$ & $\begin{array}{c}0.081 * * * \\
(0.021)\end{array}$ & $\begin{array}{c}0.020 \\
(0.019)\end{array}$ & $\begin{array}{l}-0.015 \\
(0.020)\end{array}$ \\
\hline Downstream effects t-1 & $\begin{array}{l}0.016^{*} \\
(0.009)\end{array}$ & $\begin{array}{c}0.025 * * * \\
(0.009)\end{array}$ & $\begin{array}{l}0.016^{*} \\
(0.009)\end{array}$ & $\begin{array}{l}0.024^{*} \\
(0.012)\end{array}$ & $\begin{array}{c}0.002 \\
(0.009)\end{array}$ & $\begin{array}{c}0.011 \\
(0.010)\end{array}$ & $\begin{array}{c}0.013 \\
(0.011)\end{array}$ \\
\hline Upstream effects $t-1$ & $\begin{array}{c}0.009 \\
(0.006)\end{array}$ & $\begin{array}{l}0.012 * * \\
(0.006)\end{array}$ & $\begin{array}{c}0.009 \\
(0.006)\end{array}$ & $\begin{array}{c}0.022 * * * \\
(0.008)\end{array}$ & $\begin{array}{c}0.007 \\
(0.006)\end{array}$ & $\begin{array}{c}0.010 \\
(0.007)\end{array}$ & $\begin{array}{c}0.010 \\
(0.007)\end{array}$ \\
\hline Own effects t-1 & $\begin{array}{c}0.006^{* * *} \\
(0.002)\end{array}$ & & $\begin{array}{c}0.006^{* * *} \\
(0.002)\end{array}$ & $\begin{array}{c}0.003 \\
(0.002)\end{array}$ & $\begin{array}{c}0.007 * * * \\
(0.002)\end{array}$ & $\begin{array}{c}0.008^{* * *} \\
(0.002)\end{array}$ & $\begin{array}{c}0.009 * * * \\
(0.002)\end{array}$ \\
\hline $\begin{array}{l}\text { Observations } \\
\text { p-value: Downstream=Own }\end{array}$ & $\begin{array}{l}6560 \\
0.041\end{array}$ & 6560 & $\begin{array}{l}6560 \\
0.045\end{array}$ & $\begin{array}{l}6560 \\
0.026\end{array}$ & $\begin{array}{c}6560 \\
0.712\end{array}$ & $\begin{array}{r}6560 \\
0.312\end{array}$ & $\begin{array}{c}6560 \\
0.314\end{array}$ \\
\hline
\end{tabular}


Table 5a: Foreign patent shock analysis

\begin{tabular}{|c|c|c|c|c|c|c|}
\hline & \multicolumn{2}{|c|}{$\Delta$ Log real value added } & \multicolumn{2}{|c|}{$\Delta$ Log employment } & \multicolumn{2}{|c|}{$\Delta$ Log real labor productivity } \\
\hline & $(1)$ & $(2)$ & (3) & $(4)$ & $(5)$ & $(6)$ \\
\hline$\Delta$ Dependent variable $\mathrm{t}-1$ & $\begin{array}{c}0.020 \\
(0.025)\end{array}$ & $\begin{array}{c}0.020 \\
(0.025)\end{array}$ & $\begin{array}{c}0.159 * * * \\
(0.021)\end{array}$ & $\begin{array}{c}0.138 * * * \\
(0.020)\end{array}$ & $\begin{array}{c}-0.117 * * * \\
(0.030)\end{array}$ & $\begin{array}{c}-0.120 * * * \\
(0.036)\end{array}$ \\
\hline$\Delta$ Dependent variable $\mathrm{t}-2$ & & $\begin{array}{c}0.051^{* *} \\
(0.023)\end{array}$ & & $\begin{array}{c}0.117 * * * \\
(0.020)\end{array}$ & & $\begin{array}{c}-0.057 \\
(0.038)\end{array}$ \\
\hline$\Delta$ Dependent variable $\mathrm{t}-3$ & & $\begin{array}{c}0.037^{*} \\
(0.021)\end{array}$ & & $\begin{array}{c}0.100^{* * *} \\
(0.016)\end{array}$ & & $\begin{array}{c}-0.003 \\
(0.035)\end{array}$ \\
\hline Downstream effects t-1 & $\begin{array}{c}0.043 * * * \\
(0.011)\end{array}$ & $\begin{array}{c}0.044 * * * \\
(0.011)\end{array}$ & $\begin{array}{c}0.018^{* * *} \\
(0.006)\end{array}$ & $\begin{array}{c}0.018 * * * \\
(0.006)\end{array}$ & $\begin{array}{c}0.027 * * * \\
(0.009)\end{array}$ & $\begin{array}{c}0.028 * * * \\
(0.009)\end{array}$ \\
\hline Upstream effects $\mathrm{t}-1$ & $\begin{array}{c}-0.000 \\
(0.005)\end{array}$ & $\begin{array}{c}0.000 \\
(0.005)\end{array}$ & $\begin{array}{c}-0.001 \\
(0.003)\end{array}$ & $\begin{array}{c}-0.000 \\
(0.003)\end{array}$ & $\begin{array}{c}0.001 \\
(0.004)\end{array}$ & $\begin{array}{c}0.002 \\
(0.004)\end{array}$ \\
\hline Own effects t-1 & $\begin{array}{c}-0.006 \\
(0.004)\end{array}$ & $\begin{array}{c}-0.007 * \\
(0.004)\end{array}$ & $\begin{array}{c}-0.008 * * * \\
(0.003)\end{array}$ & $\begin{array}{c}-0.006^{* *} \\
(0.003)\end{array}$ & $\begin{array}{c}0.003 \\
(0.003)\end{array}$ & $\begin{array}{c}0.002 \\
(0.004)\end{array}$ \\
\hline Observations & 6543 & 5761 & 6543 & 5761 & 6543 & 5761 \\
\hline p-value: Downstream=Own & 0.000 & 0.000 & 0.001 & 0.002 & 0.029 & 0.026 \\
\hline
\end{tabular}

Notes: See Table 2a. Estimations consider network structures and the propagation of foreign patent shocks. Baseline patent shocks for manufacturing industries are the lagged change in USPTO patents filed by overseas inventors associated with the industry. 
Table 5b: Robustness checks on foreign patent shock analysis

\begin{tabular}{|c|c|c|c|c|c|c|c|}
\hline & $\begin{array}{l}\text { Baseline } \\
\text { estimation }\end{array}$ & $\begin{array}{c}\text { Excluding } \\
\text { own lagged } \\
\text { shock }\end{array}$ & $\begin{array}{c}\text { Weighting by } \\
1991 \text { log value } \\
\text { added }\end{array}$ & $\begin{array}{c}\text { Weighting by } \\
1991 \\
\text { employees }\end{array}$ & $\begin{array}{l}\text { Adding SIC2 } \\
\text { fixed effects }\end{array}$ & $\begin{array}{l}\text { Adding SIC3 } \\
\text { fixed effects }\end{array}$ & $\begin{array}{l}\text { Adding SIC4 } \\
\text { fixed effects }\end{array}$ \\
\hline & $(1)$ & $(2)$ & $(3)$ & (4) & $(5)$ & $(6)$ & $(7)$ \\
\hline & \multicolumn{7}{|c|}{ A. $\Delta$ Log real value added } \\
\hline \multirow[t]{2}{*}{$\Delta$ Dependent variable $\mathrm{t}-1$} & 0.020 & 0.020 & 0.024 & $0.120^{*}$ & -0.012 & $-0.042 *$ & $-0.075 * * *$ \\
\hline & $(0.025)$ & $(0.025)$ & $(0.026)$ & $(0.070)$ & $(0.025)$ & $(0.024)$ & $(0.021)$ \\
\hline \multirow[t]{2}{*}{ Downstream effects t-1 } & $0.043 * * *$ & $0.039 * * *$ & $0.042 * * *$ & $0.044 * *$ & $0.040 * * *$ & $0.038 * * *$ & $0.038 * * *$ \\
\hline & $(0.011)$ & $(0.011)$ & $(0.011)$ & $(0.021)$ & $(0.011)$ & $(0.011)$ & $(0.011)$ \\
\hline \multirow[t]{2}{*}{ Upstream effects t-1 } & -0.000 & 0.000 & 0.000 & 0.007 & 0.000 & 0.000 & 0.000 \\
\hline & $(0.005)$ & $(0.005)$ & $(0.004)$ & $(0.007)$ & $(0.005)$ & $(0.004)$ & $(0.005)$ \\
\hline \multirow[t]{2}{*}{ Own effects t-1 } & -0.006 & & -0.006 & 0.004 & -0.003 & -0.003 & -0.004 \\
\hline & $(0.004)$ & & $(0.004)$ & $(0.007)$ & $(0.004)$ & $(0.004)$ & $(0.004)$ \\
\hline Observations & 6543 & 6543 & 6543 & 6543 & 6543 & 6543 & 6543 \\
\hline \multirow[t]{2}{*}{ p-value: Downstream=Own } & 0.000 & & 0.000 & 0.354 & 0.001 & 0.001 & 0.000 \\
\hline & \multicolumn{7}{|c|}{ B. $\Delta$ Log employment } \\
\hline \multirow[t]{2}{*}{$\Delta$ Dependent variable $\mathrm{t}-1$} & $0.159 * * *$ & $0.160 * * *$ & $0.163 * * *$ & $0.270 * * *$ & $0.099 * * *$ & $0.044 * *$ & 0.012 \\
\hline & $(0.021)$ & $(0.021)$ & $(0.021)$ & $(0.034)$ & $(0.020)$ & $(0.019)$ & $(0.020)$ \\
\hline \multirow[t]{2}{*}{ Downstream effects t-1 } & $0.018 * * *$ & $0.013 * *$ & $0.018 * * *$ & $0.014^{*}$ & $0.015^{* *}$ & $0.014 * *$ & $0.013 * *$ \\
\hline & $(0.006)$ & $(0.006)$ & $(0.006)$ & $(0.007)$ & $(0.006)$ & $(0.006)$ & $(0.006)$ \\
\hline \multirow[t]{2}{*}{ Upstream effects t-1 } & -0.001 & -0.000 & -0.001 & 0.001 & -0.001 & -0.000 & -0.000 \\
\hline & $(0.003)$ & $(0.003)$ & $(0.003)$ & $(0.003)$ & $(0.003)$ & $(0.003)$ & $(0.003)$ \\
\hline \multirow[t]{2}{*}{ Own effects t-1 } & $-0.008 * * *$ & & $-0.007 * * *$ & -0.004 & -0.004 & -0.003 & -0.003 \\
\hline & $(0.003)$ & & $(0.002)$ & $(0.003)$ & $(0.003)$ & $(0.002)$ & $(0.003)$ \\
\hline Observations & 6543 & 6543 & 6543 & 6543 & 6543 & 6543 & 6543 \\
\hline p-value: Downstream $=$ Own & 0.001 & & 0.001 & 0.238 & 0.008 & 0.016 & 0.023 \\
\hline
\end{tabular}

Notes: See Table 5a. 
Table 6: VAR estimations for intermediated shocks

\begin{tabular}{|c|c|c|c|c|c|c|c|c|}
\hline & \multicolumn{2}{|c|}{ China trade } & \multicolumn{2}{|c|}{ Federal spending } & \multicolumn{2}{|c|}{ TFP } & \multicolumn{2}{|c|}{ Foreign patenting } \\
\hline & $(1)$ & $(2)$ & $(3)$ & $(4)$ & $(5)$ & $(6)$ & $(7)$ & $(8)$ \\
\hline & \multicolumn{8}{|c|}{ A. $\Delta$ Log real value added } \\
\hline$\Delta$ Dependent variable $\mathrm{t}-1$ & $\begin{array}{l}-0.045 \\
(0.039)\end{array}$ & $\begin{array}{l}-0.060 \\
(0.044)\end{array}$ & $\begin{array}{l}-0.025 \\
(0.027)\end{array}$ & $\begin{array}{l}-0.011 \\
(0.041)\end{array}$ & $\begin{array}{l}-0.057 \\
(0.044)\end{array}$ & $\begin{array}{l}-0.063 \\
(0.044)\end{array}$ & $\begin{array}{c}0.312 * * * \\
(0.109)\end{array}$ & $\begin{array}{c}0.244 * * \\
(0.098)\end{array}$ \\
\hline$\Delta$ Downstream real value added $t-1$ & & $\begin{array}{c}0.038 \\
(0.112)\end{array}$ & & $\begin{array}{l}-0.036 \\
(0.116)\end{array}$ & $\begin{array}{c}0.087 * * * \\
(0.025)\end{array}$ & $\begin{array}{c}0.080^{* * *} \\
(0.025)\end{array}$ & $\begin{array}{c}-0.735^{* * *} \\
(0.268)\end{array}$ & $\begin{array}{c}-0.398^{* *} \\
(0.200)\end{array}$ \\
\hline$\Delta$ Upstream real value added $t-1$ & $\begin{array}{c}0.173 * * * \\
(0.059)\end{array}$ & $\begin{array}{c}0.171^{* * *} \\
(0.061)\end{array}$ & $\begin{array}{c}0.113 * * \\
(0.045)\end{array}$ & $\begin{array}{c}0.114 * * \\
(0.052)\end{array}$ & & $\begin{array}{c}0.017 \\
(0.011)\end{array}$ & & $\begin{array}{l}-0.162^{*} \\
(0.086)\end{array}$ \\
\hline Own shock t-1 & $\begin{array}{c}0.030 * * * \\
(0.008)\end{array}$ & $\begin{array}{c}0.030^{* * * *} \\
(0.008)\end{array}$ & $\begin{array}{c}0.006^{* *} \\
(0.003)\end{array}$ & $\begin{array}{l}0.007^{*} \\
(0.004)\end{array}$ & $\begin{array}{c}0.009 \\
(0.007)\end{array}$ & $\begin{array}{c}0.009 \\
(0.007)\end{array}$ & $\begin{array}{l}-0.012 * \\
(0.007)\end{array}$ & $\begin{array}{l}-0.006 \\
(0.006)\end{array}$ \\
\hline \multirow[t]{2}{*}{ Observations } & 6168 & 6168 & 6560 & 6560 & 6560 & 6560 & 6543 & 6543 \\
\hline & \multicolumn{8}{|c|}{ B. $\Delta$ Log employment } \\
\hline$\Delta$ Dependent variable $\mathrm{t}-1$ & $\begin{array}{c}0.132 * * * \\
(0.023)\end{array}$ & $\begin{array}{c}0.084 \\
(0.146)\end{array}$ & $\begin{array}{c}0.185 * * * \\
(0.025)\end{array}$ & $\begin{array}{c}0.079 \\
(0.080)\end{array}$ & $\begin{array}{c}0.089 * * * \\
(0.028)\end{array}$ & $\begin{array}{c}0.081 * * * \\
(0.026)\end{array}$ & $\begin{array}{c}0.310^{* * * *} \\
(0.059)\end{array}$ & $\begin{array}{c}0.268 * * * \\
(0.058)\end{array}$ \\
\hline$\Delta$ Downstream employment $\mathrm{t}-1$ & & $\begin{array}{c}0.097 \\
(0.295)\end{array}$ & & $\begin{array}{c}0.158 \\
(0.115)\end{array}$ & $\begin{array}{c}0.095^{* *} \\
(0.041)\end{array}$ & $\begin{array}{c}0.091 * * \\
(0.044)\end{array}$ & $\begin{array}{c}-0.264 * * * \\
(0.098)\end{array}$ & $\begin{array}{c}-0.278 * * * \\
(0.099)\end{array}$ \\
\hline$\Delta$ Upstream employment $\mathrm{t}-1$ & $\begin{array}{c}0.053 * * * \\
(0.014)\end{array}$ & $\begin{array}{c}0.035 \\
(0.054)\end{array}$ & $\begin{array}{l}-0.045 * \\
(0.024)\end{array}$ & $\begin{array}{l}-0.018 \\
(0.031)\end{array}$ & & $\begin{array}{c}0.017 \\
(0.025)\end{array}$ & & $\begin{array}{c}0.085 * * \\
(0.038)\end{array}$ \\
\hline Own shock t-1 & $\begin{array}{c}0.026 * * * \\
(0.004)\end{array}$ & $\begin{array}{l}0.022 * \\
(0.011)\end{array}$ & $\begin{array}{c}0.005^{* *} \\
(0.002)\end{array}$ & $\begin{array}{c}0.003 \\
(0.003)\end{array}$ & $\begin{array}{c}0.007 * * * \\
(0.002)\end{array}$ & $\begin{array}{c}0.007 * * * \\
(0.002)\end{array}$ & $\begin{array}{c}-0.012 * * * \\
(0.004)\end{array}$ & $\begin{array}{c}-0.013 * * * \\
(0.004)\end{array}$ \\
\hline Observations & 6168 & 6168 & 6560 & 6560 & 6560 & 6560 & 6543 & 6543 \\
\hline
\end{tabular}

Notes: See Tables 2a-5a. Rather than model network shocks directly, estimations consider intermediated approaches where the shock indicated by the column header instruments for changes in upstream and downstream economic activity in terms of real value added or employment. Estimations control for own shock and use two lags of upstream and downstream components. In each estimation pair, the first specification considers the focal network element for the shock in question. The second specification adds in the non-focal element where the first stage fit can be weak. 
Table 7: Joint analysis of shocks

\begin{tabular}{|c|c|c|c|c|c|}
\hline & & $\Delta \log r$ & ue added & $\Delta \log$ & yment \\
\hline & & $(1)$ & $(2)$ & $(3)$ & $(4)$ \\
\hline$\Delta$ Depen & ent variable $\mathrm{t}-1$ & -0.043 & -0.050 & $0.125 * * *$ & $0.105 * * *$ \\
\hline & & $(0.041)$ & $(0.041)$ & $(0.020)$ & $(0.020)$ \\
\hline$\Delta$ Depen & ent variable $\mathrm{t}-2$ & & $0.040 *$ & & $0.108 * * *$ \\
\hline & & & $(0.022)$ & & $(0.020)$ \\
\hline$\Delta$ Depen & ent variable $\mathrm{t}-3$ & & 0.032 & & $0.089 * * *$ \\
\hline & & & $(0.021)$ & & $(0.016)$ \\
\hline Trade: & Downstream effects $t-1$ & -0.059 & -0.042 & -0.016 & 0.008 \\
\hline & & $(0.082)$ & $(0.080)$ & $(0.044)$ & $(0.040)$ \\
\hline & Upstream effects $\mathrm{t}-1$ & $0.106 * * *$ & $0.107 * * *$ & $0.066 * * *$ & $0.054 * * *$ \\
\hline & & $(0.030)$ & $(0.031)$ & $(0.020)$ & $(0.019)$ \\
\hline & Own effects $t-1$ & $0.032 * * *$ & $0.030 * * *$ & $0.022 * * *$ & $0.017 * * *$ \\
\hline & & $(0.009)$ & $(0.009)$ & $(0.005)$ & $(0.004)$ \\
\hline Federal: & Downstream effects t- 1 & -0.006 & -0.003 & -0.008 & 0.001 \\
\hline & & $(0.023)$ & $(0.025)$ & $(0.017)$ & $(0.014)$ \\
\hline & Upstream effects $\mathrm{t}-1$ & $0.035 * *$ & $0.040 * * *$ & $0.020 * *$ & $0.023 * * *$ \\
\hline & & $(0.014)$ & $(0.014)$ & $(0.009)$ & $(0.008)$ \\
\hline & Own effects $t-1$ & 0.001 & 0.004 & 0.001 & $0.005 *$ \\
\hline & & $(0.003)$ & $(0.004)$ & $(0.003)$ & $(0.003)$ \\
\hline TFP: & Downstream effects $t-1$ & $0.062 * * *$ & $0.051 * *$ & $0.019^{*}$ & 0.014 \\
\hline & & $(0.021)$ & $(0.021)$ & $(0.010)$ & $(0.010)$ \\
\hline & Upstream effects $t-1$ & $0.030 * *$ & $0.028 * *$ & $0.013 *$ & 0.011 \\
\hline & & $(0.013)$ & $(0.014)$ & $(0.008)$ & $(0.008)$ \\
\hline & Own effects $t-1$ & 0.007 & 0.009 & $0.007 * * *$ & $0.008 * * *$ \\
\hline & & $(0.007)$ & $(0.007)$ & $(0.002)$ & $(0.002)$ \\
\hline Patent: & Downstream effects $t-1$ & $0.043 * * *$ & $0.043 * * *$ & $0.017 * * *$ & $0.016^{* *}$ \\
\hline & & $(0.011)$ & $(0.011)$ & $(0.006)$ & $(0.007)$ \\
\hline & Upstream effects $\mathrm{t}-1$ & 0.002 & 0.002 & 0.000 & 0.000 \\
\hline & & $(0.005)$ & $(0.005)$ & $(0.003)$ & $(0.003)$ \\
\hline & Own effects $t-1$ & $-0.007 *$ & $-0.007 *$ & $-0.007 * * *$ & $-0.006 * *$ \\
\hline & & $(0.004)$ & $(0.004)$ & $(0.003)$ & $(0.003)$ \\
\hline Observa & ons & 6543 & 5761 & 6543 & 5761 \\
\hline
\end{tabular}

Notes: See Table 2a. 
Table 8: Geographic and networks analysis

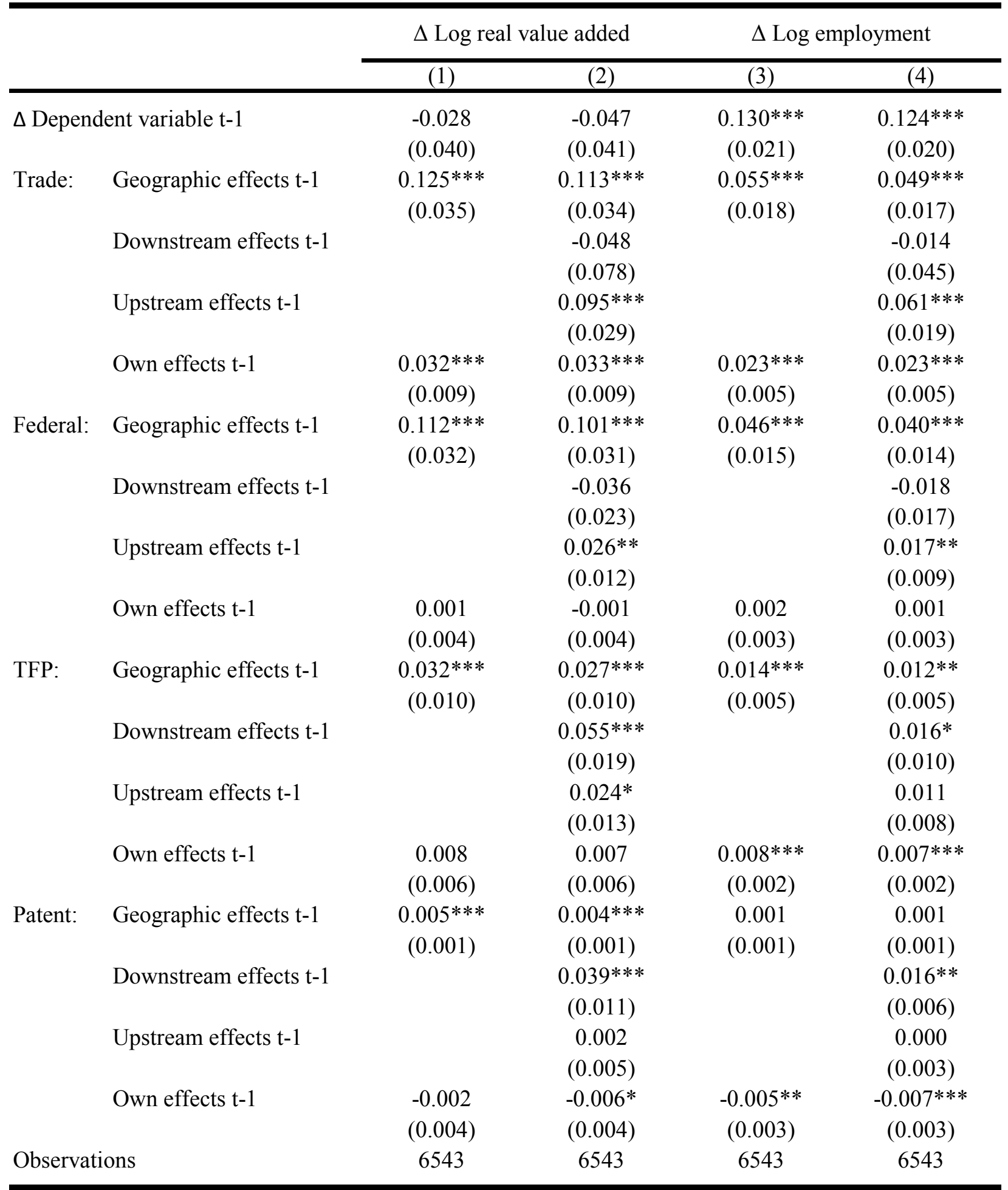

Notes: See Table 2a. Estimations include additional effects from indicated shocks and the geographic overlay of industries. Geographic overlay is measured as the sum across regions of the interaction of a focal industry's employment share in the region times the share of regional activity for other industries. Regions are defined through commuting zones and use 1991 industrial activity from the County Business Patterns database. 


\section{Appendix A: Proof of Proposition 1}

Part 1. Let us set government purchases equal to zero for this part of the proof. Recall that profit maximization implies

$$
a_{i j}=\frac{p_{j} x_{i j}}{p_{i} y_{i}}, \text { and } \alpha_{i}^{l}=\frac{w l_{i}}{p_{i} y_{i}} .
$$

Utility maximization in turn yields

$$
\frac{p_{i} c_{i}}{\beta_{i}}=\frac{p_{j} c_{j}}{\beta_{j}}
$$

Since total household income is equal to labor income and in this part we have no government purchases, we also have

$$
\sum_{i=1}^{n} p_{i} c_{i}=w l
$$

which yields

$$
p_{i} c_{i}=\beta_{i} w l, \forall i \text {. }
$$

Moreover, the first-order condition for labor supply implies

$$
-\frac{\gamma^{\prime}(l) l}{\gamma(l)}=1
$$

and thus labor supply is determined independent of the equilibrium wage rate because given the preferences in (3), income and substitutions cancel out.

Let us now take logs in (1) and totally differentiate to obtain

$$
d \ln y_{i}=d z_{i}+\alpha_{i}^{l} d \ln l_{i}+\sum_{j=1}^{n} a_{i j} d \ln x_{i j}
$$

Let us next totally differentiate (A1) to obtain

$$
d \ln y_{i}+d \ln p_{i}=d \ln x_{i j}+d \ln p_{j},
$$

and

$$
d \ln y_{i}+d \ln p_{i}=d \ln l_{i},
$$

where we have made use of the fact that the wages are chosen as the numeraire and thus $d \ln w=0$. Substituting these two equations into (A4), we have

$$
d \ln y_{i}=d z_{i}+\alpha_{i}^{l}\left(d \ln y_{i}+d \ln p_{i}\right)+\sum_{j=1}^{n} a_{i j}\left(d \ln y_{i}+d \ln p_{i}-d \ln p_{j}\right) .
$$

Next recalling that $l$ remains constant, differentiating (A2) and (A3), and combining with the previous two equations to eliminate prices, we obtain

$$
d \ln y_{i}=d z_{i}+\alpha_{i}^{l}\left(d \ln y_{i}-d \ln c_{i}\right)+\sum_{j=1}^{n} a_{i j}\left(d \ln y_{i}-d \ln c_{i}+d \ln c_{j}\right)
$$

Noting that $\alpha_{i}^{l}+\sum_{j=1}^{n} a_{i j}=1$, this simplifies to

$$
d \ln c_{i}=d z_{i}+\sum_{j=1}^{n} a_{i j} d \ln c_{j}
$$


which can be rewritten in matrix form as

$$
\mathbf{d} \ln \mathbf{c}=\mathbf{d z}+\mathbf{A d} \ln \mathbf{c}
$$

where $\mathbf{d} \ln \mathbf{c}$ and $\mathbf{d z}$ are the vectors of $d \ln c_{i}$ and $d z_{i}$ respectively, which is a unique solution given by

$$
\mathbf{d} \ln \mathbf{c}=(\mathbf{I}-\mathbf{A})^{-1} \mathbf{d z}
$$

in view of the fact that the largest eigenvalue of $\mathbf{A}$ is less than 1. Next combining (2) and (A1), we have

$$
\frac{y_{j}}{c_{j}}=1+\sum_{i=1}^{n} a_{i j} \frac{\beta_{i} y_{i}}{\beta_{j} c_{i}}
$$

which implies that

$$
\mathbf{d} \ln \mathbf{y}=\mathbf{d} \ln \mathbf{c} .
$$

Then combining (A5) with (A6) we obtain

$$
\mathbf{d} \ln \mathbf{y}=(\mathbf{I}-\mathbf{A})^{-1} \mathbf{d z} .
$$

This yields the desired result, (6).

Part 2. Normalize $\mathbf{z}=\mathbf{0}$ for this part of the proof. Consider the unit cost function of sector $i$, which is

$$
C_{i}(\mathbf{p}, w)=B_{i} w^{\alpha_{i}^{l}} \prod_{j=1}^{n} p_{j}^{a_{i j}}
$$

where

$$
B_{i}=\left[\frac{1}{\alpha_{i}^{l}}\right]^{\alpha_{i}^{l}} \prod_{j=1}^{n}\left[\frac{1}{a_{i j}}\right]^{a_{i j}}
$$

Zero profit condition for producer $i$ implies

$$
\ln p_{i}=\ln B_{i}+\alpha_{i}^{l} \ln w+\sum_{j=1}^{n} a_{i j} \ln p_{j} \text { for all } i \in\{1, . ., n\} .
$$

Since the wage is the numeraire (i.e., $w=1$ ), we have $\alpha_{i}^{l} \ln w=0$ and these equations define an $n$ equation system in $n$ prices (for a given vector of productivities $\mathbf{z}$, in this instance normalized to 1 ), with solution

$$
\ln \mathbf{p}=(\mathbf{I}-\mathbf{A})^{-1} \mathbf{b}
$$

where $\mathbf{b}$ is the vector with entries given by $\ln B_{i}$.

This shows that, for a given vector of productivities, the equilibrium price vector is uniquely determined regardless of the value of the vector of government purchases $\mathbf{G}$. Thus demandside shocks have no impact on equilibrium prices, which are entirely determined by the supply side. But then from (A3), the consumption vector remains unchanged, and from (2), total net supply of all sectors has to remain constant regardless of the change in $\mathbf{G}$. We can then obtain the change in the total production in the economy using (2) combined with (A1) and (A2), which with unchanged prices simply implies

$$
d \ln y_{i}=d \ln x_{i j} \text { and } d \ln y_{i}=d \ln l_{i} .
$$

Household maximization implies that, even though prices are fixed, labor supply will change because of changes in consumption (resulting from government purchases). In particular, the following first-order condition determines the representative household's labor supply

$$
\frac{w l}{w l-T}=-\frac{l \gamma^{\prime}(l)}{\gamma(l)},
$$


with $T=\sum_{i=1}^{n} p_{i} G_{i}$

When $\gamma(l)=(1-l)^{\lambda}$, using the fact that the wage, $w$, is chosen as the numeraire, we obtain

$$
l=\frac{1+\lambda \sum_{i=1}^{n} p_{i} G_{i}}{1+\lambda} .
$$

Therefore, we have that

$$
\begin{aligned}
p_{i} c_{i} & =\beta_{i}[l w-T] \\
& =\frac{\beta_{i}}{1+\lambda}\left[1-\sum_{j=1}^{n} p_{j} G_{j}\right]
\end{aligned}
$$

which implies

$$
d\left(p_{i} c_{i}\right)=-\frac{\beta_{i}}{(1+\lambda)} \sum_{j=1}^{n} d\left(p_{j} G_{j}\right) .
$$

The resource constraint then implies:

$$
d y_{i}=d c_{i}+\sum_{j=1}^{n} d x_{j i}+d G_{i} .
$$

Combining the previous two equations with (A1),

$$
\begin{aligned}
\frac{d\left(p_{i} y_{i}\right)}{p_{i} y_{i}} & =\sum_{j=1}^{n} a_{j i} \frac{d\left(p_{j} y_{j}\right)}{p_{i} y_{i}}+\frac{d G_{i}}{y_{i}}-\frac{\beta_{i}}{(1+\lambda)} \sum_{j=1}^{n} \frac{\left(d p_{j} G_{j}\right)}{p_{i} y_{i}} \\
& =\sum_{j=1}^{n} \hat{a}_{j i} \frac{d\left(p_{j} y_{j}\right)}{p_{j} y_{j}}+\frac{d \tilde{G}_{i}}{p_{i} y_{i}}-\frac{\beta_{i}}{(1+\lambda)} \sum_{j=1}^{n} \frac{d \tilde{G}_{j}}{p_{i} y_{i}}
\end{aligned}
$$

where $\tilde{G}_{j}=p_{j} G_{j}$. Writing this in matrix form and noting that, because prices are constant, $\frac{d\left(p_{i} y_{i}\right)}{p_{i} y_{i}}=d \ln y_{i}$, we have

$$
\begin{aligned}
\mathbf{d} \ln \mathbf{y} & =\hat{\mathbf{A}}^{T} \mathbf{d} \ln \mathbf{y}+\mathbf{\Lambda} \mathbf{d} \tilde{\mathbf{G}} \\
& =\left(\mathbf{I}-\hat{\mathbf{A}}^{T}\right)^{-1} \boldsymbol{\Lambda} \mathbf{d} \tilde{\mathbf{G}} \\
& =\hat{\mathbf{H}}^{T} \boldsymbol{\Lambda} \mathbf{d} \tilde{\mathbf{G}}
\end{aligned}
$$

where $\hat{\mathbf{H}}=(\mathbf{I}-\hat{\mathbf{A}})^{-1}, \tilde{\mathbf{G}}$ is the vector of nominal government spending levels, the $\tilde{G}$ 's,

$$
\hat{\mathbf{A}}=\left(\begin{array}{ccccc}
\hat{a}_{11} & \hat{a}_{12} & & \ldots & \\
\hat{a}_{21} & \hat{a}_{22} & & & \\
& & \ddots & & \\
& & & & \\
& & & & \hat{a}_{n n}
\end{array}\right)
$$


with entries $\hat{a}_{i j}=\frac{x_{i j}}{y_{j}}$, and

$$
\boldsymbol{\Lambda}=\left(\begin{array}{cccc}
\left(1-\frac{\beta_{1}}{(1+\lambda)}\right) \frac{1}{p_{1} y_{1}} & -\frac{\beta_{1}}{(1+\lambda)} \frac{1}{p_{1} y_{1}} & & \\
-\frac{\beta_{2}}{(1+\lambda)} \frac{1}{p_{2} y_{2}} & \left(1-\frac{\beta_{2}}{(1+\lambda)}\right) \frac{1}{p_{2} y_{2}} & & \\
& & \ddots & \\
& & & \left(1-\frac{\beta_{n}}{(1+\lambda)}\right) \frac{1}{p_{n} y_{n}}
\end{array}\right)
$$

Carrying out the second matrix multiplication, this can also be written as

$$
\mathbf{d} \ln \mathbf{y}=\hat{\mathbf{H}}^{T}\left(\begin{array}{c}
\frac{d \tilde{G}_{1}}{p_{1} y_{1}}-\frac{\beta_{1}}{(1+\lambda)} \frac{1}{p_{1} y_{1}} \sum_{j=1}^{n} d \tilde{G}_{j} \\
\frac{d \tilde{G}_{2}}{p_{2} y_{2}}-\frac{\beta_{2}}{(1+\lambda)} \frac{1}{p_{2} y_{2}} \sum_{j=1}^{n} d \tilde{G}_{j} \\
\cdot \\
\cdot \\
\cdot
\end{array}\right)
$$

or with one more round of matrix multiplication, as

$$
d \ln y_{i}=\sum_{j=1}^{n} \hat{h}_{j i} \frac{1}{p_{j} y_{j}}\left(d \tilde{G}_{j}-\frac{\beta_{j}}{1+\lambda} \sum_{k=1}^{n} d \tilde{G}_{k}\right) .
$$

Rearranging this equation yields (7).

We also note that the effects of demand-side shocks can be alternatively expressed (without the division by $p_{i} y_{i}$ in equation (A8)) in level, rather than log, changes as

$$
\mathbf{d} \tilde{\mathbf{y}}=\mathbf{H}^{T}\left(\begin{array}{c}
d \tilde{G}_{1}-\frac{\beta_{1}}{(1+\lambda)} \sum_{j=1}^{n} d \tilde{G}_{j} \\
d \tilde{G}_{2}-\frac{\beta_{2}}{(1+\lambda)} \sum_{j=1}^{n} d \tilde{G}_{j} \\
\cdot \\
\cdot
\end{array}\right)
$$

which is the general form of the expressions used in Example 2. 


\section{Appendix B: Supplemental Figures and Tables}

\section{Appendix Figure 1: VAR responses to a one standard-deviation shock taken in isolation}

A. Chinese imports (reduction), value added

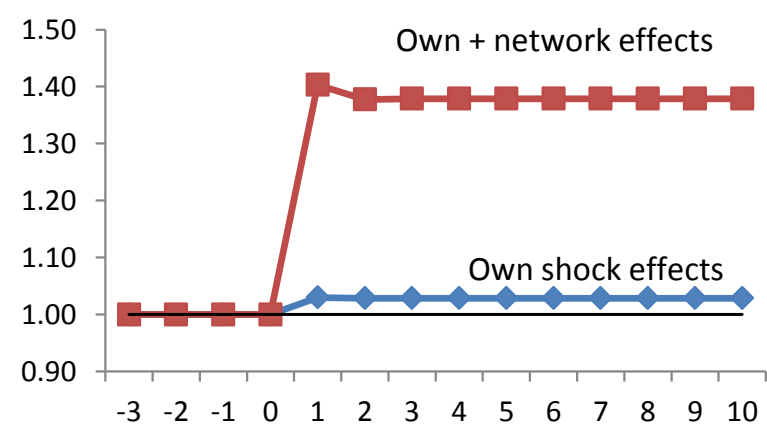

C. TFP, value added

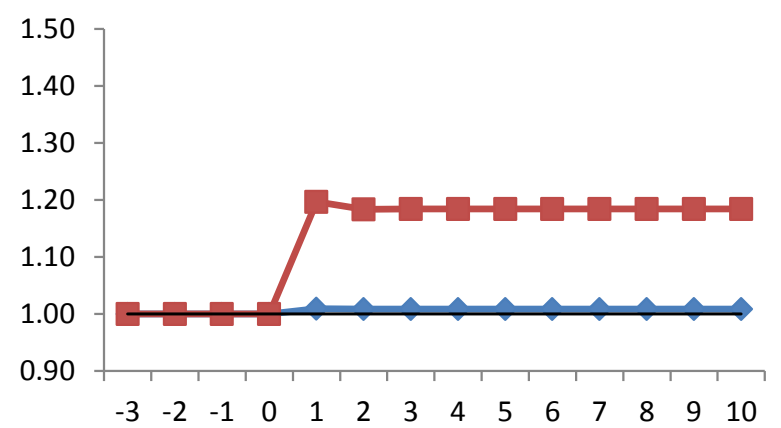

E. Federal government spending, value added

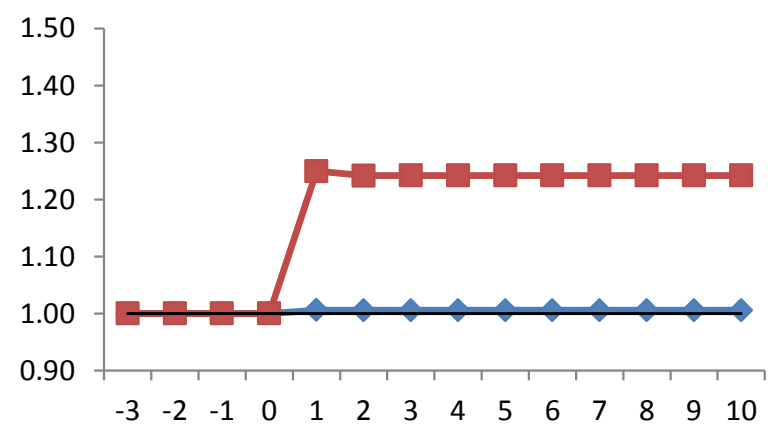

B. Chinese imports (reduction), employment

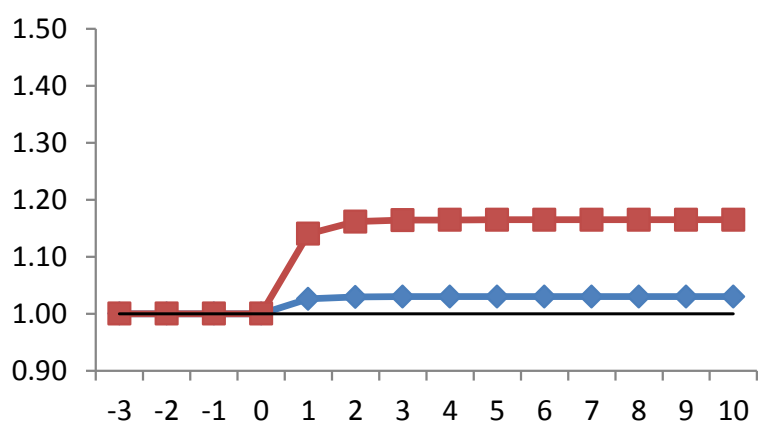

D. TFP, employment

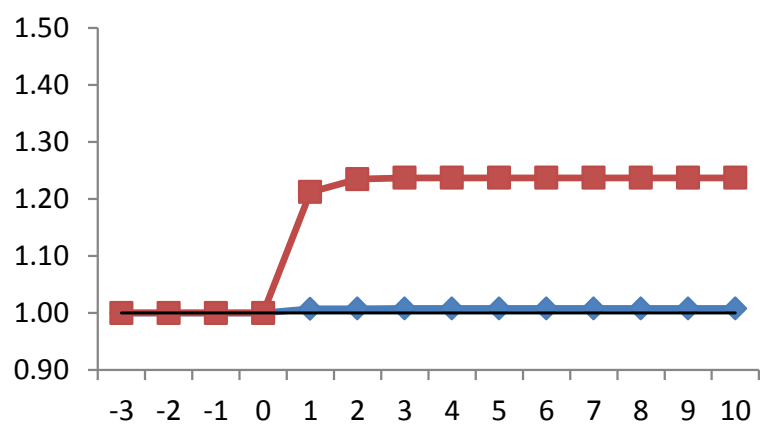

Notes: See Figure 1a. Figure plots estimated intermediated network effects akin to a VAR analysis. Estimations use upstream and downstream shocks in instrumental variable specifications where the endogenous regressor is the lagged actual value-added or employment change in the network. Results with foreign patenting and employment for federal spending are excluded. 


\section{Appendix Figure 2: Combined response to joint one standard-deviation shocks}

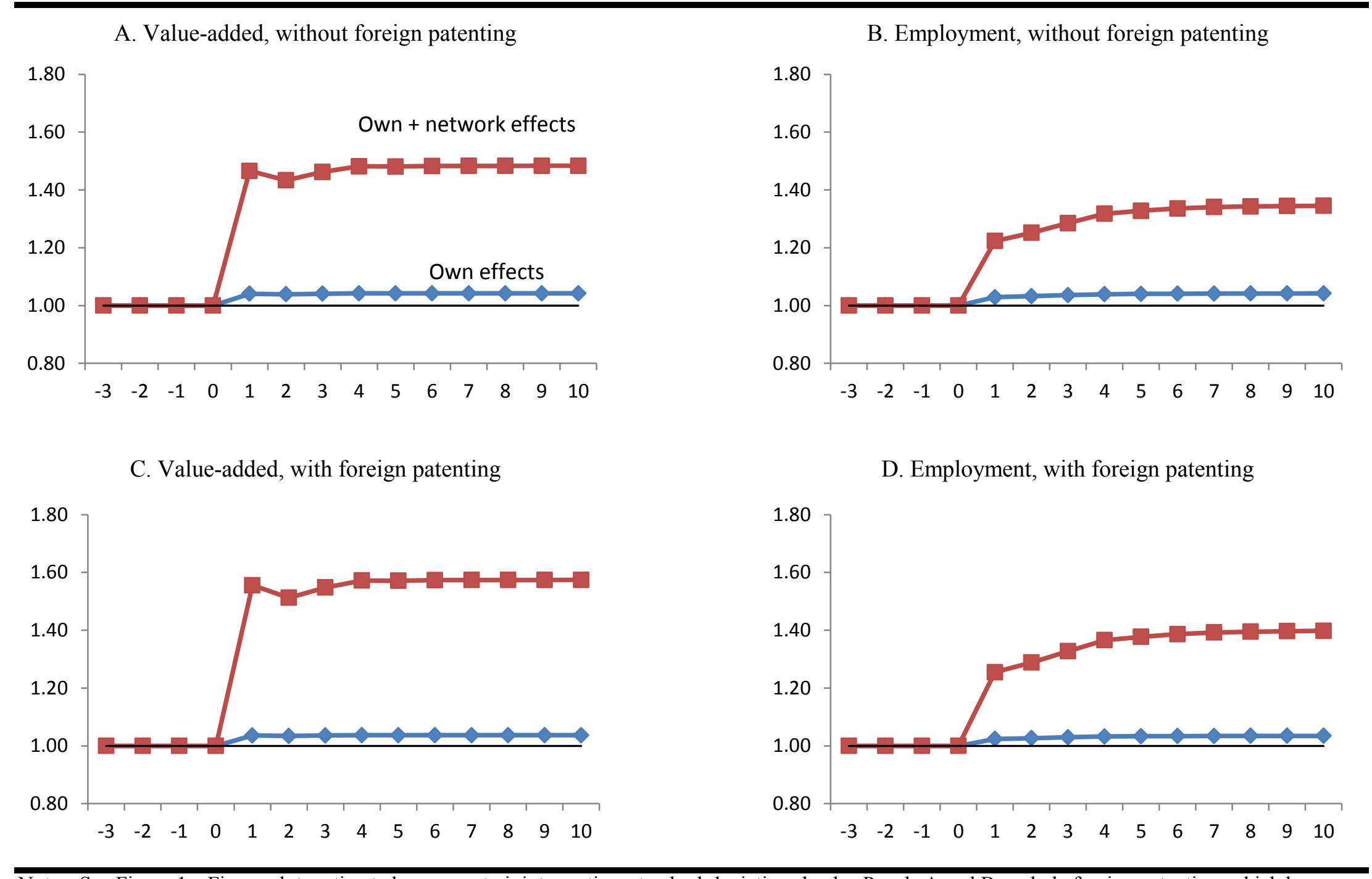

Notes: See Figure 1a. Figure plots estimated response to joint one-time standard-deviation shocks. Panels A and B exclude foreign patenting, which has a negative own effect, while Panels $\mathrm{C}$ and $\mathrm{D}$ include it. 


\section{Appendix Figure 3: Combined response to joint one standard-deviation shocks with geographic effects}

A. Value-added, without foreign patenting

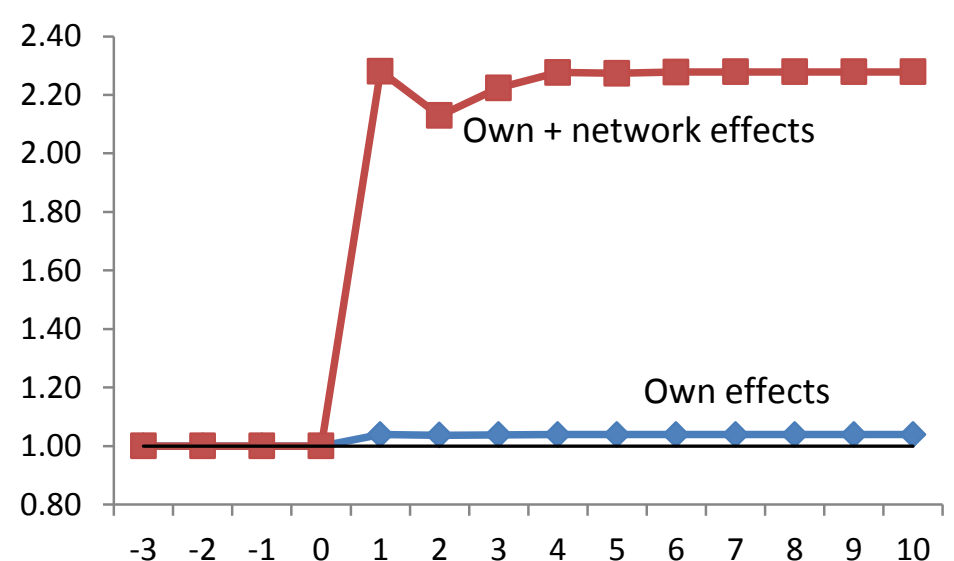

C. Value-added, with foreign patenting

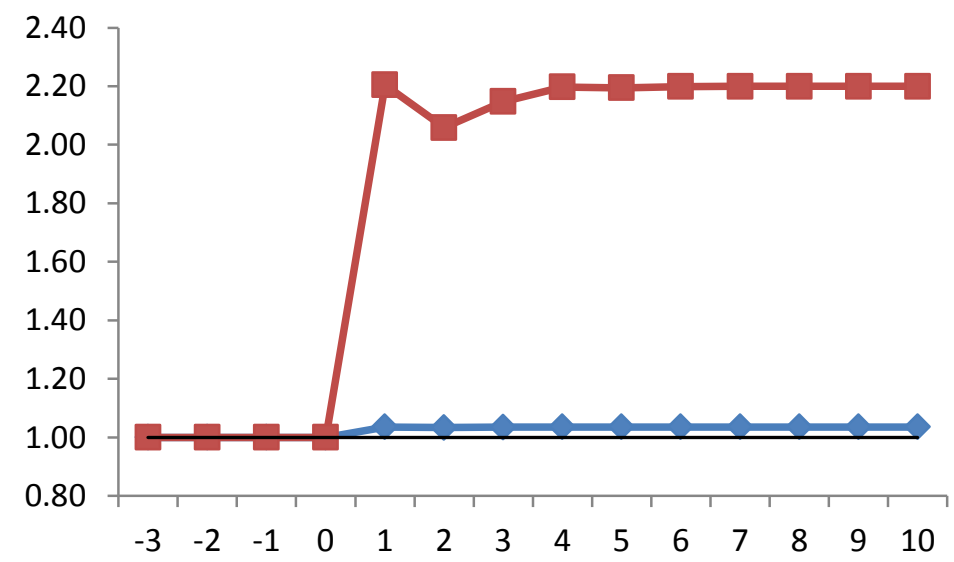

B. Employment, without foreign patenting

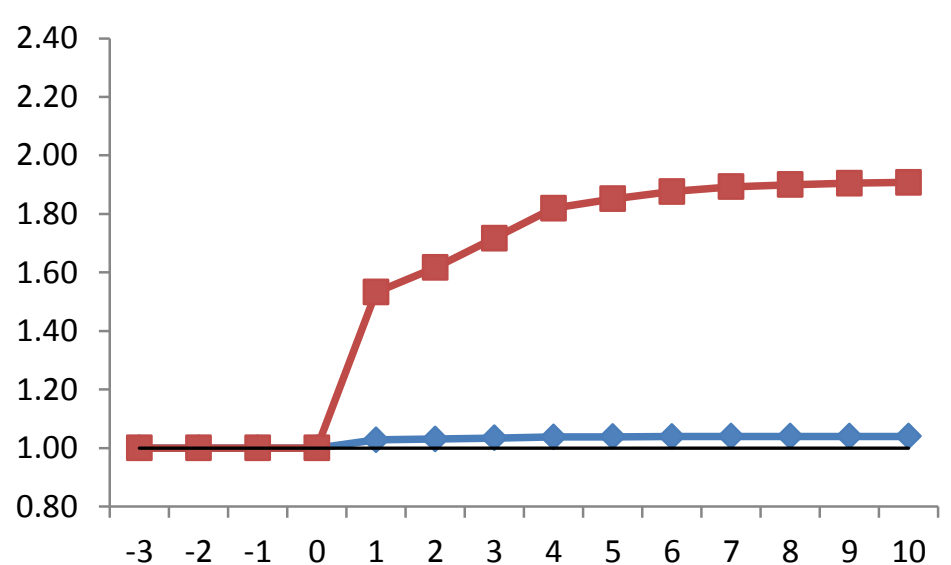

D. Employment, with foreign patenting

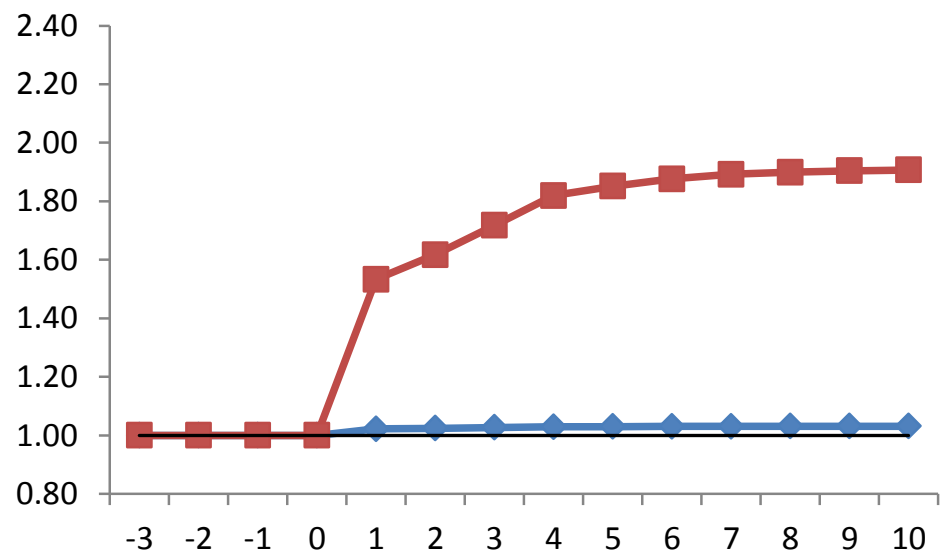

Notes: See Figures 1a and Appendix Figure 2. Figure plots estimated response to joint one-time standard-deviation shocks that includes geographic effects. 
Appendix Table 1: First-stage relationships for Chinese imports instruments

\begin{tabular}{|c|c|c|c|c|c|c|}
\hline & \multicolumn{3}{|c|}{ Real value-added growth, one lag } & \multicolumn{3}{|c|}{ Real value-added growth, three lags } \\
\hline & $\begin{array}{c}\text { Downstream } \\
\text { effects } t-1\end{array}$ & $\begin{array}{l}\text { Upstream } \\
\text { effects t-1 }\end{array}$ & Own effects $t-1$ & $\begin{array}{c}\text { Downstream } \\
\text { effects } t-1\end{array}$ & $\begin{array}{l}\text { Upstream } \\
\text { effects t-1 }\end{array}$ & Own effects $\mathrm{t}-1$ \\
\hline & $(1)$ & $(2)$ & $(3)$ & $(4)$ & $(5)$ & $(6)$ \\
\hline$\Delta$ Log real value added $t-1$ & $\begin{array}{c}-0.012 * * * \\
(0.004)\end{array}$ & $\begin{array}{l}-0.014 \\
(0.010)\end{array}$ & $\begin{array}{l}-0.008 \\
(0.084)\end{array}$ & $\begin{array}{c}-0.013 * * * \\
(0.005)\end{array}$ & $\begin{array}{l}-0.015 \\
(0.011)\end{array}$ & $\begin{array}{l}-0.023 \\
(0.082)\end{array}$ \\
\hline$\Delta$ Log real value added $t-2$ & & & & $\begin{array}{l}-0.004 \\
(0.005)\end{array}$ & $\begin{array}{c}0.032 * * \\
(0.015)\end{array}$ & $\begin{array}{l}-0.027 \\
(0.068)\end{array}$ \\
\hline$\Delta$ Log real value added $t-3$ & & & & $\begin{array}{l}-0.005 \\
(0.005)\end{array}$ & $\begin{array}{c}0.004 \\
(0.013)\end{array}$ & $\begin{array}{l}-0.018 \\
(0.080)\end{array}$ \\
\hline IV Downstream effects t-1 & $\begin{array}{c}0.638 * * * \\
(0.041)\end{array}$ & $\begin{array}{c}0.101 * * \\
(0.044)\end{array}$ & $\begin{array}{c}0.832 * * \\
(0.368)\end{array}$ & $\begin{array}{c}0.640 * * * \\
(0.041)\end{array}$ & $\begin{array}{c}0.110^{* *} \\
(0.045)\end{array}$ & $\begin{array}{c}0.835^{* *} \\
(0.364)\end{array}$ \\
\hline IV Upstream effects t-1 & $\begin{array}{c}0.005 \\
(0.009)\end{array}$ & $\begin{array}{c}0.886 * * * \\
(0.045)\end{array}$ & $\begin{array}{c}-0.244 * * \\
(0.076)\end{array}$ & $\begin{array}{c}0.005 \\
(0.009)\end{array}$ & $\begin{array}{c}0.879 * * * \\
(0.045)\end{array}$ & $\begin{array}{c}-0.237 * * * \\
(0.077)\end{array}$ \\
\hline IV Own effects t-1 & $\begin{array}{l}-0.001 \\
(0.002)\end{array}$ & $\begin{array}{c}-0.008 * * * \\
(0.003)\end{array}$ & $\begin{array}{c}0.461 * * * \\
(0.075)\end{array}$ & $\begin{array}{l}-0.001 \\
(0.002)\end{array}$ & $\begin{array}{c}-0.009 * * * \\
(0.003)\end{array}$ & $\begin{array}{c}0.458 * * * \\
(0.073)\end{array}$ \\
\hline Shea's Partial R-Squared & 0.361 & 0.514 & 0.224 & 0.360 & 0.509 & 0.222 \\
\hline
\end{tabular}

Notes: See Table 2a. 
Appendix Table 2a: Robustness checks on China trade shock analysis using real shipments growth

\begin{tabular}{|c|c|c|c|c|c|c|c|c|}
\hline & $\begin{array}{l}\text { Baseline } \\
\text { estimation }\end{array}$ & $\begin{array}{c}\text { Excluding } \\
\text { own lagged } \\
\text { shock }\end{array}$ & $\begin{array}{l}\text { Weighting by } \\
1991 \text { log value } \\
\text { added }\end{array}$ & $\begin{array}{c}\text { Weighting by } \\
1991 \\
\text { employees }\end{array}$ & $\begin{array}{l}\text { Adding SIC2 } \\
\text { fixed effects }\end{array}$ & $\begin{array}{l}\text { Adding SIC3 } \\
\text { fixed effects }\end{array}$ & $\begin{array}{l}\text { Adding SIC4 } \\
\text { fixed effects }\end{array}$ & $\begin{array}{c}\text { Adding } \\
\text { resource } \\
\text { constraints }\end{array}$ \\
\hline & (1) & (2) & (3) & (4) & (5) & (6) & (7) & (8) \\
\hline & \multicolumn{8}{|c|}{$\Delta$ Log real shipments } \\
\hline$\Delta$ Dependent variable $\mathrm{t}-1$ & $\begin{array}{c}0.176^{* * *} \\
(0.026)\end{array}$ & $\begin{array}{c}0.179 * * * \\
(0.026)\end{array}$ & $\begin{array}{c}0.182 * * * \\
(0.028)\end{array}$ & $\begin{array}{c}0.332 * * * \\
(0.065)\end{array}$ & $\begin{array}{c}0.140 * * * \\
(0.026)\end{array}$ & $\begin{array}{c}0.103 * * * \\
(0.024)\end{array}$ & $\begin{array}{c}0.061 * * * \\
(0.021)\end{array}$ & $\begin{array}{c}0.173 * * * \\
(0.027)\end{array}$ \\
\hline Downstream effects $t-1$ & $\begin{array}{c}-0.140 * * \\
(0.059)\end{array}$ & $\begin{array}{l}-0.067 \\
(0.055)\end{array}$ & $\begin{array}{c}-0.147 * * \\
(0.060)\end{array}$ & $\begin{array}{c}-0.186^{* *} \\
(0.091)\end{array}$ & $\begin{array}{l}-0.025 \\
(0.076)\end{array}$ & $\begin{array}{c}0.084 \\
(0.076)\end{array}$ & $\begin{array}{c}0.128 \\
(0.098)\end{array}$ & $\begin{array}{l}-0.176 \\
(0.067)\end{array}$ \\
\hline Upstream effects $\mathrm{t}-1$ & $\begin{array}{c}0.054 * * * \\
(0.019)\end{array}$ & $\begin{array}{c}0.048 * * * \\
(0.019)\end{array}$ & $\begin{array}{c}0.055^{* * *} \\
(0.019)\end{array}$ & $\begin{array}{l}0.045^{*} \\
(0.024)\end{array}$ & $\begin{array}{l}0.034^{*} \\
(0.020)\end{array}$ & $\begin{array}{c}0.033 \\
(0.026)\end{array}$ & $\begin{array}{c}0.031 \\
(0.035)\end{array}$ & $\begin{array}{c}0.098 * * * \\
(0.037)\end{array}$ \\
\hline Own effects $t-1$ & $\begin{array}{c}0.021 * * * \\
(0.006)\end{array}$ & & $\begin{array}{c}0.020 * * * \\
(0.006)\end{array}$ & $\begin{array}{c}0.018 \\
(0.011)\end{array}$ & $\begin{array}{c}0.007 \\
(0.006)\end{array}$ & $\begin{array}{c}0.004 \\
(0.007)\end{array}$ & $\begin{array}{c}0.002 \\
(0.010)\end{array}$ & $\begin{array}{c}0.018 * * * \\
(0.006)\end{array}$ \\
\hline $\begin{array}{l}\text { Observations } \\
\text { p-value: Upstream=Own }\end{array}$ & $\begin{array}{l}6560 \\
0.068\end{array}$ & 6560 & $\begin{array}{l}6560 \\
0.053\end{array}$ & $\begin{array}{l}6560 \\
0.143\end{array}$ & $\begin{array}{l}6560 \\
0.154\end{array}$ & $\begin{array}{l}6560 \\
0.272\end{array}$ & $\begin{array}{l}6560 \\
0.460\end{array}$ & $\begin{array}{l}6560 \\
0.027\end{array}$ \\
\hline
\end{tabular}

Notes: See Table 2a. 
Appendix Table 2b: Variations in psi parameter for China trade shock analysis

0

0.1

0.2

0.3

0.4

0.5

0.6

0.7

0.8

0.9

1

A. $\Delta$ Log real value added

\begin{tabular}{|c|c|c|c|c|c|c|c|c|c|c|c|}
\hline Downstream effects t-1 & $\begin{array}{l}-0.146^{*} \\
(0.087)\end{array}$ & $\begin{array}{l}-0.116 \\
(0.083)\end{array}$ & $\begin{array}{c}-0.086 \\
(0.080)\end{array}$ & $\begin{array}{l}-0.056 \\
(0.078)\end{array}$ & $\begin{array}{l}-0.026 \\
(0.076)\end{array}$ & $\begin{array}{c}0.004 \\
(0.074)\end{array}$ & $\begin{array}{c}0.034 \\
(0.074)\end{array}$ & $\begin{array}{c}0.065 \\
(0.074)\end{array}$ & $\begin{array}{c}0.095 \\
(0.075)\end{array}$ & $\begin{array}{c}0.125 \\
(0.077)\end{array}$ & $\begin{array}{l}0.155^{*} \\
(0.080)\end{array}$ \\
\hline Upstream effects t-1 & $\begin{array}{c}0.077 * * * \\
(0.024)\end{array}$ & $\begin{array}{c}0.073 * * * \\
(0.022)\end{array}$ & $\begin{array}{c}0.069 * * * \\
(0.021)\end{array}$ & $\begin{array}{c}0.064 * * * \\
(0.020)\end{array}$ & $\begin{array}{c}0.060 * * * \\
(0.019)\end{array}$ & $\begin{array}{c}0.056^{* * *} \\
(0.019)\end{array}$ & $\begin{array}{c}0.052 * * * \\
(0.018)\end{array}$ & $\begin{array}{c}0.048 * * * \\
(0.018)\end{array}$ & $\begin{array}{c}0.043 * * \\
(0.018)\end{array}$ & $\begin{array}{c}0.039 * * \\
(0.018)\end{array}$ & $\begin{array}{l}0.035 * \\
(0.018)\end{array}$ \\
\hline Own effects $t-1$ & $\begin{array}{c}0.034 * * * \\
(0.009)\end{array}$ & $\begin{array}{c}0.033 * * * \\
(0.009)\end{array}$ & $\begin{array}{c}0.033 * * * \\
(0.009)\end{array}$ & $\begin{array}{c}0.032 * * * \\
(0.009)\end{array}$ & $\begin{array}{c}0.032 * * * \\
(0.009)\end{array}$ & $\begin{array}{c}0.031 * * * \\
(0.009)\end{array}$ & $\begin{array}{c}0.031 * * * \\
(0.009)\end{array}$ & $\begin{array}{c}0.030 * * * \\
(0.009)\end{array}$ & $\begin{array}{c}0.030 * * * \\
(0.009)\end{array}$ & $\begin{array}{c}0.029 * * * \\
(0.010)\end{array}$ & $\begin{array}{c}0.029 * * * \\
(0.010)\end{array}$ \\
\hline & \multicolumn{11}{|c|}{ B. $\Delta$ Log employment } \\
\hline Downstream effects t-1 & $\begin{array}{c}-0.073 \\
(0.046)\end{array}$ & $\begin{array}{l}-0.062 \\
(0.042)\end{array}$ & $\begin{array}{l}-0.050 \\
(0.039)\end{array}$ & $\begin{array}{l}-0.038 \\
(0.037)\end{array}$ & $\begin{array}{l}-0.027 \\
(0.035)\end{array}$ & $\begin{array}{l}-0.015 \\
(0.034)\end{array}$ & $\begin{array}{l}-0.003 \\
(0.034)\end{array}$ & $\begin{array}{c}0.008 \\
(0.035)\end{array}$ & $\begin{array}{c}0.020 \\
(0.036)\end{array}$ & $\begin{array}{c}0.032 \\
(0.039)\end{array}$ & $\begin{array}{c}0.043 \\
(0.042)\end{array}$ \\
\hline Upstream effects t-1 & $\begin{array}{c}0.056^{* * *} \\
(0.018)\end{array}$ & $\begin{array}{c}0.052 * * * \\
(0.017)\end{array}$ & $\begin{array}{c}0.047^{* * *} \\
(0.016)\end{array}$ & $\begin{array}{c}0.042 * * * \\
(0.014)\end{array}$ & $\begin{array}{c}0.038 * * * \\
(0.013)\end{array}$ & $\begin{array}{c}0.033 * * * \\
(0.012)\end{array}$ & $\begin{array}{c}0.028 * * * \\
(0.011)\end{array}$ & $\begin{array}{c}0.024 * * \\
(0.010)\end{array}$ & $\begin{array}{c}0.019 * * \\
(0.009)\end{array}$ & $\begin{array}{c}0.014 \\
(0.009)\end{array}$ & $\begin{array}{c}0.010 \\
(0.009)\end{array}$ \\
\hline Own effects t-1 & $\begin{array}{c}0.026^{* * *} \\
(0.005)\end{array}$ & $\begin{array}{c}0.024 * * * \\
(0.005)\end{array}$ & $\begin{array}{c}0.022 * * * \\
(0.005)\end{array}$ & $\begin{array}{c}0.020 * * * \\
(0.004)\end{array}$ & $\begin{array}{c}0.018 * * * \\
(0.004)\end{array}$ & $\begin{array}{c}0.016^{* * *} \\
(0.004)\end{array}$ & $\begin{array}{c}0.014 * * * \\
(0.004)\end{array}$ & $\begin{array}{c}0.012 * * * \\
(0.004)\end{array}$ & $\begin{array}{c}0.010 * * * \\
(0.004)\end{array}$ & $\begin{array}{c}0.008 * * \\
(0.004)\end{array}$ & $\begin{array}{c}0.006 \\
(0.004)\end{array}$ \\
\hline
\end{tabular}

Notes: See Table 2a. Estimations impose the psi parameter for the lagged dependent variable dependence given in the column header. 
Appendix Table 2c: Longer changes on China trade shock analysis

\begin{tabular}{|c|c|c|c|c|c|}
\hline & $\begin{array}{c}\text { Baseline annual } \\
\text { analysis }\end{array}$ & $\begin{array}{l}\text { Using two-year } \\
\text { periods }\end{array}$ & $\begin{array}{l}\text { Using three- } \\
\text { year periods }\end{array}$ & $\begin{array}{l}\text { Using four-year } \\
\text { periods }\end{array}$ & $\begin{array}{c}\text { Using five-year } \\
\text { periods }\end{array}$ \\
\hline & $(1)$ & (2) & (3) & (4) & $(5)$ \\
\hline & \multicolumn{5}{|c|}{ A. $\Delta$ Log real value added } \\
\hline$\Delta$ Dependent variable $\mathrm{t}-1$ & $\begin{array}{c}0.019 \\
(0.025)\end{array}$ & $\begin{array}{l}0.085 * * \\
(0.037)\end{array}$ & $\begin{array}{l}0.092 * \\
(0.047)\end{array}$ & $\begin{array}{c}0.027 \\
(0.056)\end{array}$ & $\begin{array}{c}0.072 \\
(0.076)\end{array}$ \\
\hline Downstream effects t-1 & $\begin{array}{l}-0.140 \\
(0.086)\end{array}$ & $\begin{array}{c}-0.323 * * * \\
(0.120)\end{array}$ & $\begin{array}{c}-0.417 * * \\
(0.198)\end{array}$ & $\begin{array}{c}-1.549 * * * \\
(0.348)\end{array}$ & $\begin{array}{l}-1.092 \\
(0.671)\end{array}$ \\
\hline Upstream effects t- 1 & $\begin{array}{c}0.076 * * * \\
(0.024)\end{array}$ & $\begin{array}{c}0.089 * * * \\
(0.024)\end{array}$ & $\begin{array}{c}0.149 * * * \\
(0.040)\end{array}$ & $\begin{array}{c}0.292 * * * \\
(0.067)\end{array}$ & $\begin{array}{c}0.719 * * * \\
(0.175)\end{array}$ \\
\hline Own effects t-1 & $\begin{array}{c}0.034 * * * \\
(0.009)\end{array}$ & $\begin{array}{c}0.041 * * * \\
(0.010)\end{array}$ & $\begin{array}{c}0.087 * * * \\
(0.017)\end{array}$ & $\begin{array}{c}0.118 * * * \\
(0.029)\end{array}$ & $\begin{array}{c}0.153 * * * \\
(0.054)\end{array}$ \\
\hline Observations & 6560 & 3080 & 1920 & 1152 & 768 \\
\hline \multirow[t]{2}{*}{ p-value: Upstream=Own } & 0.071 & 0.035 & 0.093 & 0.005 & 0.001 \\
\hline & \multicolumn{5}{|c|}{ B. $\Delta$ Log employment } \\
\hline$\Delta$ Dependent variable $\mathrm{t}-1$ & $\begin{array}{c}0.149 * * * \\
(0.020)\end{array}$ & $\begin{array}{c}0.242 * * * \\
(0.028)\end{array}$ & $\begin{array}{c}0.284 * * * \\
(0.041)\end{array}$ & $\begin{array}{c}0.266^{* * *} \\
(0.047)\end{array}$ & $\begin{array}{c}0.297 * * * \\
(0.058)\end{array}$ \\
\hline Downstream effects t-1 & $\begin{array}{l}-0.056 \\
(0.040)\end{array}$ & $\begin{array}{l}-0.041 \\
(0.058)\end{array}$ & $\begin{array}{c}-0.207 * * * \\
(0.076)\end{array}$ & $\begin{array}{l}-0.055 \\
(0.221)\end{array}$ & $\begin{array}{l}0.685 * \\
(0.408)\end{array}$ \\
\hline Upstream effects t-1 & $\begin{array}{c}0.049 * * * \\
(0.016)\end{array}$ & $\begin{array}{c}0.063 * * * \\
(0.019)\end{array}$ & $\begin{array}{c}0.100 * * * \\
(0.027)\end{array}$ & $\begin{array}{c}0.215 * * * \\
(0.060)\end{array}$ & $\begin{array}{c}0.655 * * * \\
(0.160)\end{array}$ \\
\hline Own effects t-1 & $\begin{array}{c}0.023 * * * \\
(0.005)\end{array}$ & $\begin{array}{c}0.036 * * * \\
(0.008)\end{array}$ & $\begin{array}{c}0.067 * * * \\
(0.012)\end{array}$ & $\begin{array}{c}0.102 * * * \\
(0.027)\end{array}$ & $\begin{array}{c}0.111^{* * *} \\
(0.039)\end{array}$ \\
\hline Observations & 6560 & 3080 & 1920 & 1152 & 768 \\
\hline p-value: Upstream=Own & 0.086 & 0.138 & 0.172 & 0.066 & 0.001 \\
\hline
\end{tabular}

Notes: See Table 2a. All sample periods start with 1991 and extend as far as data allow. For example, Column 5 effectively considers 1996-2001 and 2001-2006, with lags extending back to 1991-1996. 
Appendix Table 3a: Robustness checks on federal spending shock analysis using real shipments growth

\begin{tabular}{|c|c|c|c|c|c|c|c|c|}
\hline & $\begin{array}{l}\text { Baseline } \\
\text { estimation }\end{array}$ & $\begin{array}{c}\text { Excluding } \\
\text { own lagged } \\
\text { shock }\end{array}$ & $\begin{array}{l}\text { Weighting by } \\
1991 \text { log value } \\
\text { added }\end{array}$ & $\begin{array}{c}\text { Weighting by } \\
1991 \\
\text { employees }\end{array}$ & $\begin{array}{l}\text { Adding SIC2 } \\
\text { fixed effects }\end{array}$ & $\begin{array}{l}\text { Adding SIC3 } \\
\text { fixed effects }\end{array}$ & $\begin{array}{l}\text { Adding SIC4 } \\
\text { fixed effects }\end{array}$ & $\begin{array}{c}\text { Adding } \\
\text { resource } \\
\text { constraints }\end{array}$ \\
\hline & (1) & (2) & (3) & (4) & (5) & (6) & (7) & (8) \\
\hline & \multicolumn{8}{|c|}{$\Delta$ Log real shipments } \\
\hline$\Delta$ Dependent variable $\mathrm{t}-1$ & $\begin{array}{c}0.178 * * * \\
(0.026)\end{array}$ & $\begin{array}{c}0.178 * * * \\
(0.026)\end{array}$ & $\begin{array}{c}0.184 * * * \\
(0.027)\end{array}$ & $\begin{array}{c}0.334 * * * \\
(0.061)\end{array}$ & $\begin{array}{c}0.138 * * * \\
(0.026)\end{array}$ & $\begin{array}{c}0.101 * * * \\
(0.026)\end{array}$ & $\begin{array}{c}0.058 * * * \\
(0.021)\end{array}$ & $\begin{array}{c}0.178 * * * \\
(0.026)\end{array}$ \\
\hline Downstream effects $t-1$ & $\begin{array}{l}-0.002 \\
(0.018)\end{array}$ & $\begin{array}{c}0.019 \\
(0.016)\end{array}$ & $\begin{array}{l}-0.003 \\
(0.017)\end{array}$ & $\begin{array}{l}-0.002 \\
(0.009)\end{array}$ & $\begin{array}{l}-0.022 \\
(0.018)\end{array}$ & $\begin{array}{c}0.011 \\
(0.019)\end{array}$ & $\begin{array}{l}-0.025 \\
(0.046)\end{array}$ & $\begin{array}{c}0.000 \\
(0.018)\end{array}$ \\
\hline Upstream effects $\mathrm{t}-1$ & $\begin{array}{c}0.022 * * * \\
(0.008)\end{array}$ & $\begin{array}{c}0.022 * * * \\
(0.008)\end{array}$ & $\begin{array}{c}0.021 * * * \\
(0.008)\end{array}$ & $\begin{array}{c}0.024 * * \\
(0.010)\end{array}$ & $\begin{array}{l}0.013^{*} \\
(0.007)\end{array}$ & $\begin{array}{l}0.024 * \\
(0.013)\end{array}$ & $\begin{array}{c}0.055^{* * *} \\
(0.019)\end{array}$ & $\begin{array}{l}0.017 * \\
(0.010)\end{array}$ \\
\hline Own effects $t-1$ & $\begin{array}{l}0.005^{*} \\
(0.003)\end{array}$ & & $\begin{array}{l}0.004^{*} \\
(0.003)\end{array}$ & $\begin{array}{c}0.001 \\
(0.001)\end{array}$ & $\begin{array}{c}0.003 \\
(0.003)\end{array}$ & $\begin{array}{c}0.007 \\
(0.005)\end{array}$ & $\begin{array}{c}0.010 \\
(0.010)\end{array}$ & $\begin{array}{l}0.005^{*} \\
(0.003)\end{array}$ \\
\hline $\begin{array}{l}\text { Observations } \\
\text { p-value: Upstream=Own }\end{array}$ & $\begin{array}{l}6560 \\
0.063\end{array}$ & 6560 & $\begin{array}{l}6560 \\
0.065\end{array}$ & $\begin{array}{l}6560 \\
0.019\end{array}$ & $\begin{array}{l}6560 \\
0.304\end{array}$ & $\begin{array}{l}6560 \\
0.211\end{array}$ & $\begin{array}{l}6560 \\
0.055\end{array}$ & $\begin{array}{l}6560 \\
0.259\end{array}$ \\
\hline
\end{tabular}

Notes: See Table 3a. 
Appendix Table 3b: Variations in psi parameter for federal spending shock analysis

\section{0}

\begin{abstract}
0.1
\end{abstract}

\begin{abstract}
0.2
\end{abstract}

\begin{abstract}
0.3
\end{abstract}
0.4

0.5

0.6

0.7

A. $\Delta$ Log real value added

Downstream effects t-1

Upstream effects t-1

Own effects t-1

$\begin{array}{cccc}0.017 & 0.016 & 0.014 & 0.012 \\ (0.022) & (0.020) & (0.018) & (0.016) \\ 0.022 * * & 0.020 * * & 0.018 * * & 0.017 * * \\ (0.010) & (0.009) & (0.008) & (0.007) \\ 0.004 & 0.004 & 0.003 & 0.003 \\ (0.003) & (0.003) & (0.003) & (0.002)\end{array}$

Downstream effects t-1

$\begin{array}{cccc}0.009 & 0.008 & 0.007 & 0.006 \\ (0.016) & (0.015) & (0.014) & (0.013) \\ 0.011 & 0.010 * & 0.009 * & 0.009 * \\ (0.007) & (0.006) & (0.006) & (0.005) \\ 0.003 & 0.003 & 0.003 & 0.003 \\ (0.003) & (0.003) & (0.003) & (0.003)\end{array}$

0.010
$(0.014)$
$0.015^{* *}$
$(0.006)$
0.003
$(0.002)$

0.009
$(0.012)$
$0.013 * *$
$(0.005)$
0.003
$(0.002)$

0.007

(0.011)

$0.011^{* *}$

(0.005)

$0.002 *$

(0.001)

B. $\Delta$ Log employment

0.004
$(0.011)$
$0.007 *$
$(0.004)$
0.003
$(0.002)$

0.003

(0.010)

$0.007^{*}$

(0.004)

0.003

(0.002)

(0.002)

0.005
$(0.009)$
$0.009 * *$
$(0.004)$
$0.002 * *$
$(0.001)$

0.004

(0.008)

$0.007 * *$

(0.004)

0.002 **

(0.001)

0.002

(0.009)

$0.006 *$

(0.003)

0.002

(0.001)

(0.002)

0.001
$(0.008)$
$0.005^{*}$
$(0.003)$
$0.002^{*}$
$(0.001)$

0.000

(0.008)

$0.004 *$

(0.003)

$0.002 * *$

(0.001)

$-0.001$

(0.007)

0.004

(0.003)

$0.002 * * *$

(0.001)

Notes: See Table 3a. Estimations impose the psi parameter for the lagged dependent variable dependence given in the column header. 
Appendix Table 3c: Longer changes on federal spending shock analysis

\begin{tabular}{|c|c|c|c|c|c|}
\hline & $\begin{array}{l}\text { Baseline annual } \\
\text { analysis }\end{array}$ & $\begin{array}{l}\text { Using two-year } \\
\text { periods }\end{array}$ & $\begin{array}{l}\text { Using three- } \\
\text { year periods }\end{array}$ & $\begin{array}{l}\text { Using four-year } \\
\text { periods }\end{array}$ & $\begin{array}{l}\text { Using five-year } \\
\text { periods }\end{array}$ \\
\hline & $(1)$ & $(2)$ & $(3)$ & $(4)$ & $(5)$ \\
\hline & \multicolumn{5}{|c|}{ A. $\Delta$ Log real value added } \\
\hline \multirow[t]{2}{*}{$\Delta$ Dependent variable $\mathrm{t}-1$} & 0.019 & $0.094 * *$ & $0.114 * *$ & 0.083 & $0.138^{*}$ \\
\hline & $(0.025)$ & $(0.037)$ & $(0.048)$ & $(0.059)$ & $(0.072)$ \\
\hline \multirow[t]{2}{*}{ Downstream effects t-1 } & 0.017 & 0.031 & $0.094 *$ & $0.197 * *$ & 0.122 \\
\hline & $(0.021)$ & $(0.033)$ & $(0.054)$ & $(0.095)$ & $(0.130)$ \\
\hline \multirow[t]{2}{*}{ Upstream effects t- 1} & $0.022 * *$ & 0.020 & $0.037^{*}$ & 0.056 & -0.009 \\
\hline & $(0.009)$ & $(0.014)$ & $(0.021)$ & $(0.039)$ & $(0.051)$ \\
\hline \multirow[t]{2}{*}{ Own effects t-1 } & 0.004 & $0.013 * * *$ & $0.023 * *$ & 0.011 & 0.017 \\
\hline & $(0.003)$ & $(0.005)$ & $(0.010)$ & $(0.016)$ & $(0.016)$ \\
\hline Observations & 6560 & 3080 & 1920 & 1152 & 768 \\
\hline \multirow[t]{2}{*}{ p-value: Upstream=Own } & 0.076 & 0.634 & 0.569 & 0.286 & 0.657 \\
\hline & \multicolumn{5}{|c|}{ B. $\Delta$ Log employment } \\
\hline \multirow[t]{2}{*}{$\Delta$ Dependent variable $\mathrm{t}-1$} & $0.158 * * *$ & $0.264 * * *$ & $0.332 * * *$ & $0.346^{* * *}$ & $0.379 * * *$ \\
\hline & $(0.021)$ & $(0.027)$ & $(0.040)$ & $(0.047)$ & $(0.054)$ \\
\hline \multirow[t]{2}{*}{ Downstream effects t-1 } & 0.007 & 0.029 & 0.051 & 0.044 & $0.176^{*}$ \\
\hline & $(0.015)$ & $(0.021)$ & $(0.032)$ & $(0.044)$ & $(0.102)$ \\
\hline \multirow[t]{2}{*}{ Upstream effects t- 1} & $0.010^{*}$ & $0.018^{* *}$ & $0.040 * * *$ & $0.063 * * *$ & -0.025 \\
\hline & $(0.006)$ & $(0.008)$ & $(0.013)$ & $(0.023)$ & $(0.036)$ \\
\hline \multirow[t]{2}{*}{ Own effects t-1 } & 0.003 & $0.006^{*}$ & $0.015^{* * *}$ & $0.022 * * *$ & $0.036^{* * *}$ \\
\hline & $(0.003)$ & $(0.004)$ & $(0.006)$ & $(0.008)$ & $(0.013)$ \\
\hline Observations & 6560 & 3080 & 1920 & 1152 & 768 \\
\hline p-value: Upstream=Own & 0.321 & 0.214 & 0.088 & 0.103 & 0.144 \\
\hline
\end{tabular}

Notes: See Table 3a. 
Appendix Table 4a: Robustness checks on TFP shock analysis using real shipments growth

\begin{tabular}{|c|c|c|c|c|c|c|c|}
\hline & $\begin{array}{l}\text { Baseline } \\
\text { estimation }\end{array}$ & $\begin{array}{c}\text { Excluding } \\
\text { own lagged } \\
\text { shock }\end{array}$ & $\begin{array}{l}\text { Weighting by } \\
1991 \text { log value } \\
\text { added }\end{array}$ & $\begin{array}{c}\text { Weighting by } \\
1991 \\
\text { employees }\end{array}$ & $\begin{array}{l}\text { Adding SIC2 } \\
\text { fixed effects }\end{array}$ & $\begin{array}{l}\text { Adding SIC3 } \\
\text { fixed effects }\end{array}$ & $\begin{array}{l}\text { Adding SIC4 } \\
\text { fixed effects }\end{array}$ \\
\hline & $(1)$ & $(2)$ & (3) & (4) & (5) & $(6)$ & $(7)$ \\
\hline & \multicolumn{7}{|c|}{$\Delta$ Log real shipments } \\
\hline$\Delta$ Dependent variable $\mathrm{t}-1$ & $\begin{array}{c}0.226 * * * \\
(0.026)\end{array}$ & $\begin{array}{c}0.164 * * * \\
(0.024)\end{array}$ & $\begin{array}{c}0.231 * * * \\
(0.026)\end{array}$ & $\begin{array}{c}0.307 * * * \\
(0.045)\end{array}$ & $\begin{array}{c}0.168 * * * \\
(0.026)\end{array}$ & $\begin{array}{c}0.122 * * * \\
(0.027)\end{array}$ & $\begin{array}{c}0.088 * * * \\
(0.027)\end{array}$ \\
\hline Downstream effects t-1 & $\begin{array}{c}0.054 * * * \\
(0.017)\end{array}$ & $\begin{array}{c}0.048 * * * \\
(0.017)\end{array}$ & $\begin{array}{c}0.055^{* * *} \\
(0.017)\end{array}$ & $\begin{array}{c}0.065^{* * *} \\
(0.023)\end{array}$ & $\begin{array}{l}0.037 * * \\
(0.016)\end{array}$ & $\begin{array}{l}0.026^{*} \\
(0.014)\end{array}$ & $\begin{array}{l}0.026^{*} \\
(0.014)\end{array}$ \\
\hline Upstream effects t-1 & $\begin{array}{c}0.012 \\
(0.010)\end{array}$ & $\begin{array}{c}0.010 \\
(0.010)\end{array}$ & $\begin{array}{c}0.013 \\
(0.010)\end{array}$ & $\begin{array}{c}0.039 * * * \\
(0.012)\end{array}$ & $\begin{array}{c}0.008 \\
(0.009)\end{array}$ & $\begin{array}{c}0.004 \\
(0.011)\end{array}$ & $\begin{array}{c}0.006 \\
(0.011)\end{array}$ \\
\hline Own effects t-1 & $\begin{array}{c}-0.012 * * * \\
(0.004)\end{array}$ & & $\begin{array}{c}-0.011 * * * \\
(0.004)\end{array}$ & $\begin{array}{l}-0.004 \\
(0.009)\end{array}$ & $\begin{array}{l}-0.007^{*} \\
(0.004)\end{array}$ & $\begin{array}{l}-0.005 \\
(0.004)\end{array}$ & $\begin{array}{l}-0.006^{*} \\
(0.003)\end{array}$ \\
\hline $\begin{array}{l}\text { Observations } \\
\text { p-value: Downstream }=\mathrm{Own}\end{array}$ & $\begin{array}{l}6560 \\
0.000\end{array}$ & 6560 & $\begin{array}{l}6560 \\
0.000\end{array}$ & $\begin{array}{l}6560 \\
0.034\end{array}$ & $\begin{array}{l}6560 \\
0.014\end{array}$ & $\begin{array}{l}6560 \\
0.134\end{array}$ & $\begin{array}{l}6560 \\
0.008\end{array}$ \\
\hline
\end{tabular}

Notes: See Table 4a. 
Appendix Table 4b: Variations in psi parameter for TFP shock analysis

0

0.1

0.2

0.3

0.4

0.5

0.6

0.7

0.8

0.9

1

A. $\Delta$ Log real value added

\begin{tabular}{|c|c|c|c|c|c|c|c|c|c|c|c|}
\hline Downstream effects $t-1$ & $\begin{array}{c}0.059 * * * \\
(0.020)\end{array}$ & $\begin{array}{c}0.054^{* * *} \\
(0.020)\end{array}$ & $\begin{array}{c}0.050 * * \\
(0.020)\end{array}$ & $\begin{array}{c}0.045 * * \\
(0.021)\end{array}$ & $\begin{array}{l}0.040 * \\
(0.021)\end{array}$ & $\begin{array}{c}0.035 \\
(0.022)\end{array}$ & $\begin{array}{c}0.031 \\
(0.022)\end{array}$ & $\begin{array}{c}0.026 \\
(0.023)\end{array}$ & $\begin{array}{c}0.021 \\
(0.024)\end{array}$ & $\begin{array}{c}0.017 \\
(0.024)\end{array}$ & $\begin{array}{c}0.012 \\
(0.025)\end{array}$ \\
\hline Upstream effects t-1 & $\begin{array}{c}0.023 * * \\
(0.011)\end{array}$ & $\begin{array}{l}0.021 * \\
(0.011)\end{array}$ & $\begin{array}{l}0.019 * \\
(0.011)\end{array}$ & $\begin{array}{c}0.017 \\
(0.011)\end{array}$ & $\begin{array}{c}0.015 \\
(0.012)\end{array}$ & $\begin{array}{c}0.013 \\
(0.012)\end{array}$ & $\begin{array}{c}0.011 \\
(0.012)\end{array}$ & $\begin{array}{c}0.008 \\
(0.013)\end{array}$ & $\begin{array}{c}0.006 \\
(0.013)\end{array}$ & $\begin{array}{c}0.004 \\
(0.013)\end{array}$ & $\begin{array}{c}0.002 \\
(0.014)\end{array}$ \\
\hline Own effects $t-1$ & $\begin{array}{c}0.002 \\
(0.004)\end{array}$ & $\begin{array}{c}-0.011 * * * \\
(0.004)\end{array}$ & $\begin{array}{c}-0.023 * * * \\
(0.004)\end{array}$ & $\begin{array}{c}-0.035 * * * \\
(0.004)\end{array}$ & $\begin{array}{c}-0.047 * * * \\
(0.004)\end{array}$ & $\begin{array}{c}-0.059 * * * \\
(0.005)\end{array}$ & $\begin{array}{c}-0.072 * * * \\
(0.005)\end{array}$ & $\begin{array}{c}-0.084 * * * \\
(0.005)\end{array}$ & $\begin{array}{c}-0.096 * * * \\
(0.005)\end{array}$ & $\begin{array}{c}-0.108 * * * \\
(0.005)\end{array}$ & $\begin{array}{c}-0.120 * * * \\
(0.006)\end{array}$ \\
\hline & \multicolumn{11}{|c|}{ B. $\Delta$ Log employment } \\
\hline Downstream effects t-1 & $\begin{array}{l}0.018^{*} \\
(0.010)\end{array}$ & $\begin{array}{c}0.017^{*} \\
(0.009)\end{array}$ & $\begin{array}{l}0.016^{*} \\
(0.009)\end{array}$ & $\begin{array}{c}0.015 \\
(0.009)\end{array}$ & $\begin{array}{c}0.013 \\
(0.009)\end{array}$ & $\begin{array}{c}0.012 \\
(0.009)\end{array}$ & $\begin{array}{c}0.011 \\
(0.009)\end{array}$ & $\begin{array}{c}0.010 \\
(0.010)\end{array}$ & $\begin{array}{c}0.009 \\
(0.010)\end{array}$ & $\begin{array}{c}0.007 \\
(0.011)\end{array}$ & $\begin{array}{c}0.006 \\
(0.011)\end{array}$ \\
\hline Upstream effects t-1 & $\begin{array}{c}0.010 \\
(0.006)\end{array}$ & $\begin{array}{c}0.009 \\
(0.006)\end{array}$ & $\begin{array}{c}0.009 \\
(0.006)\end{array}$ & $\begin{array}{c}0.008 \\
(0.006)\end{array}$ & $\begin{array}{c}0.007 \\
(0.006)\end{array}$ & $\begin{array}{c}0.006 \\
(0.006)\end{array}$ & $\begin{array}{c}0.005 \\
(0.007)\end{array}$ & $\begin{array}{c}0.004 \\
(0.007)\end{array}$ & $\begin{array}{c}0.003 \\
(0.007)\end{array}$ & $\begin{array}{c}0.003 \\
(0.008)\end{array}$ & $\begin{array}{c}0.002 \\
(0.008)\end{array}$ \\
\hline Own effects t-1 & $\begin{array}{c}0.010 * * * \\
(0.002)\end{array}$ & $\begin{array}{c}0.007 * * * \\
(0.002)\end{array}$ & $\begin{array}{c}0.005 * * * \\
(0.002)\end{array}$ & $\begin{array}{c}0.003 \\
(0.002)\end{array}$ & $\begin{array}{c}0.000 \\
(0.002)\end{array}$ & $\begin{array}{l}-0.002 \\
(0.002)\end{array}$ & $\begin{array}{c}-0.004 * * \\
(0.002)\end{array}$ & $\begin{array}{c}-0.007 * * * \\
(0.002)\end{array}$ & $\begin{array}{c}-0.009 * * * \\
(0.002)\end{array}$ & $\begin{array}{c}-0.011 * * * \\
(0.003)\end{array}$ & $\begin{array}{c}-0.014 * * * \\
(0.003)\end{array}$ \\
\hline
\end{tabular}

Notes: See Table 4a. Estimations impose the psi parameter for the lagged dependent variable dependence given in the column header. 
Appendix Table 4c: Longer changes on TFP shock analysis

\begin{tabular}{|c|c|c|c|c|c|}
\hline & $\begin{array}{c}\text { Baseline annual } \\
\text { analysis }\end{array}$ & $\begin{array}{l}\text { Using two-year } \\
\text { periods }\end{array}$ & $\begin{array}{l}\text { Using three- } \\
\text { year periods }\end{array}$ & $\begin{array}{l}\text { Using four-year } \\
\text { periods }\end{array}$ & $\begin{array}{l}\text { Using five-year } \\
\text { periods }\end{array}$ \\
\hline & $(1)$ & $(2)$ & (3) & $(4)$ & $(5)$ \\
\hline & \multicolumn{5}{|c|}{ A. $\Delta$ Log real value added } \\
\hline \multirow[t]{2}{*}{$\Delta$ Dependent variable $\mathrm{t}-1$} & -0.024 & 0.067 & $0.157 * * *$ & $0.123^{*}$ & $0.125^{*}$ \\
\hline & $(0.040)$ & $(0.047)$ & $(0.056)$ & $(0.069)$ & $(0.068)$ \\
\hline \multirow[t]{2}{*}{ Downstream effects t-1 } & $0.060 * * *$ & $0.189 * * *$ & $0.118^{*}$ & $0.253 * * *$ & $0.269 * *$ \\
\hline & $(0.020)$ & $(0.047)$ & $(0.067)$ & $(0.089)$ & $(0.104)$ \\
\hline \multirow[t]{2}{*}{ Upstream effects t-1 } & $0.024 * *$ & 0.033 & 0.041 & -0.055 & -0.077 \\
\hline & $(0.011)$ & $(0.021)$ & $(0.036)$ & $(0.050)$ & $(0.056)$ \\
\hline \multirow[t]{2}{*}{ Own effects t-1 } & 0.004 & -0.004 & -0.027 & -0.032 & -0.016 \\
\hline & $(0.007)$ & $(0.013)$ & $(0.022)$ & $(0.031)$ & $(0.037)$ \\
\hline Observations & 6560 & 3080 & 1920 & 1152 & 768 \\
\hline \multirow[t]{2}{*}{ p-value: Downstream=Own } & 0.005 & 0.000 & 0.092 & 0.006 & 0.025 \\
\hline & \multicolumn{5}{|c|}{ B. $\Delta$ Log employment } \\
\hline \multirow[t]{2}{*}{$\Delta$ Dependent variable $\mathrm{t}-1$} & $0.141 * * *$ & $0.252 * * *$ & $0.336 * * *$ & $0.349 * * *$ & $0.363 * * *$ \\
\hline & $(0.021)$ & $(0.028)$ & $(0.042)$ & $(0.047)$ & $(0.054)$ \\
\hline \multirow[t]{2}{*}{ Downstream effects t-1 } & $0.016^{*}$ & 0.015 & -0.016 & 0.032 & 0.053 \\
\hline & $(0.009)$ & $(0.022)$ & $(0.027)$ & $(0.036)$ & $(0.053)$ \\
\hline \multirow[t]{2}{*}{ Upstream effects t- 1} & 0.009 & 0.017 & 0.021 & $-0.069 * *$ & $-0.099 * *$ \\
\hline & $(0.006)$ & $(0.010)$ & $(0.018)$ & $(0.033)$ & $(0.039)$ \\
\hline \multirow[t]{2}{*}{ Own effects t-1 } & $0.006^{* * *}$ & 0.006 & -0.004 & -0.011 & -0.016 \\
\hline & $(0.002)$ & $(0.004)$ & $(0.006)$ & $(0.008)$ & $(0.014)$ \\
\hline Observations & 6560 & 3080 & 1920 & 1152 & 768 \\
\hline p-value: Downstream=Own & 0.041 & 0.485 & 0.690 & 0.169 & 0.217 \\
\hline
\end{tabular}

Notes: See Table 4a. 
Appendix Table 5a: Robustness checks on foreign patent shock analysis using real shipments growth

\begin{tabular}{|c|c|c|c|c|c|c|c|}
\hline & $\begin{array}{l}\text { Baseline } \\
\text { estimation }\end{array}$ & $\begin{array}{c}\text { Excluding } \\
\text { own lagged } \\
\text { shock }\end{array}$ & $\begin{array}{c}\text { Weighting by } \\
1991 \text { log value } \\
\text { added }\end{array}$ & $\begin{array}{c}\text { Weighting by } \\
1991 \\
\text { employees }\end{array}$ & $\begin{array}{l}\text { Adding SIC2 } \\
\text { fixed effects }\end{array}$ & $\begin{array}{l}\text { Adding SIC3 } \\
\text { fixed effects }\end{array}$ & $\begin{array}{l}\text { Adding SIC4 } \\
\text { fixed effects }\end{array}$ \\
\hline & $(1)$ & $(2)$ & $(3)$ & $(4)$ & $(5)$ & $(6)$ & $(7)$ \\
\hline & \multicolumn{7}{|c|}{$\Delta$ Log real shipments } \\
\hline$\Delta$ Dependent variable $\mathrm{t}-1$ & $\begin{array}{c}0.181 * * * \\
(0.026)\end{array}$ & $\begin{array}{c}0.181 * * * \\
(0.026)\end{array}$ & $\begin{array}{c}0.187 * * * \\
(0.028)\end{array}$ & $\begin{array}{c}0.342 * * * \\
(0.063)\end{array}$ & $\begin{array}{c}0.139 * * * \\
(0.027)\end{array}$ & $\begin{array}{c}0.103 * * * \\
(0.025)\end{array}$ & $\begin{array}{c}0.060 * * * \\
(0.021)\end{array}$ \\
\hline Downstream effects t-1 & $\begin{array}{c}0.022 * * * \\
(0.008)\end{array}$ & $\begin{array}{c}0.019^{* *} \\
(0.008)\end{array}$ & $\begin{array}{c}0.022 * * * \\
(0.008)\end{array}$ & $\begin{array}{c}0.025 \\
(0.019)\end{array}$ & $\begin{array}{c}0.019^{* *} \\
(0.008)\end{array}$ & $\begin{array}{c}0.017 * * \\
(0.008)\end{array}$ & $\begin{array}{c}0.018^{* *} \\
(0.008)\end{array}$ \\
\hline Upstream effects $\mathrm{t}-1$ & $\begin{array}{c}0.002 \\
(0.004)\end{array}$ & $\begin{array}{c}0.002 \\
(0.004)\end{array}$ & $\begin{array}{c}0.002 \\
(0.004)\end{array}$ & $\begin{array}{c}0.007 \\
(0.005)\end{array}$ & $\begin{array}{c}0.002 \\
(0.004)\end{array}$ & $\begin{array}{c}0.002 \\
(0.004)\end{array}$ & $\begin{array}{c}0.002 \\
(0.004)\end{array}$ \\
\hline Own effects t-1 & $\begin{array}{l}-0.003 \\
(0.003)\end{array}$ & & $\begin{array}{l}-0.003 \\
(0.003)\end{array}$ & $\begin{array}{c}0.004 \\
(0.006)\end{array}$ & $\begin{array}{l}-0.001 \\
(0.003)\end{array}$ & $\begin{array}{l}-0.001 \\
(0.003)\end{array}$ & $\begin{array}{l}-0.002 \\
(0.003)\end{array}$ \\
\hline Observations & 6543 & 6543 & 6543 & 6543 & 6543 & 6543 & 6543 \\
\hline p-value: Downstream=Own & 0.015 & & 0.021 & 0.683 & 0.039 & 0.057 & 0.025 \\
\hline
\end{tabular}

Notes: See Table 5a. 
Appendix Table 5b: Variations in psi parameter for foreign patenting shock analysis

\section{0}

0.1

0.2

0.3

0.4

0.5

0.6

0.7

0.8

0.9

1

A. $\Delta$ Log real value added

\begin{tabular}{|c|c|c|c|c|c|c|c|c|c|c|c|}
\hline Downstream effects t-1 & $\begin{array}{c}0.043 * * * \\
(0.011)\end{array}$ & $\begin{array}{c}0.041 * * * \\
(0.011)\end{array}$ & $\begin{array}{c}0.039 * * * \\
(0.011)\end{array}$ & $\begin{array}{c}0.037 * * * \\
(0.011)\end{array}$ & $\begin{array}{c}0.036^{* * *} \\
(0.012)\end{array}$ & $\begin{array}{c}0.034 * * * \\
(0.012)\end{array}$ & $\begin{array}{c}0.032 * * \\
(0.012)\end{array}$ & $\begin{array}{c}0.030 * * \\
(0.013)\end{array}$ & $\begin{array}{c}0.028 * * \\
(0.013)\end{array}$ & $\begin{array}{l}0.026 * \\
(0.014)\end{array}$ & $\begin{array}{c}0.024 \\
(0.015)\end{array}$ \\
\hline Upstream effects t-1 & $\begin{array}{l}-0.000 \\
(0.005)\end{array}$ & $\begin{array}{c}0.000 \\
(0.005)\end{array}$ & $\begin{array}{c}0.001 \\
(0.005)\end{array}$ & $\begin{array}{c}0.001 \\
(0.005)\end{array}$ & $\begin{array}{c}0.002 \\
(0.005)\end{array}$ & $\begin{array}{c}0.003 \\
(0.005)\end{array}$ & $\begin{array}{c}0.003 \\
(0.005)\end{array}$ & $\begin{array}{c}0.004 \\
(0.006)\end{array}$ & $\begin{array}{c}0.005 \\
(0.006)\end{array}$ & $\begin{array}{c}0.005 \\
(0.006)\end{array}$ & $\begin{array}{c}0.006 \\
(0.007)\end{array}$ \\
\hline Own effects $t-1$ & $\begin{array}{l}-0.006 \\
(0.004)\end{array}$ & $\begin{array}{l}-0.005 \\
(0.004)\end{array}$ & $\begin{array}{l}-0.005 \\
(0.004)\end{array}$ & $\begin{array}{c}-0.004 \\
(0.004)\end{array}$ & $\begin{array}{l}-0.003 \\
(0.004)\end{array}$ & $\begin{array}{c}-0.002 \\
(0.004)\end{array}$ & $\begin{array}{l}-0.002 \\
(0.004)\end{array}$ & $\begin{array}{c}-0.001 \\
(0.005)\end{array}$ & $\begin{array}{l}-0.000 \\
(0.005)\end{array}$ & $\begin{array}{c}0.001 \\
(0.005)\end{array}$ & $\begin{array}{c}0.001 \\
(0.006)\end{array}$ \\
\hline & \multicolumn{11}{|c|}{ B. $\Delta$ Log employment } \\
\hline Downstream effects t-1 & $\begin{array}{c}0.018 * * * \\
(0.006)\end{array}$ & $\begin{array}{c}0.018^{* * *} \\
(0.006)\end{array}$ & $\begin{array}{c}0.018 * * * \\
(0.006)\end{array}$ & $\begin{array}{c}0.018 * * * \\
(0.006)\end{array}$ & $\begin{array}{c}0.018 * * * \\
(0.006)\end{array}$ & $\begin{array}{c}0.018 * * * \\
(0.007)\end{array}$ & $\begin{array}{c}0.018 * * * \\
(0.007)\end{array}$ & $\begin{array}{c}0.018 * * \\
(0.007)\end{array}$ & $\begin{array}{c}0.018 * * \\
(0.007)\end{array}$ & $\begin{array}{c}0.018 * * \\
(0.007)\end{array}$ & $\begin{array}{c}0.018 * * \\
(0.008)\end{array}$ \\
\hline Upstream effects t-1 & $\begin{array}{l}-0.002 \\
(0.003)\end{array}$ & $\begin{array}{l}-0.001 \\
(0.003)\end{array}$ & $\begin{array}{l}-0.001 \\
(0.003)\end{array}$ & $\begin{array}{c}0.000 \\
(0.003)\end{array}$ & $\begin{array}{c}0.001 \\
(0.003)\end{array}$ & $\begin{array}{c}0.001 \\
(0.003)\end{array}$ & $\begin{array}{c}0.002 \\
(0.003)\end{array}$ & $\begin{array}{c}0.003 \\
(0.003)\end{array}$ & $\begin{array}{c}0.003 \\
(0.003)\end{array}$ & $\begin{array}{c}0.004 \\
(0.003)\end{array}$ & $\begin{array}{c}0.004 \\
(0.003)\end{array}$ \\
\hline Own effects $t-1$ & $\begin{array}{c}-0.009 * * * \\
(0.002)\end{array}$ & $\begin{array}{c}-0.008^{* * *} \\
(0.003)\end{array}$ & $\begin{array}{c}-0.007 * * * \\
(0.003)\end{array}$ & $\begin{array}{c}-0.006^{* *} \\
(0.003)\end{array}$ & $\begin{array}{c}-0.006^{* *} \\
(0.003)\end{array}$ & $\begin{array}{l}-0.005 \\
(0.003)\end{array}$ & $\begin{array}{l}-0.004 \\
(0.003)\end{array}$ & $\begin{array}{l}-0.003 \\
(0.003)\end{array}$ & $\begin{array}{l}-0.002 \\
(0.004)\end{array}$ & $\begin{array}{l}-0.001 \\
(0.004)\end{array}$ & $\begin{array}{l}-0.000 \\
(0.004)\end{array}$ \\
\hline
\end{tabular}

Notes: See Table 5a. Estimations impose the psi parameter for the lagged dependent variable dependence given in the column header. 
Appendix Table 5c: Longer changes on foreign patent shock analysis

\begin{tabular}{|c|c|c|c|c|c|}
\hline & $\begin{array}{c}\text { Baseline annual } \\
\text { analysis }\end{array}$ & $\begin{array}{l}\text { Using two-year } \\
\text { periods }\end{array}$ & $\begin{array}{l}\text { Using three- } \\
\text { year periods }\end{array}$ & $\begin{array}{l}\text { Using four-year } \\
\text { periods }\end{array}$ & $\begin{array}{c}\text { Using five-year } \\
\text { periods }\end{array}$ \\
\hline & $(1)$ & $(2)$ & (3) & (4) & $(5)$ \\
\hline & \multicolumn{5}{|c|}{ A. $\Delta$ Log real value added } \\
\hline \multirow[t]{2}{*}{$\Delta$ Dependent variable $\mathrm{t}-1$} & 0.020 & $0.099 * * *$ & $0.113 * *$ & 0.075 & $0.133^{*}$ \\
\hline & $(0.025)$ & $(0.038)$ & $(0.050)$ & $(0.060)$ & $(0.071)$ \\
\hline \multirow[t]{2}{*}{ Downstream effects $\mathrm{t}-1$} & $0.043 * * *$ & -0.032 & 0.040 & 0.088 & -0.012 \\
\hline & $(0.011)$ & $(0.023)$ & $(0.034)$ & $(0.064)$ & $(0.067)$ \\
\hline \multirow[t]{2}{*}{ Upstream effects t-1 } & -0.000 & $-0.020 * *$ & -0.013 & 0.004 & 0.014 \\
\hline & $(0.005)$ & $(0.009)$ & $(0.012)$ & $(0.018)$ & $(0.021)$ \\
\hline \multirow[t]{2}{*}{ Own effects $t-1$} & -0.006 & 0.012 & -0.015 & $0.044^{*}$ & 0.004 \\
\hline & $(0.004)$ & $(0.011)$ & $(0.017)$ & $(0.023)$ & $(0.033)$ \\
\hline Observations & 6543 & 3072 & 1915 & 1149 & 766 \\
\hline \multirow[t]{2}{*}{ p-value: Downstream=Own } & 0.000 & 0.051 & 0.144 & 0.902 & 0.592 \\
\hline & \multicolumn{5}{|c|}{ B. $\Delta$ Log employment } \\
\hline \multirow[t]{2}{*}{$\Delta$ Dependent variable $\mathrm{t}-1$} & $0.159 * * *$ & $0.265 * * *$ & $0.330 * * *$ & $0.324 * * *$ & $0.347 * * *$ \\
\hline & $(0.021)$ & $(0.028)$ & $(0.041)$ & $(0.046)$ & $(0.053)$ \\
\hline \multirow[t]{2}{*}{ Downstream effects $t-1$} & $0.018 * * *$ & 0.005 & $0.046 * *$ & $0.104 * * *$ & 0.039 \\
\hline & $(0.006)$ & $(0.012)$ & $(0.023)$ & $(0.037)$ & $(0.048)$ \\
\hline \multirow[t]{2}{*}{ Upstream effects t-1 } & -0.001 & $-0.011 * *$ & -0.009 & 0.005 & 0.006 \\
\hline & $(0.003)$ & $(0.005)$ & $(0.008)$ & $(0.012)$ & $(0.015)$ \\
\hline \multirow[t]{2}{*}{ Own effects t-1 } & $-0.008 * * *$ & -0.002 & $-0.022 * *$ & -0.006 & -0.006 \\
\hline & $(0.003)$ & $(0.007)$ & $(0.010)$ & $(0.015)$ & $(0.030)$ \\
\hline Observations & 6543 & 3072 & 1915 & 1149 & 766 \\
\hline p-value: Downstream=Own & 0.001 & 0.890 & 0.030 & 0.055 & 0.616 \\
\hline
\end{tabular}

Notes: See Table 5a. 
Appendix Table 6: Comparison of alternatives to real value added growth

\begin{tabular}{|c|c|c|c|c|c|c|c|c|}
\hline & \multicolumn{4}{|c|}{ China trade shocks } & \multicolumn{4}{|c|}{ Federal spending shocks } \\
\hline & $\begin{array}{c}\Delta \text { Log real } \\
\text { value added }\end{array}$ & $\begin{array}{l}\Delta \text { Log nominal } \\
\text { value added }\end{array}$ & $\begin{array}{l}\Delta \text { Log real } \\
\text { shipments }\end{array}$ & $\begin{array}{l}\Delta \text { Log nominal } \\
\text { shipments }\end{array}$ & $\begin{array}{l}\Delta \text { Log real } \\
\text { value added }\end{array}$ & $\begin{array}{l}\Delta \text { Log nominal } \\
\text { value added }\end{array}$ & $\begin{array}{l}\Delta \text { Log real } \\
\text { shipments }\end{array}$ & $\begin{array}{c}\Delta \text { Log nominal } \\
\text { shipments }\end{array}$ \\
\hline & $(1)$ & $(2)$ & (3) & $(4)$ & $(5)$ & (6) & $(7)$ & $(8)$ \\
\hline$\Delta$ Dependent variable $\mathrm{t}-1$ & $\begin{array}{c}0.019 \\
(0.025)\end{array}$ & $\begin{array}{l}0.034^{*} \\
(0.021)\end{array}$ & $\begin{array}{c}0.176 * * * \\
(0.026)\end{array}$ & $\begin{array}{c}0.201 * * * \\
(0.020)\end{array}$ & $\begin{array}{c}0.019 \\
(0.025)\end{array}$ & $\begin{array}{l}0.034^{*} \\
(0.020)\end{array}$ & $\begin{array}{c}0.178 * * * \\
(0.026)\end{array}$ & $\begin{array}{c}0.201 * * * \\
(0.019)\end{array}$ \\
\hline Downstream effects t-1 & $\begin{array}{l}-0.140 \\
(0.086)\end{array}$ & $\begin{array}{l}-0.013 \\
(0.073)\end{array}$ & $\begin{array}{c}-0.140 * * \\
(0.059)\end{array}$ & $\begin{array}{l}-0.025 \\
(0.050)\end{array}$ & $\begin{array}{c}0.017 \\
(0.021)\end{array}$ & $\begin{array}{c}0.014 \\
(0.019)\end{array}$ & $\begin{array}{c}-0.002 \\
(0.018)\end{array}$ & $\begin{array}{l}-0.004 \\
(0.016)\end{array}$ \\
\hline Upstream effects t-1 & $\begin{array}{c}0.076^{* * * *} \\
(0.024)\end{array}$ & $\begin{array}{c}0.077 * * * \\
(0.025)\end{array}$ & $\begin{array}{c}0.054 * * * \\
(0.019)\end{array}$ & $\begin{array}{c}0.056 * * * \\
(0.021)\end{array}$ & $\begin{array}{l}0.022 * * \\
(0.009)\end{array}$ & $\begin{array}{l}0.020 * * \\
(0.009)\end{array}$ & $\begin{array}{c}0.022 * * * \\
(0.008)\end{array}$ & $\begin{array}{c}0.019 * * \\
(0.008)\end{array}$ \\
\hline Own effects t-1 & $\begin{array}{c}0.034 * * * \\
(0.009)\end{array}$ & $\begin{array}{c}0.044 * * * \\
(0.011)\end{array}$ & $\begin{array}{c}0.021 * * * \\
(0.006)\end{array}$ & $\begin{array}{c}0.029 * * * \\
(0.007)\end{array}$ & $\begin{array}{c}0.004 \\
(0.003)\end{array}$ & $\begin{array}{c}0.003 \\
(0.003)\end{array}$ & $\begin{array}{l}0.005^{*} \\
(0.003)\end{array}$ & $\begin{array}{c}0.004 \\
(0.002)\end{array}$ \\
\hline Observations & 6560 & 6560 & 6560 & 6560 & 6560 & 6560 & 6560 & 6560 \\
\hline \multicolumn{9}{|c|}{ Appendix Table 6, continued } \\
\hline & \multicolumn{4}{|c|}{ TFP shocks } & \multicolumn{4}{|c|}{ Foreign patenting shocks } \\
\hline & $\begin{array}{c}\Delta \text { Log real } \\
\text { value added }\end{array}$ & $\begin{array}{l}\Delta \text { Log nominal } \\
\text { value added }\end{array}$ & $\begin{array}{c}\Delta \text { Log real } \\
\text { shipments }\end{array}$ & $\begin{array}{l}\Delta \text { Log nominal } \\
\text { shipments }\end{array}$ & $\begin{array}{c}\Delta \text { Log real } \\
\text { value added }\end{array}$ & $\begin{array}{l}\Delta \text { Log nominal } \\
\text { value added }\end{array}$ & $\begin{array}{l}\Delta \text { Log real } \\
\text { shipments }\end{array}$ & $\begin{array}{c}\Delta \text { Log nominal } \\
\text { shipments }\end{array}$ \\
\hline & $(1)$ & $(2)$ & $(3)$ & $(4)$ & $(5)$ & $(6)$ & $(7)$ & $(8)$ \\
\hline$\Delta$ Dependent variable $\mathrm{t}-1$ & $\begin{array}{l}-0.024 \\
(0.040)\end{array}$ & $\begin{array}{c}0.058^{* *} \\
(0.029)\end{array}$ & $\begin{array}{c}0.226 * * * \\
(0.026)\end{array}$ & $\begin{array}{c}0.246 * * * \\
(0.021)\end{array}$ & $\begin{array}{c}0.020 \\
(0.025)\end{array}$ & $\begin{array}{c}0.032 \\
(0.020)\end{array}$ & $\begin{array}{c}0.181 * * * \\
(0.026)\end{array}$ & $\begin{array}{c}0.201 * * * \\
(0.020)\end{array}$ \\
\hline Downstream effects t-1 & $\begin{array}{c}0.060 * * * \\
(0.020)\end{array}$ & $\begin{array}{c}0.018 \\
(0.016)\end{array}$ & $\begin{array}{c}0.054 * * * \\
(0.017)\end{array}$ & $\begin{array}{c}0.026^{* *} \\
(0.012)\end{array}$ & $\begin{array}{c}0.043 * * * \\
(0.011)\end{array}$ & $\begin{array}{c}0.037 * * * \\
(0.010)\end{array}$ & $\begin{array}{c}0.022 * * * \\
(0.008)\end{array}$ & $\begin{array}{l}0.018^{* *} \\
(0.007)\end{array}$ \\
\hline Upstream effects $t-1$ & $\begin{array}{l}0.024^{* *} \\
(0.011)\end{array}$ & $\begin{array}{c}0.039 * * * \\
(0.011)\end{array}$ & $\begin{array}{c}0.012 \\
(0.010)\end{array}$ & $\begin{array}{c}0.031 * * * \\
(0.008)\end{array}$ & $\begin{array}{l}-0.000 \\
(0.005)\end{array}$ & $\begin{array}{c}-0.012 * * * \\
(0.005)\end{array}$ & $\begin{array}{c}0.002 \\
(0.004)\end{array}$ & $\begin{array}{c}-0.008^{* *} \\
(0.003)\end{array}$ \\
\hline Own effects $t-1$ & $\begin{array}{c}0.004 \\
(0.007)\end{array}$ & $\begin{array}{c}-0.008^{* *} \\
(0.004)\end{array}$ & $\begin{array}{c}-0.012 * * * \\
(0.004)\end{array}$ & $\begin{array}{c}-0.013 * * * \\
(0.003)\end{array}$ & $\begin{array}{l}-0.006 \\
(0.004)\end{array}$ & $\begin{array}{c}-0.011^{* * *} \\
(0.004)\end{array}$ & $\begin{array}{l}-0.003 \\
(0.003)\end{array}$ & $\begin{array}{c}-0.007 * * \\
(0.003)\end{array}$ \\
\hline Observations & 6560 & 6560 & 6560 & 6560 & 6543 & 6543 & 6543 & 6543 \\
\hline
\end{tabular}


Appendix Table 7: Summed coefficients over deeper lags

\begin{tabular}{|c|c|c|c|c|c|c|c|c|}
\hline & \multicolumn{4}{|c|}{$\Delta$ Log real value added } & \multicolumn{4}{|c|}{$\Delta$ Log employment } \\
\hline & $(1)$ & $(2)$ & $(3)$ & $(4)$ & $(5)$ & $(6)$ & $(7)$ & $(8)$ \\
\hline Include 3 lags of DV & Yes & Yes & Yes & Yes & Yes & Yes & Yes & Yes \\
\hline Include 3 lags of own shock & & Yes & & Yes & & Yes & & Yes \\
\hline Include 3 lags of network shocks & & & Yes & Yes & & & Yes & Yes \\
\hline \multicolumn{9}{|l|}{ Table 2a: Imports } \\
\hline Downstream effects & -0.124 & -0.121 & $-0.191^{*}$ & $-0.225^{* *}$ & -0.044 & -0.040 & -0.034 & $-0.065^{*}$ \\
\hline Upstream effects & $0.076 * * *$ & $0.079 * * *$ & $0.069 * * *$ & $0.074 * * *$ & $0.039 * * *$ & $0.045 * * *$ & $0.038 * * *$ & $0.043 * * *$ \\
\hline Own effects & $0.031 * * *$ & $0.042 * * *$ & $0.030 * * *$ & $0.046^{* * *}$ & $0.018 * * *$ & $0.029 * * *$ & $0.018 * * *$ & $0.032 * * *$ \\
\hline \multicolumn{9}{|l|}{ Table 3a: Federal Spending } \\
\hline Downstream effects & 0.023 & 0.023 & $0.042 *$ & $0.036^{*}$ & 0.013 & 0.013 & 0.015 & 0.015 \\
\hline Upstream effects & $0.020 * *$ & $0.020 * *$ & $0.018 * *$ & $0.018 * *$ & $0.011 * *$ & $0.011 * *$ & $0.013 * * *$ & $0.013 * * *$ \\
\hline Own effects & $0.008 * *$ & $0.010 * * *$ & $0.008 * *$ & $0.009 * * *$ & $0.006 * * *$ & $0.007 * * *$ & $0.006^{* * *}$ & $0.006 * * *$ \\
\hline \multicolumn{9}{|l|}{ Table 4a: TFP } \\
\hline Downstream effects & $0.047 * *$ & $0.048 * *$ & $0.085 * *$ & $0.087 * *$ & 0.011 & 0.012 & -0.005 & -0.003 \\
\hline Upstream effects & $0.020 *$ & $0.019 *$ & 0.017 & 0.017 & 0.008 & 0.008 & 0.013 & $0.014^{*}$ \\
\hline Own effects & 0.007 & -0.001 & 0.007 & -0.002 & $0.007 * * *$ & $0.005 *$ & $0.007 * * *$ & $0.006^{*}$ \\
\hline \multicolumn{9}{|l|}{ Table 5a: Foreign Patent } \\
\hline Downstream effects & $0.044 * * *$ & $0.043 * * *$ & $0.037 *$ & 0.030 & $0.018 * * *$ & $0.018 * * *$ & $0.022 * *$ & $0.021 * *$ \\
\hline Upstream effects & 0.000 & 0.001 & $-0.014 * *$ & $-0.014 * *$ & -0.000 & 0.000 & $-0.009 * *$ & $-0.009 * *$ \\
\hline Own effects & $-0.007 *$ & 0.001 & $-0.007^{*}$ & 0.003 & $-0.006 * *$ & -0.004 & $-0.006 * *$ & -0.005 \\
\hline
\end{tabular}

Notes: Table documents the sum of coefficients across variations of lag structure. Columns 1 and 5 are baseline specifications from respective tables. 


\begin{tabular}{|c|c|c|c|c|c|}
\hline & & \multicolumn{2}{|c|}{$\Delta$ Log real value added } & \multicolumn{2}{|c|}{$\Delta$ Log employment } \\
\hline & & $(1)$ & $(2)$ & $(3)$ & $(4)$ \\
\hline \multicolumn{2}{|c|}{$\Delta$ Dependent variable $\mathrm{t}-1$} & $\begin{array}{l}-0.040 \\
(0.041)\end{array}$ & $\begin{array}{c}-0.048 \\
(0.041)\end{array}$ & $\begin{array}{c}0.126 * * * \\
(0.020)\end{array}$ & $\begin{array}{c}0.105 * * * \\
(0.020)\end{array}$ \\
\hline \multicolumn{2}{|c|}{$\Delta$ Dependent variable $\mathrm{t}-2$} & & $\begin{array}{l}0.041 * \\
(0.022)\end{array}$ & & $\begin{array}{c}0.108 * * * \\
(0.020)\end{array}$ \\
\hline \multicolumn{2}{|c|}{$\Delta$ Dependent variable $\mathrm{t}-3$} & & $\begin{array}{c}0.033 \\
(0.021)\end{array}$ & & $\begin{array}{c}0.090 * * * \\
(0.016)\end{array}$ \\
\hline \multirow[t]{3}{*}{ Trade: } & Downstream effects $\mathrm{t}-1$ & $\begin{array}{c}-0.042 \\
(0.083)\end{array}$ & $\begin{array}{c}-0.025 \\
(0.081)\end{array}$ & $\begin{array}{l}-0.006 \\
(0.043)\end{array}$ & $\begin{array}{c}0.017 \\
(0.040)\end{array}$ \\
\hline & Upstream effects t-1 & $\begin{array}{c}0.106 * * * \\
(0.030)\end{array}$ & $\begin{array}{c}0.107 * * * \\
(0.031)\end{array}$ & $\begin{array}{c}0.065 * * * \\
(0.020)\end{array}$ & $\begin{array}{c}0.054 * * * \\
(0.020)\end{array}$ \\
\hline & Own effects t-1 & $\begin{array}{c}0.030 * * * \\
(0.009)\end{array}$ & $\begin{array}{c}0.028 * * * \\
(0.009)\end{array}$ & $\begin{array}{c}0.022 * * * \\
(0.005)\end{array}$ & $\begin{array}{c}0.016^{* * *} \\
(0.004)\end{array}$ \\
\hline \multirow[t]{3}{*}{ Federal: } & Downstream effects $\mathrm{t}-1$ & $\begin{array}{c}-0.003 \\
(0.024)\end{array}$ & $\begin{array}{c}0.001 \\
(0.025)\end{array}$ & $\begin{array}{c}-0.006 \\
(0.017)\end{array}$ & $\begin{array}{c}0.003 \\
(0.014)\end{array}$ \\
\hline & Upstream effects t-1 & $\begin{array}{c}0.036 * * \\
(0.014)\end{array}$ & $\begin{array}{c}0.041 * * * \\
(0.014)\end{array}$ & $\begin{array}{c}0.021 * * \\
(0.009)\end{array}$ & $\begin{array}{c}0.023 * * * \\
(0.008)\end{array}$ \\
\hline & Own effects t-1 & $\begin{array}{c}0.001 \\
(0.003)\end{array}$ & $\begin{array}{c}0.004 \\
(0.004)\end{array}$ & $\begin{array}{c}0.001 \\
(0.003)\end{array}$ & $\begin{array}{l}0.005^{*} \\
(0.003)\end{array}$ \\
\hline \multirow[t]{3}{*}{ TFP: } & Downstream effects $\mathrm{t}-1$ & $\begin{array}{c}0.061 * * * \\
(0.020)\end{array}$ & $\begin{array}{c}0.049 * * \\
(0.020)\end{array}$ & $\begin{array}{l}0.019^{*} \\
(0.010)\end{array}$ & $\begin{array}{c}0.013 \\
(0.010)\end{array}$ \\
\hline & Upstream effects t-1 & $\begin{array}{c}0.029 * * \\
(0.013)\end{array}$ & $\begin{array}{c}0.027 * * \\
(0.013)\end{array}$ & $\begin{array}{l}0.013 * \\
(0.007)\end{array}$ & $\begin{array}{c}0.011 \\
(0.008)\end{array}$ \\
\hline & Own effects t-1 & $\begin{array}{c}0.007 \\
(0.007)\end{array}$ & $\begin{array}{c}0.009 \\
(0.007)\end{array}$ & $\begin{array}{c}0.007 * * * \\
(0.002)\end{array}$ & $\begin{array}{c}0.008 * * * \\
(0.002)\end{array}$ \\
\hline \multicolumn{2}{|c|}{ Observations } & 6560 & 5776 & 6560 & 5776 \\
\hline
\end{tabular}

Notes: See Table 7. 
Appendix Table 9a: Robustness checks on joint geographic analysis

\begin{tabular}{|c|c|c|c|c|c|c|c|c|}
\hline & & $\begin{array}{l}\text { Baseline } \\
\text { estimation }\end{array}$ & $\begin{array}{l}\text { Excluding } \\
\text { own lagged } \\
\text { shock }\end{array}$ & $\begin{array}{c}\text { Weighting by } \\
1991 \text { log value } \\
\text { added }\end{array}$ & $\begin{array}{c}\text { Weighting by } \\
1991 \\
\text { employees }\end{array}$ & $\begin{array}{l}\text { Adding SIC2 } \\
\text { fixed effects }\end{array}$ & $\begin{array}{l}\text { Adding SIC3 } \\
\text { fixed effects }\end{array}$ & $\begin{array}{l}\text { Adding SIC4 } \\
\text { fixed effects }\end{array}$ \\
\hline & & $(1)$ & $(2)$ & (3) & (4) & $(5)$ & (6) & $(7)$ \\
\hline & & \multicolumn{7}{|c|}{ A. $\Delta$ Log real value added } \\
\hline \multirow{2}{*}{\multicolumn{2}{|c|}{$\Delta$ Dependent variable $\mathrm{t}-1$}} & -0.028 & 0.009 & -0.027 & -0.065 & $-0.074 *$ & $-0.120 * * *$ & $-0.139 * * *$ \\
\hline & & $(0.040)$ & $(0.023)$ & $(0.040)$ & $(0.070)$ & $(0.039)$ & $(0.038)$ & $(0.038)$ \\
\hline \multirow[t]{4}{*}{ Trade: } & Geographic effects t-1 & $0.125 * * *$ & $0.121 * * *$ & $0.121 * * *$ & $0.068 * *$ & $0.090 * * *$ & $0.074 * *$ & 0.047 \\
\hline & & $(0.035)$ & $(0.034)$ & $(0.035)$ & $(0.029)$ & $(0.032)$ & $(0.030)$ & $(0.031)$ \\
\hline & Own effects t-1 & $0.032 * * *$ & & $0.031 * * *$ & $0.020^{*}$ & $0.020 * *$ & $0.020 * *$ & $0.023 *$ \\
\hline & & $(0.009)$ & & $(0.009)$ & $(0.011)$ & $(0.009)$ & $(0.010)$ & $(0.013)$ \\
\hline \multirow[t]{4}{*}{ Federal: } & Geographic effects t-1 & $0.112 * * *$ & $0.112 * * *$ & $0.110 * * *$ & $0.063 * *$ & $0.086^{* * *}$ & $0.075 * * *$ & 0.012 \\
\hline & & $(0.032)$ & $(0.030)$ & $(0.032)$ & $(0.026)$ & $(0.029)$ & $(0.028)$ & $(0.030)$ \\
\hline & Own effects t-1 & 0.001 & & 0.000 & -0.001 & -0.001 & 0.004 & 0.014 \\
\hline & & $(0.004)$ & & $(0.004)$ & $(0.003)$ & $(0.004)$ & $(0.005)$ & $(0.009)$ \\
\hline \multirow[t]{4}{*}{ TFP: } & Geographic effects t-1 & $0.032 * * *$ & $0.032 * * *$ & $0.030 * * *$ & $0.011^{*}$ & $0.025 * * *$ & $0.022 * *$ & $0.018 * *$ \\
\hline & & $(0.010)$ & $(0.010)$ & $(0.010)$ & $(0.006)$ & $(0.010)$ & $(0.009)$ & $(0.009)$ \\
\hline & Own effects t-1 & 0.008 & & 0.008 & $0.031 * *$ & $0.011^{*}$ & $0.015^{* *}$ & $0.013 * *$ \\
\hline & & $(0.006)$ & & $(0.007)$ & $(0.014)$ & $(0.006)$ & $(0.006)$ & $(0.005)$ \\
\hline \multirow[t]{4}{*}{ Patent: } & Geographic effects t-1 & $0.005 * * *$ & $0.005 * * *$ & $0.005 * * *$ & $0.002 * * *$ & $0.005 * * *$ & $0.005 * * *$ & $0.004 * * *$ \\
\hline & & $(0.001)$ & $(0.001)$ & $(0.001)$ & $(0.001)$ & $(0.001)$ & $(0.001)$ & $(0.001)$ \\
\hline & Own effects t-1 & -0.002 & & -0.001 & 0.007 & 0.000 & -0.000 & -0.001 \\
\hline & & $(0.004)$ & & $(0.004)$ & $(0.006)$ & $(0.004)$ & $(0.004)$ & $(0.004)$ \\
\hline \multicolumn{2}{|c|}{ Observations } & 6543 & 6560 & 6543 & 6543 & 6543 & 6543 & 6543 \\
\hline
\end{tabular}

Notes: See Table 8. 
Appendix Table 9a, continued

\begin{tabular}{|c|c|c|c|c|c|c|c|c|}
\hline & & $\begin{array}{l}\text { Baseline } \\
\text { estimation }\end{array}$ & $\begin{array}{l}\text { Excluding } \\
\text { own lagged } \\
\text { shock }\end{array}$ & $\begin{array}{l}\text { Weighting by } \\
1991 \text { log value } \\
\text { added }\end{array}$ & $\begin{array}{c}\text { Weighting by } \\
1991 \\
\text { employees }\end{array}$ & $\begin{array}{l}\text { Adding SIC2 } \\
\text { fixed effects }\end{array}$ & $\begin{array}{l}\text { Adding SIC3 } \\
\text { fixed effects }\end{array}$ & $\begin{array}{l}\text { Adding SIC4 } \\
\text { fixed effects }\end{array}$ \\
\hline & & $(1)$ & $(2)$ & $(3)$ & $(4)$ & $(5)$ & $(6)$ & $(7)$ \\
\hline & & \multicolumn{7}{|c|}{ B. $\Delta$ Log employment } \\
\hline \multirow{2}{*}{\multicolumn{2}{|c|}{$\Delta$ Dependent variable $\mathrm{t}-1$}} & $0.130 * * *$ & $0.156^{* * *}$ & $0.135 * * *$ & $0.240 * * *$ & $0.081 * * *$ & 0.020 & -0.019 \\
\hline & & $(0.021)$ & $(0.020)$ & $(0.020)$ & $(0.034)$ & $(0.021)$ & (0.019) & (0.019) \\
\hline \multirow[t]{4}{*}{ Trade: } & Geographic effects t-1 & $0.055 * * *$ & $0.057 * * *$ & $0.053 * * *$ & $0.030 * *$ & $0.027^{*}$ & $0.030^{*}$ & $0.036 * *$ \\
\hline & & $(0.018)$ & $(0.017)$ & $(0.017)$ & $(0.012)$ & $(0.015)$ & $(0.015)$ & $(0.018)$ \\
\hline & Own effects t-1 & $0.023 * * *$ & & $0.023 * * *$ & $0.022 * * *$ & $0.011 * * *$ & $0.007 *$ & 0.004 \\
\hline & & $(0.005)$ & & $(0.005)$ & $(0.007)$ & $(0.004)$ & $(0.004)$ & $(0.004)$ \\
\hline \multirow[t]{4}{*}{ Federal: } & Geographic effects t-1 & $0.046^{* * *}$ & $0.050 * * *$ & $0.043 * * *$ & $0.027 * * *$ & $0.022 *$ & 0.021 & 0.010 \\
\hline & & $(0.015)$ & $(0.014)$ & $(0.014)$ & $(0.010)$ & $(0.013)$ & $(0.013)$ & $(0.017)$ \\
\hline & Own effects t-1 & 0.002 & & 0.002 & 0.000 & 0.001 & $0.009 * *$ & $0.021 * * *$ \\
\hline & & $(0.003)$ & & $(0.002)$ & $(0.001)$ & $(0.003)$ & $(0.004)$ & $(0.007)$ \\
\hline \multirow[t]{4}{*}{ TFP: } & Geographic effects t-1 & $0.014 * * *$ & $0.014 * * *$ & $0.013 * * *$ & $0.006^{* *}$ & $0.008 *$ & $0.009 *$ & $0.011 * *$ \\
\hline & & $(0.005)$ & $(0.005)$ & $(0.005)$ & $(0.003)$ & $(0.005)$ & $(0.005)$ & $(0.005)$ \\
\hline & Own effects t-1 & $0.008 * * *$ & & $0.008 * * *$ & $0.006 * * *$ & $0.008 * * *$ & $0.009 * * *$ & $0.010 * * *$ \\
\hline & & $(0.002)$ & & $(0.002)$ & $(0.002)$ & $(0.002)$ & $(0.002)$ & $(0.002)$ \\
\hline \multirow[t]{4}{*}{ Patent: } & Geographic effects t-1 & 0.001 & 0.001 & 0.001 & 0.001 & 0.001 & 0.001 & 0.000 \\
\hline & & $(0.001)$ & $(0.001)$ & $(0.001)$ & $(0.000)$ & $(0.001)$ & $(0.001)$ & $(0.001)$ \\
\hline & Own effects t-1 & $-0.005 * *$ & & $-0.005 * *$ & -0.002 & -0.003 & -0.002 & -0.002 \\
\hline & & $(0.003)$ & & $(0.002)$ & $(0.003)$ & $(0.002)$ & $(0.002)$ & $(0.002)$ \\
\hline \multicolumn{2}{|c|}{ Observations } & 6543 & 6560 & 6543 & 6543 & 6543 & 6543 & 6543 \\
\hline
\end{tabular}

Notes: See Table 8. 
Appendix Table 9b: Geographic effects and networks analysis with single shocks

$\Delta$ Log real value added

\begin{tabular}{|c|c|c|c|c|c|c|c|c|c|}
\hline & $(1)$ & $(2)$ & (3) & (4) & $(5)$ & $(6)$ & $(7)$ & $(8)$ \\
\hline \multicolumn{2}{|c|}{$\Delta$ Dependent variable $\mathrm{t}-1$} & 0.022 & 0.019 & 0.018 & 0.017 & -0.013 & -0.024 & 0.021 & 0.020 \\
\hline \multirow[t]{4}{*}{ Trade: } & Geographic effects t-1 & $\begin{array}{c}0.001 \\
(0.007)\end{array}$ & $\begin{array}{c}0.002 \\
(0.007)\end{array}$ & & & & & & \\
\hline & Downstream effects $\mathrm{t}-1$ & & $\begin{array}{l}-0.142 * \\
(0.086)\end{array}$ & & & & & & \\
\hline & Upstream effects $\mathrm{t}-1$ & & $\begin{array}{c}0.076^{* * *} \\
(0.024)\end{array}$ & & & & & & \\
\hline & Own effects $\mathrm{t}-1$ & $\begin{array}{c}0.032 * * * \\
(0.009)\end{array}$ & $\begin{array}{c}0.034 * * * \\
(0.009)\end{array}$ & & & & & & \\
\hline \multirow[t]{4}{*}{ Federal: } & Geographic effects t-1 & & & $\begin{array}{c}0.021^{* *} \\
(0.009)\end{array}$ & $\begin{array}{l}0.018^{* *} \\
(0.009)\end{array}$ & & & & \\
\hline & Downstream effects $t-1$ & & & & $\begin{array}{c}0.005 \\
(0.021)\end{array}$ & & & & \\
\hline & Upstream effects $t-1$ & & & & $\begin{array}{c}0.018^{* *} \\
(0.008)\end{array}$ & & & & \\
\hline & Own effects $t-1$ & & & $\begin{array}{c}0.004 \\
(0.003)\end{array}$ & $\begin{array}{c}0.003 \\
(0.003)\end{array}$ & & & & \\
\hline \multirow[t]{4}{*}{ TFP: } & Geographic effects t-1 & & & & & $\begin{array}{c}0.005 \\
(0.005)\end{array}$ & $\begin{array}{c}0.003 \\
(0.005)\end{array}$ & & \\
\hline & Downstream effects $t-1$ & & & & & & $\begin{array}{c}0.060^{* * * *} \\
(0.020)\end{array}$ & & \\
\hline & Upstream effects $t-1$ & & & & & & $\begin{array}{c}0.023 * * \\
(0.011)\end{array}$ & & \\
\hline & Own effects $t-1$ & & & & & $\begin{array}{c}0.007 \\
(0.007)\end{array}$ & $\begin{array}{c}0.004 \\
(0.007)\end{array}$ & & \\
\hline \multirow[t]{4}{*}{ Patent: } & Geographic effects t-1 & & & & & & & $\begin{array}{c}0.004 * * * \\
(0.001)\end{array}$ & $\begin{array}{c}0.003^{* * *} \\
(0.001)\end{array}$ \\
\hline & Downstream effects $t-1$ & & & & & & & & $\begin{array}{c}0.041 * * * \\
(0.011)\end{array}$ \\
\hline & Upstream effects t-1 & & & & & & & & $\begin{array}{c}-0.001 \\
(0.004)\end{array}$ \\
\hline & Own effects $t-1$ & & & & & & & $\begin{array}{l}-0.002 \\
(0.004)\end{array}$ & $\begin{array}{c}-0.006 \\
(0.004)\end{array}$ \\
\hline \multicolumn{2}{|c|}{ Observations } & 6560 & 6560 & 6560 & 6560 & 6560 & 6560 & 6543 & 6543 \\
\hline
\end{tabular}

Notes: See Table 8. 
Appendix Table 9b, continued

$\Delta$ Log employment

\begin{tabular}{|c|c|c|c|c|c|c|c|c|c|}
\hline & & \multicolumn{8}{|c|}{$\Delta$ Log employment } \\
\hline & & $(1)$ & $(2)$ & (3) & (4) & (5) & (6) & (7) & $(8)$ \\
\hline \multicolumn{2}{|c|}{$\Delta$ Dependent variable $\mathrm{t}-1$} & $0.152 * * *$ & $0.149 * * *$ & $0.159 * * *$ & $0.158 * * *$ & $0.142 * * *$ & $0.141^{* * *}$ & $0.159 * * *$ & $0.159 * * *$ \\
\hline \multirow[t]{4}{*}{ Trade: } & Geographic effects t- 1 & $\begin{array}{c}0.004 \\
(0.004)\end{array}$ & $\begin{array}{c}0.004 \\
(0.004)\end{array}$ & & & & & & \\
\hline & Downstream effects $t-1$ & & $\begin{array}{c}-0.059 \\
(0.041)\end{array}$ & & & & & & \\
\hline & Upstream effects $t-1$ & & $\begin{array}{c}0.049 * * * \\
(0.016)\end{array}$ & & & & & & \\
\hline & Own effects $t-1$ & $\begin{array}{c}0.022 * * * \\
(0.005)\end{array}$ & $\begin{array}{c}0.023 * * * \\
(0.005)\end{array}$ & & & & & & \\
\hline \multirow[t]{4}{*}{ Federal: } & Geographic effects t- 1 & & & $\begin{array}{c}0.005 \\
(0.003)\end{array}$ & $\begin{array}{c}0.004 \\
(0.003)\end{array}$ & & & & \\
\hline & Downstream effects $t-1$ & & & & $\begin{array}{c}0.005 \\
(0.014)\end{array}$ & & & & \\
\hline & Upstream effects t-1 & & & & $\begin{array}{c}0.009 \\
(0.006)\end{array}$ & & & & \\
\hline & Own effects $\mathrm{t}-1$ & & & $\begin{array}{c}0.003 \\
(0.002)\end{array}$ & $\begin{array}{c}0.003 \\
(0.003)\end{array}$ & & & & \\
\hline \multirow[t]{4}{*}{ TFP: } & Geographic effects t- 1 & & & & & $\begin{array}{c}0.003 \\
(0.003)\end{array}$ & $\begin{array}{c}0.002 \\
(0.003)\end{array}$ & & \\
\hline & Downstream effects $t-1$ & & & & & & $\begin{array}{l}0.016^{*} \\
(0.009)\end{array}$ & & \\
\hline & Upstream effects t- 1 & & & & & & $\begin{array}{c}0.009 \\
(0.006)\end{array}$ & & \\
\hline & Own effects $t-1$ & & & & & $\begin{array}{c}0.007 * * * \\
(0.002)\end{array}$ & $\begin{array}{c}0.006^{* * *} \\
(0.002)\end{array}$ & & \\
\hline \multirow[t]{4}{*}{ Patent: } & Geographic effects t- 1 & & & & & & & $\begin{array}{c}0.000 \\
(0.001)\end{array}$ & $\begin{array}{c}0.000 \\
(0.001)\end{array}$ \\
\hline & Downstream effects $t-1$ & & & & & & & & $\begin{array}{c}0.018 * * * \\
(0.006)\end{array}$ \\
\hline & Upstream effects t-1 & & & & & & & & $\begin{array}{c}-0.001 \\
(0.003)\end{array}$ \\
\hline & Own effects $t-1$ & & & & & & & $\begin{array}{c}-0.006^{* *} \\
(0.003)\end{array}$ & $\begin{array}{c}-0.008^{* * * *} \\
(0.003)\end{array}$ \\
\hline \multicolumn{2}{|c|}{ Observations } & 6560 & 6560 & 6560 & 6560 & 6560 & 6560 & 6543 & 6543 \\
\hline
\end{tabular}

Notes: See Table 8. 


\begin{tabular}{|c|c|c|c|c|c|}
\hline & & \multicolumn{2}{|c|}{$\Delta$ Log real value added } & \multicolumn{2}{|c|}{$\Delta$ Log employment } \\
\hline & & (1) & $(2)$ & (3) & (4) \\
\hline \multicolumn{2}{|c|}{$\Delta$ Dependent variable $\mathrm{t}-1$} & $\begin{array}{c}-0.052 \\
(0.041)\end{array}$ & $\begin{array}{l}-0.055 \\
(0.042)\end{array}$ & $\begin{array}{c}0.103 * * * \\
(0.020)\end{array}$ & $\begin{array}{c}0.103 * * * \\
(0.019)\end{array}$ \\
\hline \multicolumn{2}{|c|}{$\Delta$ Dependent variable $\mathrm{t}-2$} & $\begin{array}{c}0.032 \\
(0.021)\end{array}$ & $\begin{array}{c}0.033 \\
(0.021)\end{array}$ & $\begin{array}{c}0.106 * * * \\
(0.019)\end{array}$ & $\begin{array}{c}0.106 * * * \\
(0.019)\end{array}$ \\
\hline \multicolumn{2}{|c|}{$\Delta$ Dependent variable $\mathrm{t}-3$} & $\begin{array}{c}0.022 \\
(0.019)\end{array}$ & $\begin{array}{c}0.023 \\
(0.019)\end{array}$ & $\begin{array}{c}0.089 * * * \\
(0.016)\end{array}$ & $\begin{array}{c}0.088 * * * \\
(0.016)\end{array}$ \\
\hline \multirow[t]{4}{*}{ Trade: } & Geographic effects t-1 & $\begin{array}{c}0.193 * * * \\
(0.044)\end{array}$ & $\begin{array}{c}0.147 * * * \\
(0.039)\end{array}$ & $\begin{array}{c}0.074 * * * \\
(0.021)\end{array}$ & $\begin{array}{c}0.066^{* * *} \\
(0.019)\end{array}$ \\
\hline & Downstream effects $\mathrm{t}-1$ & $\begin{array}{c}-0.006 \\
(0.076)\end{array}$ & $\begin{array}{c}-0.027 \\
(0.076)\end{array}$ & $\begin{array}{c}0.021 \\
(0.041)\end{array}$ & $\begin{array}{c}0.012 \\
(0.041)\end{array}$ \\
\hline & Upstream effects t-1 & $\begin{array}{c}0.090 * * * \\
(0.030)\end{array}$ & $\begin{array}{c}0.095 * * * \\
(0.030)\end{array}$ & $\begin{array}{c}0.048^{* *} \\
(0.019)\end{array}$ & $\begin{array}{c}0.049 * * * \\
(0.019)\end{array}$ \\
\hline & Own effects $t-1$ & $\begin{array}{c}0.029 * * * \\
(0.009)\end{array}$ & $\begin{array}{c}0.031 * * * \\
(0.009)\end{array}$ & $\begin{array}{c}0.017 * * * \\
(0.004)\end{array}$ & $\begin{array}{c}0.017 * * * \\
(0.004)\end{array}$ \\
\hline \multirow[t]{4}{*}{ Federal: } & Geographic effects t-1 & $\begin{array}{c}0.178 * * * \\
(0.040)\end{array}$ & $\begin{array}{c}0.134 * * * \\
(0.036)\end{array}$ & $\begin{array}{c}0.063 * * * \\
(0.019)\end{array}$ & $\begin{array}{c}0.055 * * * \\
(0.017)\end{array}$ \\
\hline & Downstream effects $\mathrm{t}-1$ & $\begin{array}{l}-0.048 * \\
(0.025)\end{array}$ & $\begin{array}{l}-0.041 * \\
(0.025)\end{array}$ & $\begin{array}{l}-0.012 \\
(0.015)\end{array}$ & $\begin{array}{l}-0.012 \\
(0.015)\end{array}$ \\
\hline & Upstream effects t-1 & $\begin{array}{c}0.028 * * \\
(0.013)\end{array}$ & $\begin{array}{c}0.030 * * \\
(0.013)\end{array}$ & $\begin{array}{c}0.020 * * \\
(0.008)\end{array}$ & $\begin{array}{c}0.020 * * \\
(0.008)\end{array}$ \\
\hline & Own effects t-1 & $\begin{array}{c}0.002 \\
(0.005)\end{array}$ & $\begin{array}{c}0.002 \\
(0.004)\end{array}$ & $\begin{array}{c}0.004 \\
(0.003)\end{array}$ & $\begin{array}{c}0.004 \\
(0.003)\end{array}$ \\
\hline \multirow[t]{4}{*}{ TFP: } & Geographic effects t-1 & $\begin{array}{c}0.047 * * * \\
(0.013)\end{array}$ & $\begin{array}{c}0.044 * * * \\
(0.013)\end{array}$ & $\begin{array}{c}0.020 * * * \\
(0.006)\end{array}$ & $\begin{array}{c}0.020 * * * \\
(0.006)\end{array}$ \\
\hline & Downstream effects $\mathrm{t}-1$ & $\begin{array}{l}0.040 * * \\
(0.019)\end{array}$ & $\begin{array}{c}0.043 * * \\
(0.019)\end{array}$ & $\begin{array}{c}0.009 \\
(0.010)\end{array}$ & $\begin{array}{c}0.010 \\
(0.010)\end{array}$ \\
\hline & Upstream effects t-1 & $\begin{array}{c}0.015 \\
(0.013)\end{array}$ & $\begin{array}{c}0.019 \\
(0.013)\end{array}$ & $\begin{array}{c}0.006 \\
(0.008)\end{array}$ & $\begin{array}{c}0.007 \\
(0.008)\end{array}$ \\
\hline & Own effects t-1 & $\begin{array}{c}0.008 \\
(0.006)\end{array}$ & $\begin{array}{c}0.009 \\
(0.006)\end{array}$ & $\begin{array}{c}0.007 * * * \\
(0.002)\end{array}$ & $\begin{array}{c}0.007 * * * \\
(0.002)\end{array}$ \\
\hline \multirow[t]{4}{*}{ Patent: } & Geographic effects t- 1 & & $\begin{array}{c}0.005 * * * \\
(0.001)\end{array}$ & & $\begin{array}{c}0.001 \\
(0.001)\end{array}$ \\
\hline & Downstream effects $\mathrm{t}-1$ & & $\begin{array}{c}0.040 * * * \\
(0.011)\end{array}$ & & $\begin{array}{c}0.016 * * \\
(0.007)\end{array}$ \\
\hline & Upstream effects t-1 & & $\begin{array}{c}0.002 \\
(0.005)\end{array}$ & & $\begin{array}{c}0.000 \\
(0.003)\end{array}$ \\
\hline & Own effects $t-1$ & & $\begin{array}{c}-0.006 \\
(0.004)\end{array}$ & & $\begin{array}{c}-0.006 * * \\
(0.003)\end{array}$ \\
\hline \multicolumn{2}{|c|}{ Observations } & 5776 & 5761 & 5776 & 5761 \\
\hline
\end{tabular}

Notes: See Table 2a. 


\section{Appendix C: Omitted Proofs and Results and Monte Carlo Ex- ercises}

\section{Details for Example 1}

The expressions and Example 1 follow readily from equation (6) in the text or equation (A7) in Appendix A. We provide the detailed algebra here for completeness and verification. Suppose, for this purpose and without loss of any generality, that $u\left(c_{1}, c_{2}, c_{3}, l\right)=\gamma(l) \prod_{i=1}^{3} c_{i}^{1 / 3}$ (since in this case preference heterogeneity does not matter). Recall that the production function for sector $i \in\{1,2,3\}$ is:

$$
y_{i}=e^{z_{i}} l_{i}^{\alpha_{i}^{l}} x_{i j}^{a_{i j}}
$$

In what follows, we denote the supplier of the focal sector $i$ by $j$ and the customer of $i$ by $k$ (for instance, $\{i, j, k\}=\{1,2,3\},\{i, j, k\}=\{2,3,1\}$, and $\{i, j, k\}=\{3,1,2\}$ ). With this convention, the resource market clearing condition can be written as

$$
y_{i}=c_{i}+x_{k i} .
$$

Combining the first-order conditions of the representative household and firms to eliminate prices, we can write

$$
a_{i j}=\frac{c_{i} x_{i j}}{c_{j} y_{i}} \text { and } \alpha_{i}^{l}=\frac{3 c_{i} l_{i}}{y_{i}}
$$

Substituting this expression into (C1) we obtain

$$
c_{i}=e^{z_{i}} \Omega_{i j} c_{j}^{a_{i j}}
$$

where $\Omega_{i j} \equiv\left(\alpha_{i}^{l}\right)^{\alpha_{i}^{l}} a_{i j}^{a_{i j}} 3^{-\alpha_{i}^{l}}$ for $i=1,2,3$. Solving these three equations summarized in (C3) jointly, we have

$$
c_{i}=\tilde{\Omega}_{i} e^{\delta_{i}}
$$

where

$$
\delta_{i} \equiv \frac{z_{i}+z_{j} a_{i j}+z_{c} a_{i j} a_{j k}}{1-a_{i j} a_{j k} a_{k i}}
$$

and $\tilde{\Omega}_{i}$ is a constant. Using the production functions $(\mathrm{C} 1)$ and optimal labor choices $(\mathrm{C} 2)$ and the equilibrium consumption choices (C4), we can express express $y_{i}$ in terms of its intermediate input use, $x_{i j}$, only. Then combining these with the resource constraints we obtain

$$
y_{i}=\tilde{\Omega}_{i} e^{\delta_{i}}+y_{k} e_{k}^{\frac{\alpha_{k}^{l} \delta_{k}-z_{k}}{1-\alpha_{k}^{l}}} \Gamma_{i}
$$

where the $\Gamma_{i}$ 's denote constants. Solving this system of equations gives:

$$
y_{i}=e^{\delta_{i}} \frac{\left[\tilde{\Omega}_{i}+\tilde{\Omega}_{k} \Gamma_{k}+\tilde{\Omega}_{j} \Gamma_{j} \Gamma_{k}\right]}{1-\Gamma_{i} \Gamma_{j} \Gamma_{k}} .
$$

Finally, taking the logs and differentiating this expression delivers the desired result:

$$
d \ln y_{i}=\frac{d z_{i}+a_{i j} d z_{j}+a_{i j} a_{j k} d z_{c}}{1-a_{i j} a_{j k} a_{k i}} \text { for each } i=1,2,3 \text {. }
$$




\section{Details for Example 2}

Once again the expressions in Example 2 follow from our general results, in particular equation (A10) in Appendix A (recalling that in this case $\left.u\left(c_{1}, c_{2}, c_{3}, l\right)=\gamma(l) \prod_{i=1}^{3} c_{i}^{1 / 3}\right)$. Once again we provide the algebraic detail for completeness. Note that the unit cost functions for the three sectors can be written as

$$
C_{i}(\mathbf{p}, w)=\mu_{i} w^{\alpha_{i}^{l}} p_{j}^{a_{i j}}
$$

where $\mu_{i} \equiv\left(\frac{\alpha_{i}^{l}}{a_{i j}}\right)^{a_{i j}}+\left(\frac{a_{i j}}{\alpha_{i}^{l}}\right)^{\alpha_{i}^{l}}$. In equilibrium, we have

$$
p_{i}=C_{i}(\mathbf{p}, w)=\mu_{i} w^{\alpha_{i}^{l}} p_{j}^{a_{i j}} .
$$

Using the fact that the wage is the numeraire, we can solve for the price system in (C5) as

$$
p_{i}=\gamma^{\frac{1}{1-a_{i j} a_{j k} a_{k i}}}
$$

where $\gamma \equiv \mu_{i} \mu_{j}^{a_{i j}} \mu_{k}^{a_{i j} a_{j k}}$, confirming our general results that prices are constant regardless of demand shocks. Given this constancy, we switch to working with nominal values, which we denote by a tilde, " $~ "$. Then the resource constraint implies

$$
d \tilde{y}_{i}=d \tilde{c}_{i}+d \tilde{x}_{k i}+d \tilde{G}_{i} .
$$

Using the first-order condition of firms, $a_{i j}=\frac{\tilde{x}_{i j}}{\tilde{y}_{i}}$, we have

$$
d \tilde{x}_{i j}=a_{i j} d \tilde{y}_{i}
$$

Combining this with the resource constraint, we obtain

$$
d \tilde{y}_{i}=d \tilde{c}_{i}+a_{k i} d \tilde{y}_{k}+d \tilde{G}_{i}
$$

Recall that the household optimization implies

$$
\tilde{c}_{i}=\frac{1}{(1+\lambda) 3}-\frac{\tilde{G}_{i}+\tilde{G}_{j}+\tilde{G}_{k}}{(1+\lambda) 3} .
$$

Differentiating this expression yields

$$
d \tilde{c}_{i}=-\frac{d \tilde{G}_{j}+d \tilde{G}_{i}+\tilde{G}_{k}}{(1+\lambda) 3}
$$

Combining (C7) in (C6), we arrive at the system of equation (for $i=1,2,3$ ):

$$
d \tilde{y}_{i}=-\frac{d \tilde{G}_{i}+d \tilde{G}_{j}+\tilde{G}_{k}}{(1+\lambda) 3}+a_{k i} d \tilde{y}_{k}+d \tilde{G}_{i}
$$

Solving this system of equations delivers the desired result:

$$
d \tilde{y}_{i}=\frac{1}{1-a_{i j} a_{j k} a_{k i}}\left\{\begin{array}{c}
d \tilde{G}_{i}+a_{k i} a_{j k} d \tilde{G}_{j}+a_{k i} d \tilde{G}_{k} \\
-\frac{\left(1+a_{k i}+a_{k i} a_{j k}\right)}{(1+\lambda) 3}\left[d \tilde{G}_{i}+d \tilde{G}_{j}+d \tilde{G}_{k}\right]
\end{array}\right\} .
$$




\section{The Long and Plosser (1983) Model}

Long and Plosser's (1983) model is closely related to the one we studied in the main text, with the main difference that there is a one period delay in production, so that inputs dated $t-1$ produce output dated $t$, which implies that shocks spread across industries only slowly. More specifically, the production function for sector $i$ at time $t$ is

$$
y_{i, t}=e^{z_{i, t}} l_{i, t-1}^{\alpha_{i}^{l}} \prod_{j=1}^{n} x_{i j, t-1}^{a_{i j}} .
$$

The Long-Plosser model also includes capital, from which we abstract to simplify the discussion here. We also assume that the government budget has to be balanced at each date.

The preferences of the representative household are now defined over sequences of consumption bundles as

$$
\sum_{t=0}^{\infty} \delta^{t}\left[\ln \gamma\left(l_{t}\right)+\beta_{i} \sum_{i=1}^{n} \ln c_{i, t}\right],
$$

where $\delta \in(0,1)$ is the discount factor. ${ }^{1}$ The representative household can save using a risk-free asset, with gross interest rate $R_{t}$ at time $t$ (meaning that one dollar invested at time $t-1$ in this risk-free asset pays $R_{t}$ dollars for sure at time $t$ ), and because there is no capital, this asset must be in zero net supply.

Since there is no capital, the resource constraint takes the same form as in the static economy:

$$
y_{i, t}=c_{i, t}+\sum_{j=1}^{n} x_{j i, t}+G_{i, t-1},
$$

where we have adopted the timing convention that government spending decisions from time $t-1$ are implemented at time $t$.

An equilibrium is now defined as sequence of prices such that markets at each date clear. The equilibrium in this dynamic model continues to be very tractable and can be represented by a log-linear equation for the evolution of sectoral outputs as shown in the next proposition.

Proposition C1 In the dynamic Long-Plosser model:

1. The equilibrium evolution of sectoral outputs in the presence of technology shocks (and no government spending shocks) is given by

$$
\mathbf{d} \ln \mathbf{y}_{t+1}=\mathbf{A} \times \mathbf{d} \ln \mathbf{y}_{t}+\mathbf{d} \mathbf{z}_{t+1} .
$$

2. Suppose that Suppose $\gamma(l)=(1-l)^{\lambda}$. Then the equilibrium evolution of sectoral output in the presence of government spending shocks (and no technology shocks) is given by

$$
\mathbf{d} \tilde{\mathbf{y}}_{t+1}=\left(\mathbf{I}-\delta \mathbf{A}^{T}\right)^{-1}\left(-\frac{\sum_{j=1}^{n} d \tilde{G}_{j, t}}{1+\lambda} \boldsymbol{\beta}+\mathbf{d} \tilde{\mathbf{G}}_{t}\right),
$$

where $\tilde{\mathbf{G}}_{t}$ is the vector of nominal government spending across sectors at time $t$, and $\tilde{\mathbf{y}}_{t}$ denotes the vector of nominal sectoral output at time $t$.

\footnotetext{
${ }^{1}$ Differently from the static model, the utility function is no longer invariant to monotone transformations, thus Cobb-Douglas and log preferences are no longer equivalent, and we adopt the standard log preferences used by Long and Plosser (1983).
} 
Proof. Part 1. Since there is no capital, the profit maximization of sector $i$ at time $t$ can be written as

$$
\max _{l_{i, t}, x_{i j, t}}\left\{\frac{p_{i, t+1}}{R_{t}} e^{z_{i, t+1}} l_{i, t}^{\alpha_{i}^{l}} \prod_{j=1}^{n} x_{i j, t}^{\alpha_{i j}}-w_{t} l_{i, t}-\sum_{j=1}^{n} p_{j, t} x_{i j, t}\right\}
$$

where output prices are discounted by the gross interest rate between dates $t$ and $t+1, R_{t}$, because they accrue with one period delay. Consider the dual of this problem, which gives the unit cost function for sector $i$ as

$$
C_{i, t+1}\left(\mathbf{p}_{t}, w_{t}\right)=e^{-z_{i, t+1}} B_{i} w_{t}^{\alpha_{i}^{l}} \prod_{j=1}^{n} p_{j, t}^{a_{i j}}
$$

where $B_{i} \equiv\left[1 / \alpha_{i}^{l}\right]^{\alpha_{i}^{l}} \prod_{j=1}^{n}\left[\frac{1}{a_{i j}}\right]^{a_{i j}}$. In the competitive equilibrium, we have

$$
\frac{p_{i, t+1}}{R_{t}}=e^{-z_{i, t+1}} B_{i} w_{t}^{\alpha_{i}^{l}} \prod_{j=1}^{n} p_{j, t}^{a_{i j}}
$$

to ensure zero profits (recall that $R_{t}$ is known at time $t$ ). Given the interest rates representing intertemporal prices, we can set wages in each period as the numeraire, i.e., $w_{t}=1$ for all $t$, and taking logs, we arrive at

$$
\ln p_{i, t+1}-\ln R_{t}=-z_{i, t+1}+\ln B_{i}+\sum_{j=1}^{n} a_{i j} \ln p_{j, t} .
$$

The representative household's problem can be represented as

$$
\mathbb{E}_{0} \sum_{t=0}^{\infty} \delta^{t}\left\{\ln \gamma\left(l_{t}\right)+\sum_{j=1}^{n} \beta_{i} \ln c_{i, t}+\mu_{t}\left[R_{t} A_{t}+w_{t} l_{t}-A_{t+1}-\sum_{j=1}^{n} p_{i, t} c_{i, t}\right]\right\}
$$

where the term in square brackets is the flow dynamic budget constraint of the household, with $A_{t}$ denoting asset holdings, and $\mu_{t}$ is the Lagrange multiplier or the marginal value of income at time $t$. This problem has the familiar first-order conditions given by

$$
\begin{aligned}
c_{i, t} & : \quad \frac{\beta_{i}}{p_{i, t} c_{i, t}}=\mu_{t} \Longrightarrow \ln \beta_{i}-\ln c_{i, t}-\ln \mu_{t}=\ln p_{i, t} \\
A_{t+1} & : \quad-\delta^{t} \mu_{t}+\delta^{t+1} R_{t} \mathbb{E}_{t} \mu_{t+1}=0 \\
l_{t} & : \frac{\gamma^{\prime}\left(l_{t}\right)}{\gamma\left(l_{t}\right)}+\mu_{t} w_{t}=0
\end{aligned}
$$

Combining (C13) and (C14), we obtain

$$
\ln \beta_{i}-\ln c_{i, t+1}-\ln \mathbb{E}_{t} \mu_{t+1}-\ln R_{t}=-z_{i, t+1}+\ln B_{i}+\sum_{j=1}^{n} a_{i j}\left[\ln \beta_{j}-\ln c_{j, t}-\ln \mu_{t}\right]
$$

or

$$
d \ln c_{i, t+1}+d \ln \mathbb{E}_{t} \mu_{t+1}+d \ln R_{t}=d z_{i, t+1}+\sum_{j=1}^{n} a_{i j}\left[d \ln c_{j, t}+d \ln \mu_{t}\right]
$$


Because the risk-free asset is in zero net supply, we must have $A_{t}=0$ for all $t$, so that from the representative household's budget constraint

$$
l_{t} w_{t}=\frac{p_{i, t} c_{i, t}}{\beta_{i}}=\frac{p_{j, t} c_{j, t}}{\beta_{j}}
$$

for all $i, j$ and $t$. Combining this equation with (C14), we obtain

$$
\mu_{t}=\frac{1}{l_{t}},
$$

which together with (C16) implies

$$
1=-\frac{l_{t} \gamma^{\prime}\left(l_{t}\right)}{\gamma\left(l_{t}\right)}
$$

and thus

$$
l_{t}=l^{*} \text { for all } t .
$$

Finally combining this result with $(\mathrm{C} 15)$ and $(\mathrm{C} 19)$, we obtain that, regardless of the realization of the stochastic shocks,

$$
\mu_{t}=\mu^{*} \text { and } R_{t}=\frac{1}{\delta} .
$$

This equation, combined with (C17) gives the law of motion of consumption of the output of different sectors as

$$
d \ln c_{i, t+1}=\sum_{j=1}^{n} a_{i j} d \ln c_{j, t}+d z_{i, t+1}
$$

or as

$$
\mathbf{d} \ln \mathbf{c}_{t+1}=\mathbf{A} \times \mathbf{d} \ln \mathbf{c}_{t}+\mathbf{d} \mathbf{z}_{t+1} .
$$

Consider next the first-order conditions of the profit-maximization problem, (C12):

$$
a_{i j} \frac{p_{i, t+1}}{R_{t}} y_{i, t+1}=p_{j, t} x_{i j, t} .
$$

Using this expression for substituting for $x_{j i, t}$ in the resource constraint, (C9), using the fact that in this part, $G_{i, t-1}=0$, and rearranging, we obtain:

$$
1=\frac{c_{i, t}}{y_{i, t}}+\delta \sum_{j=1}^{n} a_{j i} \frac{p_{j, t+1} y_{j, t+1}}{p_{i, t} y_{i, t}},
$$

and finally, since from $(\mathrm{C} 18) \frac{p_{i, t} c_{i, t}}{\beta_{i}}=l^{*}$, this equation can be written as

$$
\beta_{i} \frac{y_{i, t}}{c_{i, t}}=\beta_{i}+\delta \sum_{j=1}^{n} a_{j i} \beta_{j} \frac{y_{j, t+1}}{c_{j, t+1}},
$$

or defining $\psi_{i, t} \equiv \beta_{i} \frac{y_{i, t}}{c_{i, t}}$ and denoting the vector of $\psi_{i, t}$ 's by $\boldsymbol{\psi}_{t}$, as

$$
\boldsymbol{\psi}_{t}=\boldsymbol{\beta}+\delta \mathbf{A}^{T} \boldsymbol{\psi}_{t+1}
$$

Substituting this equation forward, we obtain

$$
\boldsymbol{\psi}_{t}=\boldsymbol{\beta}+\delta \mathbf{A}^{T} \boldsymbol{\beta}+\delta^{2}\left(\mathbf{A}^{T}\right)^{2} \boldsymbol{\beta}+\ldots+\delta^{K}\left(\mathbf{A}^{T}\right)^{K} \boldsymbol{\psi}_{t+K} .
$$


Because A's largest eigenvalue is less than 1 in absolute value, as $K \rightarrow \infty$, the last term converges to zero, yielding

$$
\boldsymbol{\psi}_{t}=\left(\mathbf{I}-\delta \mathbf{A}^{T}\right)^{-1} \boldsymbol{\beta},
$$

which implies that $\psi_{i, t}$ is constant for all $i$ and $t$, and thus

$$
d \ln y_{i, t}=d \ln c_{i, t} .
$$

Combined with (C21), this yields (C10).

Part 2. The analysis until equation (C18) from part 1 still applies. This equation needs to be modified, however, because of taxes to finance government spending. In particular, $A_{t}=0$ now implies

$$
\begin{aligned}
l_{t} w_{t}-T_{t} & =\frac{p_{i, t} c_{i, t}}{\beta_{i}}=\frac{p_{j, t} c_{j, t}}{\beta_{j}} \\
& =\frac{1}{\mu_{t}}
\end{aligned}
$$

with the second line following from (C14). Combining (C16) with (C23), we obtain

$$
\begin{aligned}
l_{t} & =\frac{1+\lambda T_{t}}{1+\lambda} \\
\mu_{t} & =\frac{1+\lambda}{1-T_{t}} \\
R_{t} & =\frac{1-\mathbb{E}_{t} T_{t+1}}{\delta\left(1-T_{t}\right)}
\end{aligned}
$$

where the last equation of (C24) has expected taxes next period, because next period's government spending shocks and thus taxes are unknown at time $t$. Since, by assumption, $\mathbb{E}_{t} \tilde{\mathbf{G}}_{\tau}=\tilde{\mathbf{G}}_{t}$ for all $\tau>t$, we also have $\mathbb{E}_{t} T_{t+1}=T_{t}$, and thus

$$
R_{t}=\left(\frac{1-\mathbb{E}_{t+1} T_{t+1}}{\delta\left(1-T_{t}\right)}\right)=\frac{1}{\delta}
$$

Next multiplying the resource constraint, (C9), with $p_{i, t}$ to convert it into nominal terms and substituting $p_{i, t} c_{i, t}=\frac{\beta_{i}}{\mu_{t}}$ (from (C23)), and using (C22), we have

$$
\tilde{y}_{i, t}=\frac{\beta_{i}}{\mu_{t}}+\sum_{j=1}^{n} a_{j i} \frac{\tilde{y}_{j, t+1}}{R_{t}}+\tilde{G}_{i, t-1}
$$

where note that we write $\tilde{y}_{i, t+1}$ instead of $\mathbb{E}_{t} \tilde{y}_{i, t+1}$, since there are no productivity shocks and thus given the input choices at time $t, \tilde{y}_{i, t+1}$ is known at time $t$. Substituting for $\mu_{t}$ from (C24) and for $R_{t}$ from (C25), and writing it in matrix notation, we have

$$
\tilde{\mathbf{y}}_{t}=g_{t-1} \boldsymbol{\beta}+\delta \mathbf{A}^{\mathbf{T}} \tilde{\mathbf{y}}_{t+1}+\tilde{\mathbf{G}}_{t-1}
$$

where $g_{t} \equiv \frac{1-\sum_{j=1}^{n} d \tilde{G}_{j, t}}{1+\lambda}$. Writing the same equation at future dates and taking expectations at time $t$, we have

$$
\tilde{\mathbf{y}}_{t+1}=g_{t} \boldsymbol{\beta}+\delta \mathbf{A}^{\mathbf{T}} \tilde{\mathbf{y}}_{t+2}+\tilde{\mathbf{G}}_{t}
$$


and

$$
\mathbb{E}_{t} \tilde{\mathbf{y}}_{t+k}=\mathbb{E}_{t} g_{t+k-1} \boldsymbol{\beta}+\delta \mathbf{A}^{\mathbf{T}} \mathbb{E}_{t} \tilde{\mathbf{y}}_{t+k+1}+\mathbb{E}_{t} \tilde{\mathbf{G}}_{t+k-1} .
$$

Substituting these terms forward, we obtain

$\tilde{\mathbf{y}}_{t}=g_{t-1} \boldsymbol{\beta}+\tilde{\mathbf{G}}_{t-1}+\delta \mathbf{A}^{\mathbf{T}}\left(\mathbb{E}_{t} g_{t} \boldsymbol{\beta}+\mathbb{E}_{t} \tilde{\mathbf{G}}_{t}\right)+\delta^{2}\left(\mathbf{A}^{\mathbf{T}}\right)^{2} \times\left(\mathbb{E}_{t} g_{t+1} \boldsymbol{\beta}+\mathbb{E}_{t} \tilde{\mathbf{G}}_{t+1}\right)+\ldots+\delta^{K}\left(\mathbf{A}^{\mathbf{T}}\right)^{K} \times \mathbb{E}_{t} \tilde{\mathbf{y}}_{t+K}$

Using the fact that $\delta^{K}\left(\mathbf{A}^{\mathbf{T}}\right)^{K} \rightarrow 0$ as $K \rightarrow \infty$ (again because $\mathbf{A}$ 's largest eigenvalues less than one in absolute value) and that $\mathbb{E}_{t} \tilde{\mathbf{G}}_{\tau}=\tilde{\mathbf{G}}_{t}$ for all $\tau>t$, and leading by one period, we have

$$
\tilde{\mathbf{y}}_{t+1}=g_{t} \boldsymbol{\beta}+\tilde{\mathbf{G}}_{t}+\delta \mathbf{A}^{\mathbf{T}} \times\left(g_{t} \boldsymbol{\beta}+\tilde{\mathbf{G}}_{t}\right)+\delta^{2}\left(\mathbf{A}^{\mathbf{T}}\right)^{2}\left(g_{t} \boldsymbol{\beta}+\tilde{\mathbf{G}}_{t}\right)+\ldots
$$

Finally, differentiating, we obtain

$$
\begin{aligned}
\mathbf{d} \tilde{\mathbf{y}}_{t+1} & =d g_{t} \boldsymbol{\beta}+\mathbf{d} \tilde{\mathbf{G}}_{t}+\delta\left(\mathbf{A}^{\mathbf{T}}\left(d g_{t} \boldsymbol{\beta}+\mathbf{d} \tilde{\mathbf{G}}_{t}\right)+\delta^{2}\left(\left(\mathbf{A}^{\mathbf{T}}\right)^{2}\left(d g_{t} \boldsymbol{\beta}+\mathbf{d} \tilde{\mathbf{G}}_{t}\right)+\ldots\right.\right. \\
& =\left(\mathbf{I}-\delta \mathbf{A}^{\mathbf{T}}\right)^{-1}\left(-\frac{\sum_{j=1}^{n} d \tilde{G}_{j, t}}{1+\lambda} \boldsymbol{\beta}+\mathbf{d} \tilde{\mathbf{G}}_{t}\right)
\end{aligned}
$$

verifying $(\mathrm{C} 11)$.

There are three important features to emphasize. First, despite the intertemporal nature of the linkages, the equilibrium still takes a simple form, with many of the same features as the ones that emerged in our static economy. Secondly, and relatedly, equilibrium dynamics in the case of technology/productivity shocks, summarized in equation (C10), are particularly close to the responses in the static model derived in the main text. Dynamics in the presence of government spending shocks are a little more complicated, however, because in this dynamic environment, changes in government spending affect the interest rate and via this channel sectoral prices (whereas in the static model prices remained constant in response to changes in government spending). This complication notwithstanding, equation (C11) still takes relatively simple form and shows how sectoral outputs evolve in response to changes in government spending patterns (and we will see its close relationship to equation (7) in the text in the next proposition). Finally, equilibrium dynamics now depend on the input-output matrix, $\mathbf{A}$ or $\hat{\mathbf{A}}$, and not on the Leontief inverse. This is because, given that one period delay in converting inputs into output, indirect effects take place over time. Consequently, for tracing the effect of last period's output on today's output, which focuses on direct effect, it is the input-output matrix that is relevant. Nevertheless, because the indirect effects now accumulate over time, the long-run response to shocks is again given by the Leontief inverse as we show in the next proposition.

Proposition C2 1. Consider a one-time productivity shock to industries, $\mathbf{d} \mathbf{z}_{t}$ (with $\mathbf{d z}_{t}=$ 0 for all $\tau>t$ ). Then

$$
\mathbf{d} \ln \mathbf{y}_{\infty}=(\mathbf{I}-\mathbf{A})^{-1} \times \mathbf{d} \mathbf{z}_{t}
$$

2. Consider a one-time government spending shock to industries at time $t, \mathbf{d} \tilde{\mathbf{G}}_{t}$ (with $\mathbf{d} \tilde{\mathbf{G}}_{\tau}=$ 0 for all $\tau>t$ ), and suppose that $\delta \rightarrow 1$. Then

$$
\mathbf{d} \tilde{\mathbf{y}}_{t+1}=\mathbf{H}^{T}\left(-\frac{\sum_{j=1}^{n} d \tilde{G}_{j, t}}{1+\lambda} \boldsymbol{\beta}+\mathbf{d} \tilde{\mathbf{G}}_{t}\right),
$$


or in $\log$ form

$$
\mathbf{d} \ln \tilde{\mathbf{y}}_{t+1}=\hat{\mathbf{H}}^{\mathbf{T}} \boldsymbol{\Lambda} \mathbf{d} \tilde{\mathbf{G}}_{t} .
$$

where $\boldsymbol{\Lambda}_{t}$ is the date-t version of the matrix defined in Appendix A equation (A8), given in equation (C29) below.

Proof. Part 1. Take $t=0$ for simplicity. Then, from equation (C10), we have

$$
\begin{aligned}
\ln \mathbf{y}_{0}= & \mathbf{A} \times \ln \mathbf{y}_{-1}+\mathbf{z}_{0} \\
\ln \mathbf{y}_{1}= & \mathbf{A}^{2} \times \ln \mathbf{y}_{-1}+\mathbf{A} \times \mathbf{z}_{0}+\mathbf{z}_{1} \\
& \vdots \\
\ln \mathbf{y}_{K}= & \mathbf{A}^{K+1} \times \ln \mathbf{y}_{-1}+\mathbf{A}^{K} \times \mathbf{z}_{0}+\mathbf{A}^{K-1} \times \mathbf{z}_{1}+\ldots+\mathbf{z}_{K}
\end{aligned}
$$

Since $\mathbf{d} \mathbf{z}_{t}=\mathbf{0}$ for all $t>0, \mathbf{z}_{t}=\mathbf{z}_{0}$ for all $t>0$, and thus

$$
\ln \mathbf{y}_{K}=\mathbf{A}^{K+1} \times \ln \mathbf{y}_{-1}+\mathbf{A}^{K} \times \mathbf{z}_{0}+\mathbf{A}^{K-1} \times \mathbf{z}_{0}+\ldots+\mathbf{z}_{0} .
$$

Differentiating, we have

$$
\mathbf{d} \ln \mathbf{y}_{K}=\left[\mathbf{A}^{K}+\mathbf{A}^{K-1}+\ldots+\mathbf{I}\right] \mathbf{d} \mathbf{z}_{0} .
$$

As $K \rightarrow \infty$, we obtain (C27).

Part 2. This result is obtained directly from (C11) by taking the limit $\delta \rightarrow 1$, which yields

$$
\mathbf{d} \tilde{\mathbf{y}}_{t+1}=\mathbf{H} \times\left(\begin{array}{c}
d \tilde{G}_{1, t}-\frac{\beta_{1}}{1+\lambda} \sum_{j=1}^{n} d \tilde{G}_{j, t} \\
d \tilde{G}_{2, t}-\frac{\beta_{1}}{1+\lambda} \sum_{j=1}^{n} d \tilde{G}_{j, t} \\
\vdots
\end{array}\right)
$$

verifying equation (A10) in Appendix A. Moreover, following the same steps as in Appendix A (in particular, equation (A8)), we can equivalently write this in log form as follows:

$$
\begin{aligned}
d \tilde{y}_{i, t+1} & =\sum_{j=1}^{n} h_{j i}\left(d \tilde{G}_{j, t}-\frac{\beta_{j}}{1+\lambda} \sum_{k=1}^{n} d \tilde{G}_{k, t}\right) \text { for each } i \\
\frac{d \tilde{y}_{i, t+1}}{\tilde{y}_{i, t+1}} & =\sum_{j=1}^{n} \hat{h}_{j i} \frac{1}{\tilde{y}_{j, t}}\left(d \tilde{G}_{j, t}-\frac{\beta_{j}}{1+\lambda} \sum_{k=1}^{n} d \tilde{G}_{k, t}\right)
\end{aligned}
$$

and thus

$$
\mathbf{d} \ln \tilde{\mathbf{y}}_{t+1}=\hat{\mathbf{H}}^{T} \boldsymbol{\Lambda}_{t} \mathbf{d} \tilde{\mathbf{G}}_{t}
$$

where where

$$
\boldsymbol{\Lambda}_{t}=\left(\begin{array}{cccc}
\left(1-\frac{\beta_{1}}{(1+\lambda)}\right) \frac{1}{p_{1, t} y_{1, t}} & -\frac{\beta_{1}}{(1+\lambda)} \frac{1}{p_{1, t} y_{1, t}} & & \\
-\frac{\beta_{2}}{(1+\lambda)} \frac{1}{p_{2, t} y_{2, t}} & \left(1-\frac{\beta_{2}}{(1+\lambda)}\right) \frac{1}{p_{2, t} y_{2, t}} & & \\
& & \ddots & \\
& & & \left(1-\frac{\beta_{n}}{(1+\lambda)}\right) \frac{1}{p_{n, t} y_{n, t}}
\end{array}\right)
$$


thus yielding the desired result.

The most noteworthy results in this proposition are the coincidence of equations $(\mathrm{C} 27)$ and (C28) with (6) and (7) in the text. In particular, (C27) highlights that the long-run response to a one-time (permanent) technology shock in this dynamic model is identical to the equilibrium response to technology shocks in the static model given by (6). Equation (C28), on the other hand, highlights that the dynamic response to a one-time (permanent) government spending shock is identical to the equilibrium response to government shocks in the static model given by (7) provided that the discount factor $\delta$ is close enough to 1 . These results underpin our claims that our results and empirical strategy continue to be valid even if data are generated by a dynamic model in which shocks spread across sectors over time.

\section{Monte Carlo Evidence}

We now use the results of the previous subsection as the basis of our Monte Carlo exercise. We use the equations of the Long-Plosser model, (C10) and (C11), derived above to trace out the dynamics of output in response to technology in government spending shocks. We also add an additional error term to capture other sources of productivity and demand shocks (as well as measurement error). In the case of technology shocks, equation (C10) thus becomes

$$
\text { technology shocks : } \mathbf{d} \ln \mathbf{y}_{t}=\mathbf{A} \times \mathbf{d} \ln \mathbf{y}_{t-1}+\mathbf{z}_{t}^{t f p}+\boldsymbol{\epsilon}_{t}^{t f p}
$$

where $\mathbf{z}_{t}^{t f p}$ denotes the vector of technology shocks, and $\boldsymbol{\epsilon}_{t}^{t f p}$ is the vector of additional shocks assumed to be iid. We take productivity and government spending shocks to be persistent (since we are considering short time periods, such as months or quarters, which will then be time averaged into annual observations). In particular, we assume that

$$
z_{i, t}^{t f p}=\rho z_{i, t-1}^{t f p}+\nu_{t}
$$

where $\nu_{t} \sim N(0,1)$. When time periods correspond to quarters, we set $\rho=0.85$, which implies an annual persistence of 0.52 , corresponding approximately to the average persistence of the shocks we study in our empirical work.

For equation (C11), we approximate $R_{t} \simeq 1 / \delta \simeq 1$, since time periods are taken to be short (quarters or months), and then use the same steps as in the proof of Proposition C2 to convert the equation in nominal terms into log changes and thus write (C11) as

$$
\mathbf{d} \ln \mathbf{y}_{t+1}=\hat{\mathbf{H}}^{T} \boldsymbol{\Lambda}_{t} \mathbf{d} \tilde{\mathbf{G}}_{t}
$$

where

$$
\boldsymbol{\Lambda}_{t}=\left(\begin{array}{cccc}
\left(1-\frac{\beta_{1}}{(1+\lambda)}\right) \frac{1}{p_{1, t} y_{1, t}} & -\frac{\beta_{1}}{(1+\lambda)} \frac{1}{p_{1, t} y_{1, t}} & & \\
-\frac{\beta_{2}}{(1+\lambda)} \frac{1}{p_{2, t} y_{2, t}} & \left(1-\frac{\beta_{2}}{(1+\lambda)}\right) \frac{1}{p_{2, t} y_{2, t}} & & \\
& & \ddots & \\
& & & \left(1-\frac{\beta_{n}}{(1+\lambda)}\right) \frac{1}{p_{n, t} y_{n, t}}
\end{array}\right) .
$$

Thus the equation we use to generate our simulated data the case of government spending shocks is 


$$
\text { government spending shocks : } \mathbf{d} \ln \mathbf{y}_{t}=\hat{\mathbf{H}}^{T} \boldsymbol{\Lambda}_{t} \mathbf{z}_{t}^{G}+\boldsymbol{\epsilon}_{t}^{G},
$$

where $\mathbf{z}_{t}^{G}$ denotes the vector of government spending shocks, and $\boldsymbol{\epsilon}_{t}^{G}$ denotes the additional shock in this case. We again take this latter shock to be $i i d$, and impose the same persistence structure on our shock of interest, i.e.,

$$
z_{i, t}^{G}=\rho z_{i, t-1}^{G}+\nu_{t}
$$

We also assume that $\boldsymbol{\epsilon}_{t}^{t f p}, \boldsymbol{\epsilon}_{t}^{G}$ are iid and distributed $N(0,10)$ so as to generate sufficient noise in our simulated data. Throughout, we take the number of sectors to be 392 as in our empirical work, and we use the actual input-output matrices from the U.S. data that featured in our empirical work.

For quarterly data, we burn the first 160 quarters of simulated data, and then take 20 years of quarterly data, which we then time-average into annual observations, thus giving us 20 years of annual data with 392 sectors, which matches our empirical frame. We repeat this procedure 1000 times.

We then estimate our main specification from the text, equation (12), on these simulated datasets. As in our main text, upstream and downstream effects are computed from equations (13) and (14). The following regression equation reports mean values and the standard deviation of the estimates across the 1000 runs, starting with the case of technology shocks:

$$
\mathbf{d} \ln \mathbf{y}_{t}=\underset{(0.012)}{0.002} \times \mathbf{d} \ln \mathbf{y}_{t-1}+\underset{(0.037)}{0.770} \times \mathbf{d} \mathbf{z}_{t-1}^{t f p}+\underset{(0.206)}{0.014} \times \mathbf{d} \mathbf{z}_{t-1}^{t f p, u p}+\underset{(0.327)}{0.881} \times \mathbf{d} \mathbf{z}_{t-1}^{t f p, \text { down }} .
$$

Panels A-D of Appendix Figure 4 illustrate the distributions of each coefficient across these 1000 simulations. Both our summary equation and the figure clearly show that we estimate no upstream effect and significant downstream effects as predicted by theory. The coefficient on the lagged dependent variable is zero, reflecting the fact that there is no other source of persistence (such as capital accumulation) in our simulated data. Panel E of the figure turns to the implied tests of the theoretical restriction (where we again follow the theory and include all indirect effects from own shocks together with the own shock). It plots the distribution of $p$-values of the test for this theory-implied restriction. We see that this restriction is rejected in about $18 \%$ of the cases at the $5 \%$ level. This somewhat high rejection rate is a consequence of the fact that time averaging the simulated data affects the own and downstream effects differentially. Nevertheless, we find it encouraging that in the great majority of the cases, this restriction is not rejected. 
A. $\Delta \ln Y(\mathrm{t}-1)$

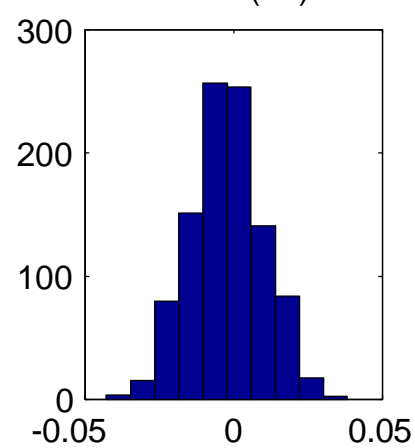

D. Downstream(t-1)

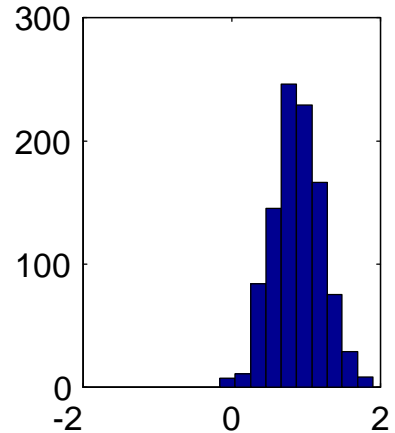

B. $\Delta \mathrm{Z}(\mathrm{t}-1)$

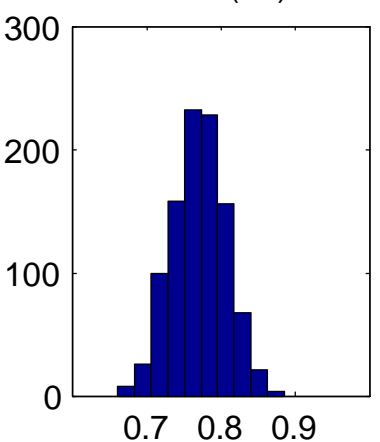

E. P-value of Equality Test

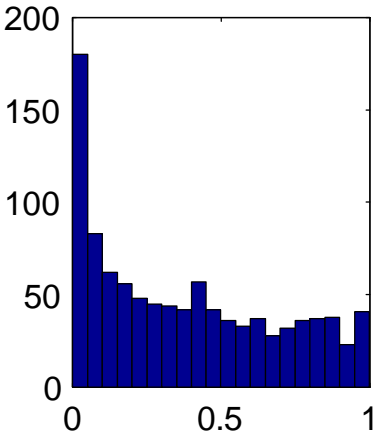

C. Upstream(t-1)

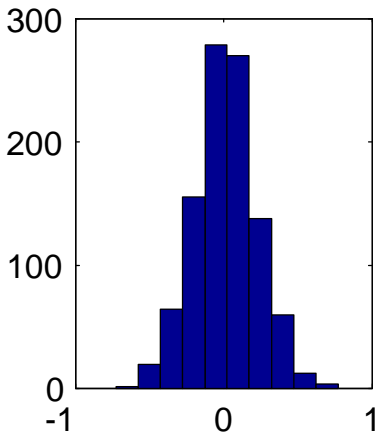

Appendix Figure 4. Distribution of coefficient estimates and p-values for coefficient equality tests from 1000 Monte Carlo simulations in response to technology shocks at quarterly frequency.

The next equation summarizes the results from government spending shocks, with the full results shown in Appendix Figure 5. The overall pattern is very similar and again consistent with our theoretical predictions, with one notable difference that, in this case, despite timeaveraging the theory-implied restriction between own and network effects is rejected in about $4 \%$ of the cases at the $5 \%$ level, approximately as we would expect.

$$
\mathbf{d} \ln \mathbf{y}_{t}=\underset{(0.011)}{-0.012} \times \mathbf{d} \ln \mathbf{y}_{t-1}+\underset{(0.034)}{0.781} \times \mathbf{d} \mathbf{z}_{\mathbf{t}-\mathbf{1}}^{\mathbf{G}}+\underset{(0.182)}{0.761} \times \mathbf{d} \mathbf{z}_{t-1}^{G, u p}-\underset{(0.221)}{0.008} \times \mathbf{d z}_{t-1}^{G, \text { down }} .
$$


A. $\Delta \ln Y(\mathrm{t}-1)$

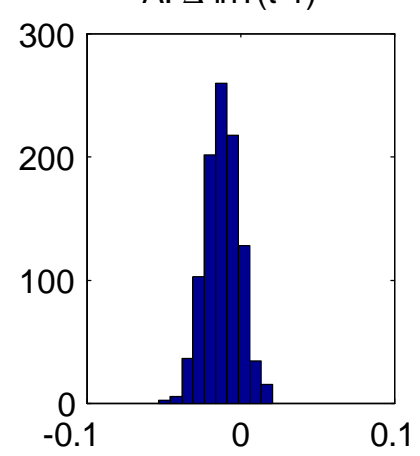

D. Downstream(t-1)

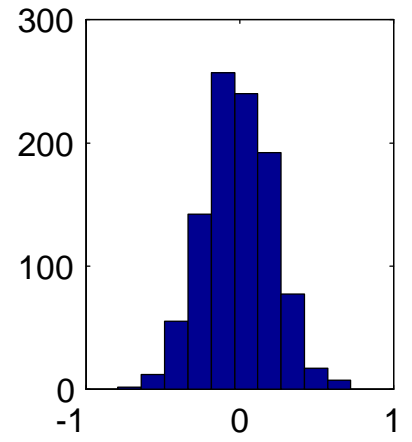

B. $\Delta \mathrm{Z}(\mathrm{t}-1)$

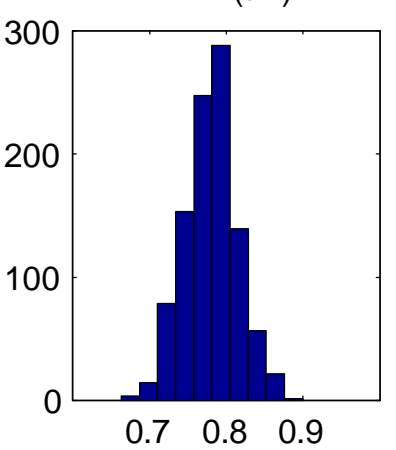

E. P-value of Equality Test

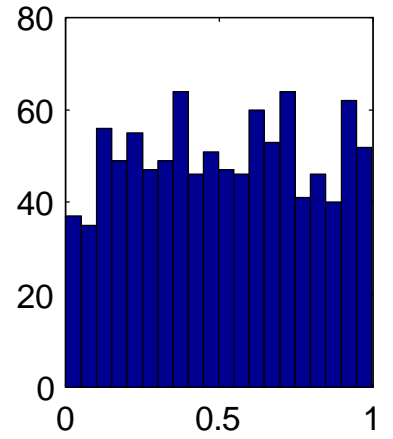

C. Upstream(t-1)

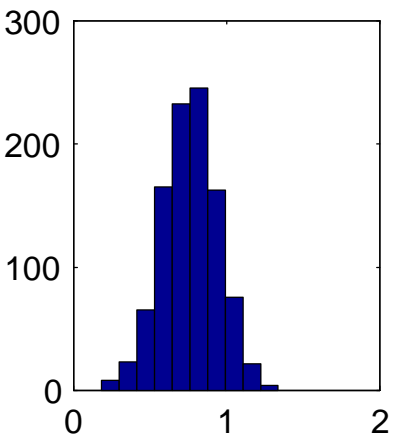

Appendix Figure 5. Distribution of coefficient estimates and p-values for coefficient equality tests from 1000 Monte Carlo simulations in response to government spending shocks at quarterly frequency.

We next depict the same analysis when simulating the model at the monthly frequency, which in particular implies that we set $\rho_{\text {month }}=0.947$, so that we have the same annual persistence of shocks. We now use 1000 runs of 20 years each, and again burned the equivalent of 20 years of data (480 months). The results for technology shocks are once again similar, as summarized in the next equation and in Appendix Figure 6 below.

$$
\mathbf{d} \ln \mathbf{y}_{t}=\underset{(0.014)}{0.031} \times \mathbf{d} \ln \mathbf{y}_{t-1}+\underset{(0.022)}{0.730} \times \mathbf{d} \mathbf{z}_{t-1}^{t f p}+\underset{(0.092)}{0.002} \times \mathbf{d} \mathbf{z}_{t-1}^{t f p, u p}+\underset{(0.133)}{0.769} \times \mathbf{d} \mathbf{z}_{t-1}^{t f p, \text { down }} .
$$


based on

A. $\Delta \ln Y(\mathrm{t}-1)$

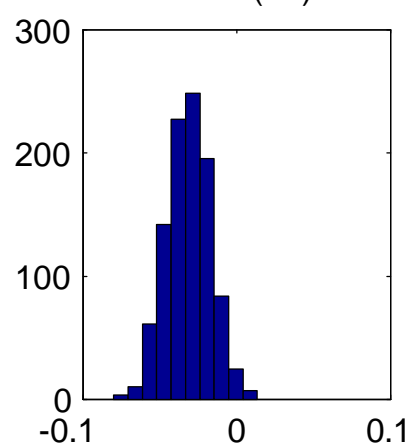

B. $\Delta \mathrm{Z}(\mathrm{t}-1)$

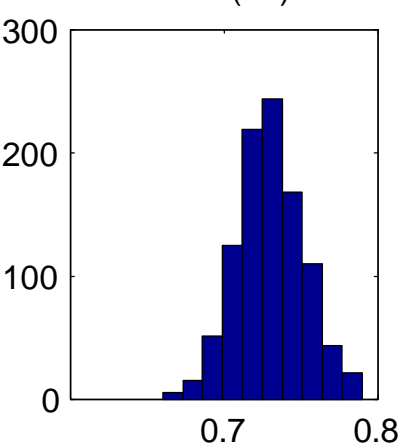

C. Upstream(t-1)

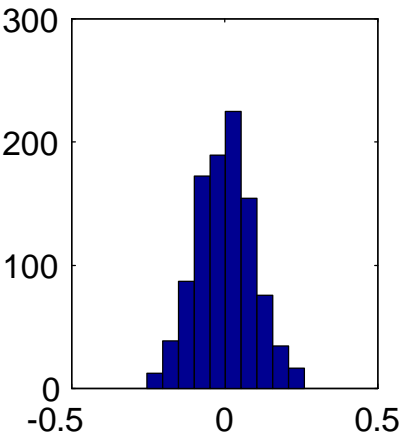

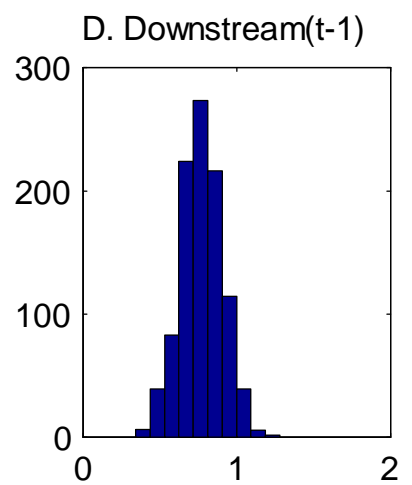
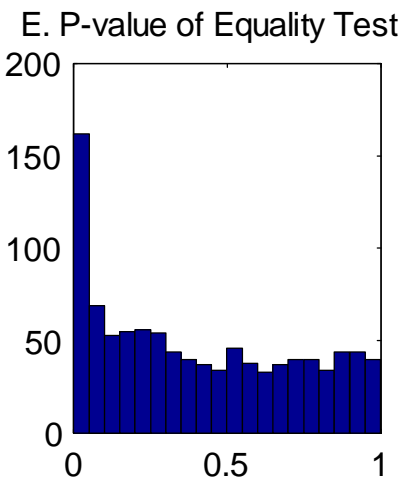

Appendix Figure 6. Distribution of coefficient estimates and p-values for coefficient equality tests from 1000 Monte Carlo simulations in response to technology shocks at monthly frequency.

Once again, in response to technology shocks, there are no upstream effects and wellestimated downstream effects, and theory-implied restrictions are accepted in the majority of the cases.

Turning next to government spending shocks, we find a similar pattern consistent with theory as summarized in the next equation and in Appendix Figure 7:

$$
\mathbf{d} \ln \mathbf{y}_{t}=\underset{(0.014)}{-0.035} \times \mathbf{d} \ln \mathbf{y}_{t-1}+\underset{(0.020)}{0.734} \times \mathbf{d} \mathbf{z}_{\mathbf{t}-\mathbf{1}}^{\mathbf{G}}+\underset{(0.089)}{0.711} \times \mathbf{d} \mathbf{z}_{t-1}^{G, u p}-\underset{(0.098)}{0.0003} \times \mathbf{d} \mathbf{z}_{t-1}^{G, \text { down }} .
$$


A. $\Delta \ln Y(t-1)$

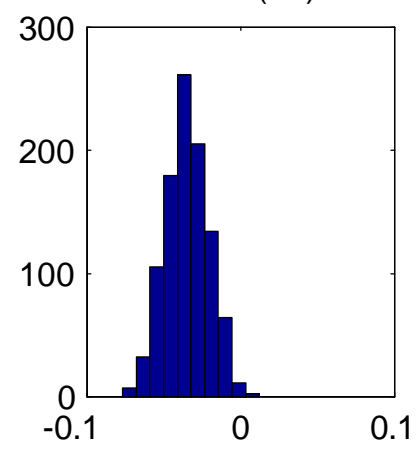

D. Downstream(t-1)

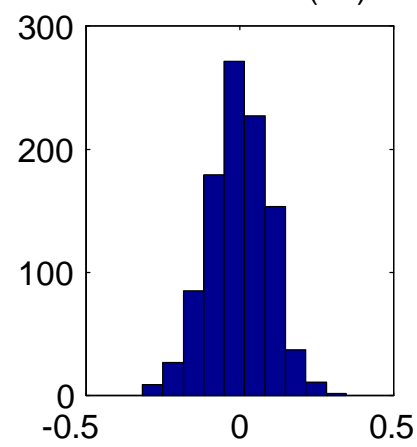

B. $\Delta \mathrm{Z}(\mathrm{t}-1)$

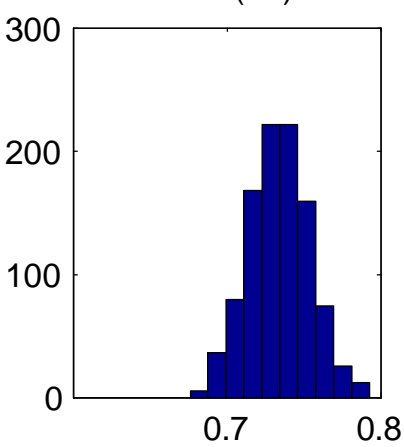

E. P-value of Equality Test

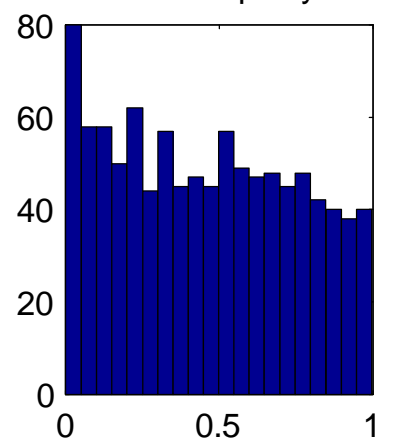

C. Upstream(t-1)

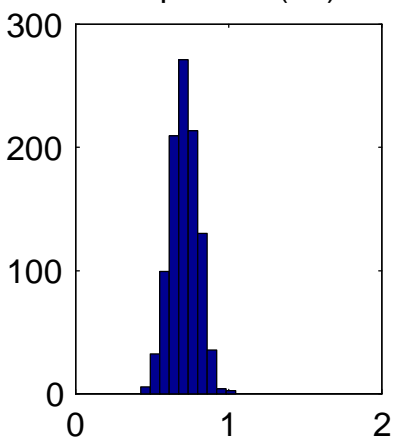

Appendix Figure 7. Distribution of coefficient estimates and p-values for coefficient equality tests from 1000 Monte Carlo simulations in response to government spending shocks at monthly frequency.

\section{Measurement Error}

Our second Monte Carlo exercise investigates whether measurement error in the input-output matrix will lead to incorrect inference (partly because this measurement error might be magnified in the Leontief inverse). For this exercise, we directly simulate data at the annual frequency from our baseline model (thus using the Leontief inverse matrices), and since we would like to investigate whether, in the presence of measurement error, network effects from technology shocks might be incorrectly identified as resulting from government shocks and vice versa, we combine (C10) and (C11) and simulate the data in the presence of both types of shocks procreating according to theory as well as additional noise representing other shocks. Namely, we use the equation

$$
\mathbf{d} \ln \mathbf{y}_{t+1}=\gamma \times \mathbf{d} \ln \mathbf{y}_{t}+\alpha^{\text {down }} \times \mathbf{H} \times \mathbf{d} \mathbf{z}_{t}^{t f p}+\alpha^{u p} \times \hat{\mathbf{H}} \times \boldsymbol{\Lambda}_{\mathbf{t}} \times \mathbf{d} \mathbf{z}_{t}^{G}+\boldsymbol{\epsilon}_{t},
$$

where $\mathbf{d} \mathbf{z}_{t}^{t f p}$ and $\mathbf{d} \mathbf{z}_{t}^{G}$ are the vectors of technology and government spending shocks, and we take them to be iid and distributed $N(0,1)$. The additional noise $\epsilon_{t}$ is assume to be distributed $N(0,1 / 12)$. We set $\gamma$ to the average of its empirical estimates, 0.085 , and we again use the Leontief inverse matrices $\mathbf{H}$ and $\hat{\mathbf{H}}$ from the data as in our empirical work. To investigate whether positive downstream (upstream) effects will be correctly identified and whether we 
will also be able to estimate precisely zero effects when such propagation is absent, we consider four different scenarios for $\alpha^{u p}$ and $\alpha^{\text {down}}$ : $(i) \alpha^{u p}=1, \alpha^{\text {down }}=1,(i i) \alpha^{u p}=1, \alpha^{\text {down }}=0$, (iii) $\alpha^{u p}=0, \alpha^{\text {down }}=1$, and $(i v) \alpha^{u p}=0, \alpha^{\text {down }}=0$, covering all four possibilities (where the normalization of the positive effects to 1 is without loss of any generality). We again run 1000 simulations in each case.

In estimating our main empirical model, equation (12), we introduce randomly-generated measurement error on the actual matrix, so that the matrix we use in the estimation becomes

$$
\mathbf{A}^{\epsilon}=\left(\begin{array}{ccccc}
a_{11}+\epsilon_{11} & a_{12}+\epsilon_{12} & & \ldots & \\
a_{21}+\epsilon_{21} & a_{22}+\epsilon_{22} & & \\
& & \ddots & & \\
& & & & \\
& & & & a_{n n}+\epsilon_{n n}
\end{array}\right)
$$

and $\hat{\mathbf{A}}^{\epsilon}$ is constructed analogously. To make this demanding test of our empirical strategy, we introduce a considerable amount of measurement error and set the standard deviation of $\epsilon$ equal to the average entry of the input-output matrix, $\bar{a} \equiv \frac{1}{n^{2}} \sum_{i} \sum_{j} a_{i j}$. That is,

$$
\epsilon_{i j}, \hat{\epsilon}_{i j} \sim N(0, \bar{a})
$$

and different draws are independent. With this amount of measurement error, the ranking of the entries of the input-output matrices can be considerably different than what we measure. We then compute the Leontief inverses in the usual manner: $\mathbf{H}^{\epsilon}=\left(\mathbf{I}-\mathbf{A}^{\epsilon}\right)^{-1}$ and $\hat{\mathbf{H}}^{\epsilon}=$ $\left(\mathbf{I}-\hat{\mathbf{A}}^{\epsilon T}\right)^{-1}$. We again estimate equation (12) computing the downstream and upstream effects according to equations (13) and (14).

We next report the results of this exercise, starting with the benchmark of no measurement error when there are both upstream and downstream effects, and then moving to the four cases indicated above. Throughout, given our motivation explained above, we estimate network effects from technology and government spending shocks simultaneously. ${ }^{2}$

Case 0, No Measurement Error, $\alpha^{u p}=1, \alpha^{\text {down }}=1$

In this case, both own effects and network effects are precisely estimated, and are consistent with theory. In particular, we find downstream propagation of technology shocks and zero upstream propagation of these shocks, and upstream propagation but no downstream propagation of government spending shocks. Quantitatively, own shocks and the relevant network effects are of the same magnitude as predicted by theory. These results are summarized in the next equation.

$$
d \ln \mathbf{y}_{t+1}=\left\{\begin{array}{c}
0.085 \times d \ln \mathbf{y}_{t}-\underset{(0.006)}{0.0034)} \times \mathbf{z}_{t}^{t f p, u p}+\underset{(0.0565)}{1.002} \times \mathbf{z}_{t}^{t f p, \text { down }}+\underset{(0.000)}{1.000} \times \mathbf{z}_{t}^{\text {tfp,own }} \\
\underset{(0.055)}{0.980} \times \mathbf{z}_{t}^{G, \text { up }}-\underset{(0.064)}{0.004} \times \mathbf{z}_{t}^{G, \text { down }}+\underset{(0.010)}{1.000} \times \mathbf{z}_{t}^{G, \text { own }}
\end{array}\right\}
$$

\footnotetext{
${ }^{2}$ The results are similar if the two types of network effects are estimated separately.
} 
Case 1, Measurement Error, $\alpha^{u p}=1, \alpha^{\text {down }}=1$

In this case, as shown by the next summary equation, we find the expected pattern of downstream propagation of technology shocks and upstream propagation of government spending shocks, and no upstream propagation from technology shocks and no downstream propagation from government spending shocks. Moreover, despite the sizable amount of measurement error in the input-output matrices, the estimated magnitudes of the relevant network effects are consistent with theory: on average, downstream network effects from technology shocks have the same magnitude as the own effect of technology shocks, and upstream network effects from government spending shocks likewise have the same magnitude as the own effect of government spending shocks.

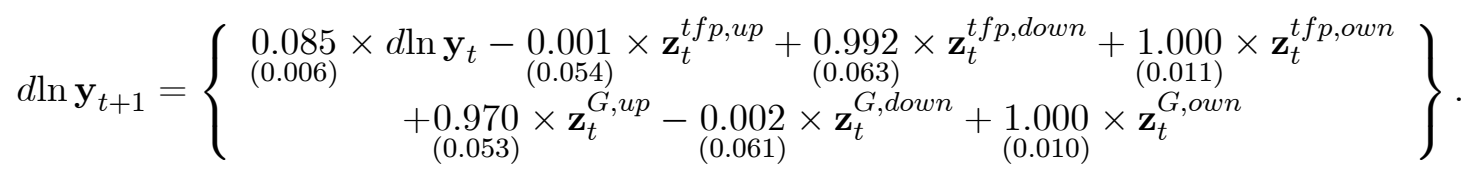

The full distribution of the parameter estimates, focusing on upstream effect, downstream effects and own effects, are shown in Appendix Figure 8.

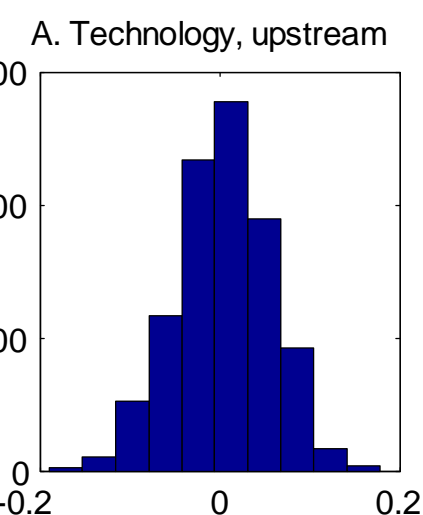

D. Government, upstream

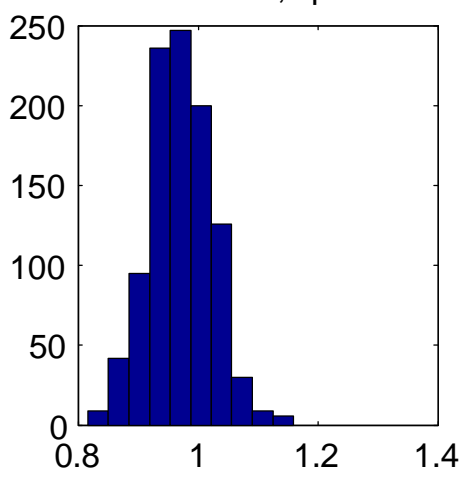

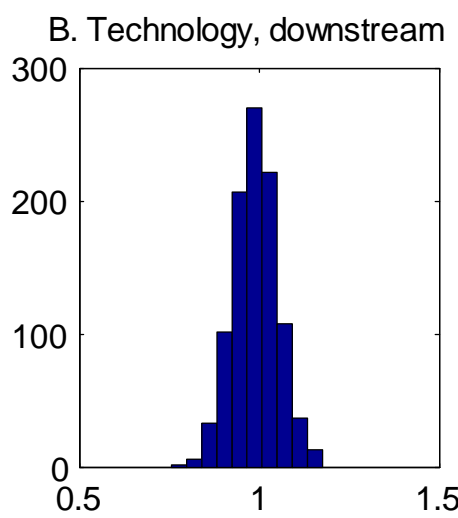

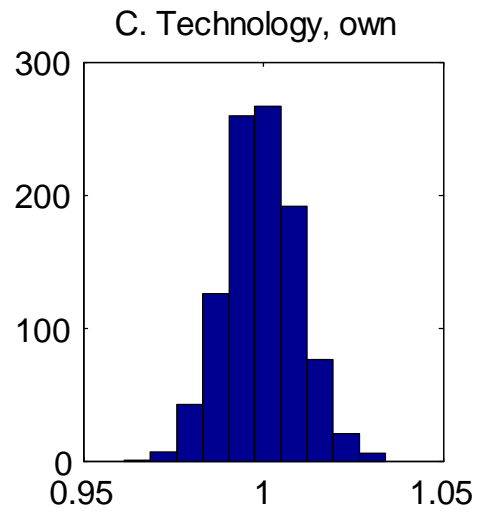

E. Government, downstream

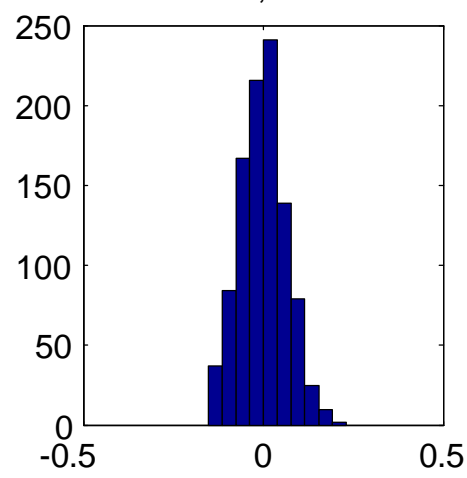

\section{F. Government, own}

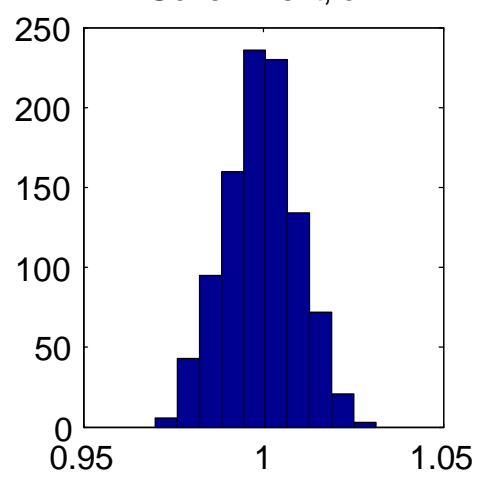

Appendix Figure 8 .

Distribution of coefficient estimates from 1000 Monte Carlo simulations in response to technology and government spending shocks with measurement error and $\alpha^{u p}=1$ and $\alpha^{\text {down }}=1$. 
In summary, in this case, with both government spending and technology shocks, despite the substantial amount of measurement error, our regressions correctly identify the theory-implied network effects and estimate zero propagation when there should not be any.

Case 2, Measurement Error, $\alpha^{u p}=1, \alpha^{\text {down }}=0$

We next turn to the (hypothetical) case in which the data generating process includes upstream propagation in response to government spending shocks, but no downstream propagation in response to technology shocks. ${ }^{3}$ The results are again encouraging for our empirical strategy as summarized by the next equation and Appendix Figure 9, and show that our regressions estimate the relevant network effects correctly and estimate zero effects when there are no network effects.

$$
d \ln \mathbf{y}_{t+1}=\left\{\begin{array}{c}
0.085 \times d \ln \mathbf{y}_{t}+\underset{(0.006)}{0.001 \times 2)} \times \mathbf{z}_{t}^{t f p, u p}-\underset{(0.066)}{0.001} \times \mathbf{z}_{t}^{t f p, \text { down }}+\underset{(0.010)}{0.000} \times \mathbf{z}_{t}^{t f p, \text { own }} \\
+\underset{(0.056)}{0.974} \times \mathbf{z}_{t}^{G, u p}-\underset{(0.063)}{0.005} \times \mathbf{z}_{t}^{G, \text { down }}+\underset{(0.010)}{1.000} \times \mathbf{z}_{t}^{G, \text { own }}
\end{array}\right\} .
$$

\footnotetext{
${ }^{3}$ This case is not possible when our theory applies, since upstream propagation in response to government spending shocks and downstream propagation in response to technology shocks are determined by the same input-output linkages. Nevertheless, this hypothetical case enables us to investigate whether our regressions will correctly identify the presence or the absence of these effects when one is present and the other one is not as might be the case under alternative theories.
} 

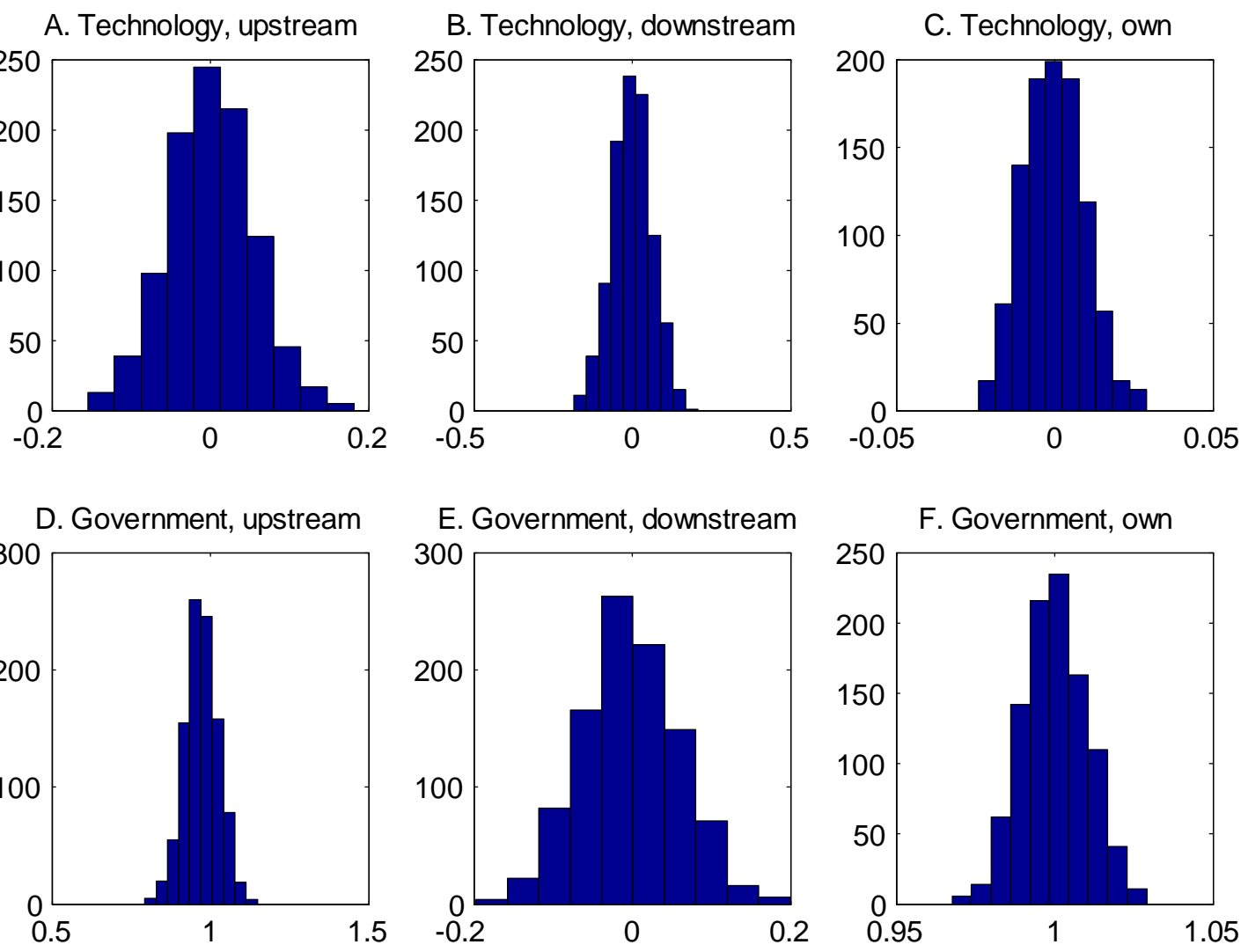

Appendix Figure 9. Distribution of coefficient estimates from 1000 Monte Carlo simulationsin response to government spending shocks with measurement error and $\alpha^{u p}=1$ and $\alpha^{\text {down }}=0$.

The results show zero own effects and zero network effects from technology shocks, and zero downstream propagation from government spending shocks, and correctly identify the own effects and upstream propagation from government spending shocks, with the right magnitudes.

Case 3, Measurement Error, $\alpha^{u p}=0, \alpha^{\text {down }}=1$

We find the same pattern when there is downstream propagation in response to technology shocks but no upstream propagation in response to government shocks as summarized next:

$$
d \ln \mathbf{y}_{t+1}=\left\{\begin{array}{c}
0.085 \times d \ln \mathbf{y}_{t}+\underset{(0.008)}{0.004} \times \mathbf{z}_{t}^{t f p, u p}+\underset{(0.062)}{0.989} \times \mathbf{z}_{t}^{\text {tfp } p \text { down }}+\underset{(0.011)}{1.001} \times \mathbf{z}_{t}^{\text {tfp,own }} \\
\underset{(0.052)}{0.003} \times \mathbf{z}_{t}^{G, \text { up }}-\underset{(0.061)}{0.002} \times \mathbf{z}_{t}^{G, \text { down }}+\underset{(0.010)}{0.000} \times \mathbf{z}_{t}^{G, \text { own }}
\end{array}\right\} .
$$



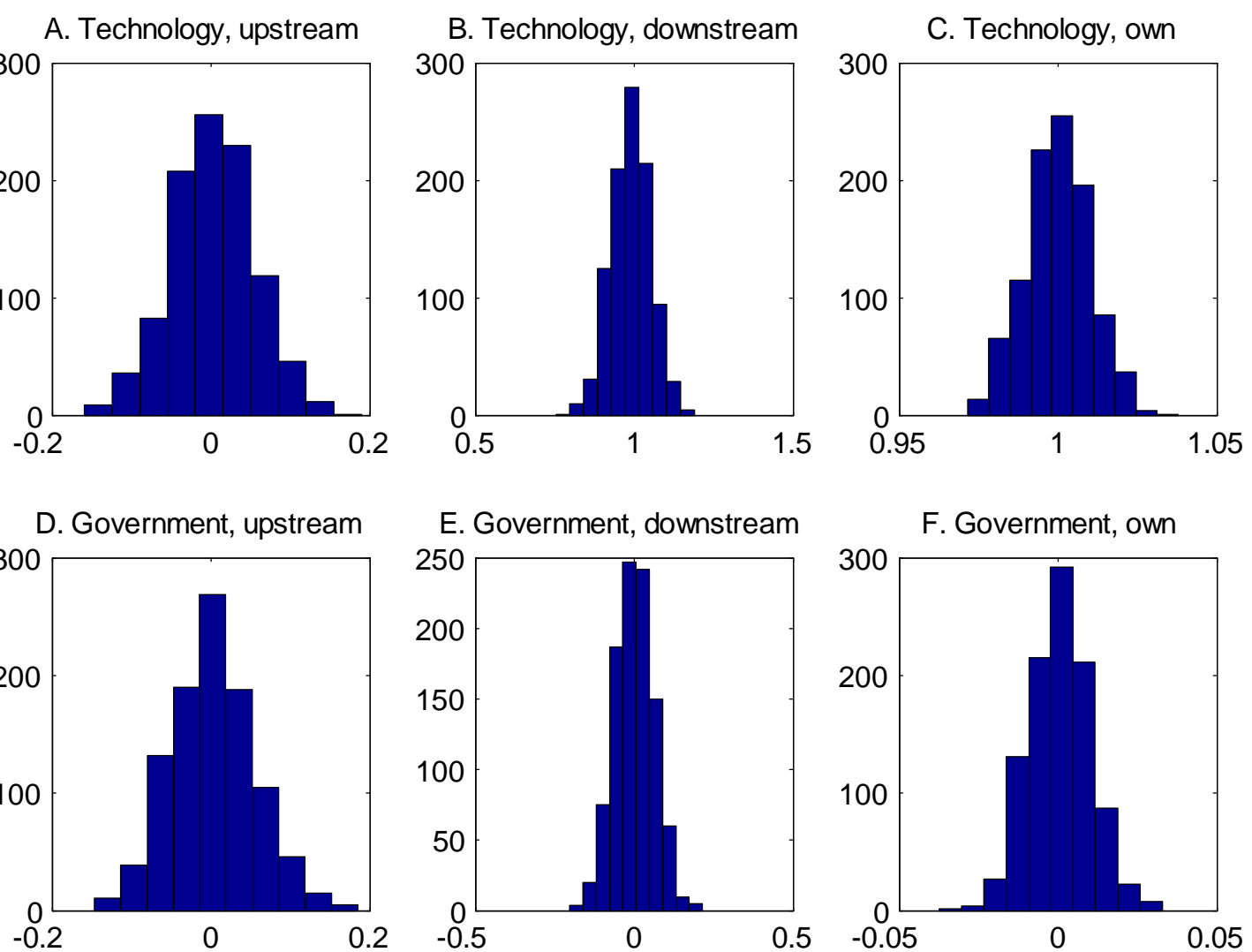

Appendix Figure 10.

Distribution of coefficient estimates from 1000 Monte Carlo simulations in response to technology and government spending shocks with measurement error and $\alpha^{\text {up }}=0$ and $\alpha^{\text {down }}=1$.

Case 4, $\alpha^{u p}=0, \alpha^{\text {down }}=0$

Finally, we turn to the case in which there are no network effects, and in this case our equations, as summarized next, correctly identify no upstream or downstream propagation in response to either government spending or technology shocks (as well as no own effects).

$$
d \ln \mathbf{y}_{t+1}=\left\{\begin{array}{c}
\underset{(0.011)}{0.085} \times d \ln \mathbf{y}_{t}+\underset{(0.052)}{0.000} \times \mathbf{z}_{t}^{t f p, u p}+\underset{(0.062)}{0.002} \times \mathbf{z}_{t}^{t f p, \text { down }}+\underset{(0.010)}{0.000} \times \mathbf{z}_{t}^{\text {tfp,own }} \\
\underset{(0.053)}{0.001} \times \mathbf{z}_{t}^{G, u p}+\underset{(0.064)}{0.000} \times \mathbf{z}_{t}^{G, \text { down }}+\underset{(0.010)}{0.000} \times \mathbf{z}_{t}^{G, \text { own }}
\end{array}\right\} .
$$



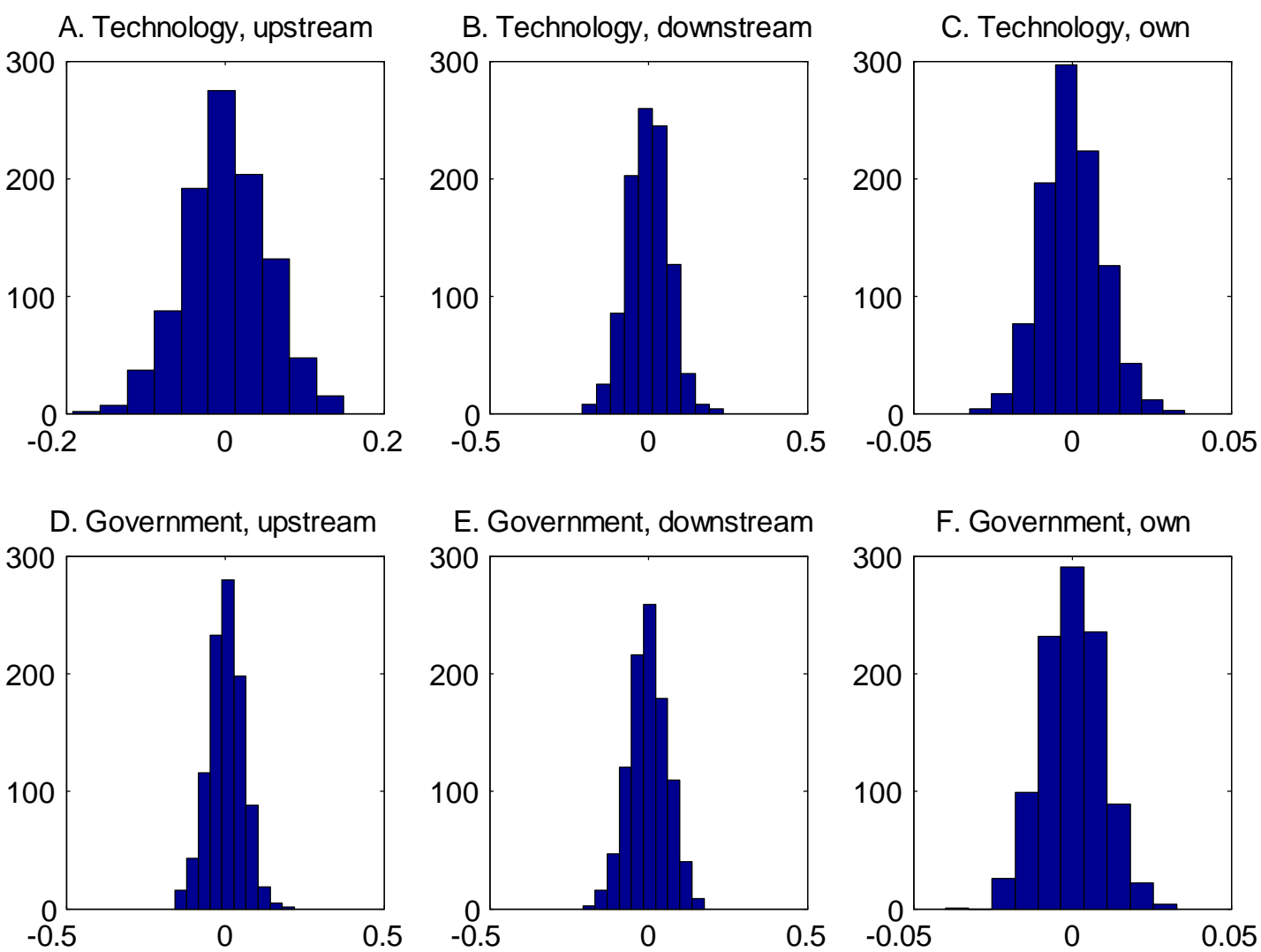

\section{Appendix Figure 11.}

Distribution of coefficient estimates from 1000 Monte Carlo simulations in response to technology and government spending shocks with measurement error and $\alpha^{u p}=0$ and $\alpha^{\text {down }}=0$.

Overall, these results bolster our confidence in the reliability of our empirical strategy, even in the presence of substantial measurement error. 